\title{
Review of Thermodynamic Diesel Engine Simulations under Transient Operating Conditions
}

\author{
C.D. Rakopoulos and E.G. Giakoumis \\ School of Mechanical Engineering, National Technical University of Athens
}

Copyright @ 2006 SAE International

\begin{abstract}
Study and modeling of transient operation is an important scientific objective. This is due to the fact that the majority of daily vehicle driving conditions involve transient operation, with non-linear situations experienced during engine transients. Thus, proper interconnection is needed between engine, governor, fuel pump, turbocharger and load. This paper surveys the publications available in the open literature concerning diesel engine simulations under transient operating conditions. Only those models that include both full engine thermodynamic calculations and dynamic powertrain modeling are taken into account, excluding those that focus on control design and optimization. Most of the attention is concentrated to the simulations that follow the filling and emptying modeling approach. A historical overview is given covering, in more detail, research groups with continuous and consistent study of transient operation. One of the main purposes of this paper is to summarize basic equations and modeling aspects concerning in-cylinder calculations, friction, turbocharger, engine dynamics, governor, fuel pump operation, and exhaust emissions during transients. The various limitations of the models are discussed together with the main aspects of transient operation (e.g. turbocharger lag, combustion and friction deterioration), which diversify it from the steady-state. Some of the most important findings in the field during the last 30 years are presented and discussed. The survey extends to special cases of transient diesel engine simulation, such as second-law analysis, response when the turbocharger compressor experiences surge, and whole vehicle performance. Several methods of improving transient response are also mentioned, based on the various simulations. An easy-to-read tabulation of all research groups dealing with the subject, that includes details about each model developed and engines/parameters studied, is also provided at the end of the paper.
\end{abstract}

\section{INTRODUCTION}

The turbocharged compression ignition (diesel) engine is nowadays the most preferred prime mover in medium and medium-large units applications (truck driving, land traction, ship propulsion, electrical generation). Moreover, it continuously increases its share in the highly competitive automotive market, owing to its reliability that is combined with excellent fuel efficiency.

At the same time, the stringent regulations concerning engine exhaust emissions dominate the automotive industry, forcing manufacturers to new developments. Sophisticated, high pressure common rail injection systems, exhaust gas recirculation and variable geometry turbochargers are applied for reduction of fuel consumption, pollutant emissions and noise. In the last years, various emission directives, in the form of Transient Cycles [1,2], have furthermore directed engine manufacturers in the European Union, Japan and the US to appropriate dealing of (vehicles') transient performance, since it is well established that the instationary operation contributes much more to the total amount of emissions than the stationary one.

Typical transient cases experienced by diesel engines, lasting from a few seconds up to several minutes, are:

1. Load acceptance (change) with constant governor setting,

2. Speed change under constant load e.g., acceleration,

3. Simultaneous speed and load change,

4. Vehicle acceleration, e.g., gear shift,

5. Transient cycles, which consist of several of the above mentioned transients, and

6. Starting.

In this work, the term transient will be used to describe any of the aforementioned forced changes in load and/or fueling ${ }^{1}$.

In various diesel engine applications (e.g. marine propulsion, electrical generation) the turbocharger and the engine are optimized to achieve the rated power and maximum torque output. In automotive applications the

\footnotetext{
Engines or vehicles encounter several other situations that can loosely be termed "transient", such as cyclic variation, (cylinder wall) temperature oscillations, compression braking of heavy vehicles etc. These are not considered in this review.
} 
matching is usually achieved for steady-state conditions and low specific fuel consumption. Thus, the turbocharger size is determined for high torque output, which usually leads to high moment of inertia and consequently slow air charge response. This slow air flow charge cannot match the required fast fueling commands during transients and causes rich air-to-fuel ratio mixtures that result in high levels of visible smoke. To make things worse, the above-mentioned nonoptimum transient performance of turbocharged diesel engines (for many years now the majority of the diesels produced worldwide) is further enhanced by the increase in rating. Possible counter-measures sometimes conflict with other important aspects of engine operation, such as fuel consumption or exhaust emissions.

In any case, reliable governing is required as well as quick changes in the operating conditions for both vehicle movement and ship propelling. For diesel engines used in industrial applications, rapid loading is required together with zero (final) speed droop for the base units, as well as rapid start-up for the stand-by ones. Rapid load changes can prove very demanding in terms of engine response and also in the reliability of fuel pumps and governors-controllers. Transient operation study and modeling is thus an important objective, since:

- The majority of daily driving conditions involves transient operation,

- Extreme, non-linear and non-steady-state conditions are experienced by the engine and its subsystems during transients,

- Proper interconnection between engine, governor, fuel pump, turbocharger and load is required,

- Short-term exhaust overshoot is noticed during turbocharger lag,

- Various control strategies should be employed and investigated for better engine response, further enhanced by the proliferating use of variable geometry turbines and exhaust gas recirculation systems.

Diesel engine simulation has contributed enormously during the last 40 years towards new evaluation and development [3-11]. Thermodynamic cycle simulations give access to data that otherwise can only be measured with complicated and costly techniques. Moreover, they provide an opportunity to investigate different design solutions early in the development process, optimize key parameters of the system, and perform sensitivity analyses.

In particular, as regards transient performance, the various simulation models have paved the way for an indepth study of transient operation. However, the excursion to off-design and off-steady-state conditions experienced during transients cannot be dealt with conventional modeling techniques based on steadystate philosophy. This holds true especially for combustion and friction [12,13], but also for the operation of various engine subsystems such as the turbocharger.

Reliable study of pollutants emissions during transient operation via the use of suitable models is an important objective, whose accomplishment is limited at the moment by the large computational time required for the analysis of hundreds of cycles. In addition, the transient response has not been accurately analyzed as yet and diversified from the steady-state one, with complete account for its unsteady nature characteristics. Simulation constants of the individual sub-models behave differently during transient operation and thus care has to be taken for proper modeling.

In this work the publications concerning transient diesel engine simulation will be surveyed, provided they include both engine thermodynamic and powertrain dynamic submodels. To maintain the paper size at an acceptable level, it was decided that works which put emphasis on controllers design rather than thermodynamics, i.e. applying optimization algorithms, or Bode diagrams, will not be covered. Most of the attention will be paid to the simulations that follow the filling and emptying modeling technique. This, to the opinion of the authors, has proven so far to be the best approach to adequately shed light into the engine processes during transients. Moreover, taking into account its computational requirements, it is the most promising one for successful transient exhaust emissions predictions.

A typical transient case of load acceptance (30-60 engine cycles) needs approximately 1 second on a modern PC when quasi-linear modeling is used, while it needs 1 minute via single-zone modeling and almost 24 hours when quasi-dimensional analysis is adopted. The above times are increased proportionally if separate analyses for each cylinder are applied. Moreover, as regards zero-dimensional studies, a multi-zone model would increase the required time almost linearly to the number of zones analyzed.

Ideally, a complete diesel engine transient simulation code should include true 'transient' sub-models for each cylinder separately, as well as for the fuel pump, the turbocharger, the dynamometer and the manifolds. However, this would considerably increase the computational time, cost and effort to simulate all these delicate and complex phenomena. The main simulations aspects as well as the limitations imposed by the need for relatively fast simulation codes will thus be among the main subjects of the paper. Some of the most important findings in the field during the last 35 years will be presented and analyzed. The survey will extend to special cases of transient diesel engine simulation, such as second-law analysis, operation under turbocharger compressor surging, and whole vehicle performance. The measures will also be highlighted, which can help decrease turbocharger lag and consequently improve transient response. 


\section{HISTORICAL OVERVIEW}

To the best of the authors' knowledge, the first thermodynamic models analyzing transient diesel engine operation were published in the early seventies at the University of Manchester, UMIST [14-19]. These models that are known as quasi-linear were based on the assumption that transient operation behaves as a series of steady-state operating points. These models paved the way for other more fundamental approaches, pointing out important aspects of transient operation such as turbocharger lag.

From the mid-seventies until the early eighties, the most fundamental transient simulations were published, based on a degree crank angle $\left({ }^{\circ} \mathrm{CA}\right.$ ) analysis (zerodimensional models of the filling and emptying type), initially from the Imperial College researchers. Late Professor Watson and Dr. Marzouk reported a pioneering simulation [20], which was used as a basis for the majority of the upcoming models, becoming very popular in the industry too. Extensive parametric study was also conducted mainly as regards improvement in engine and turbocharger response [21-23]. Various limitations of the modeling techniques were discussed in [24], and two-stage turbocharging was proposed as one of possible methods for smoothing turbocharger lag [25].

In parallel, at the University of Manchester, the studies included two-stroke instationary engine operation [26], and extended research on methods for improving transient response [27-Pt.1], mainly by injecting air into the compressor. The research group of Professor Winterbone introduced vehicle acceleration equations [27-Pt.2]. They advanced to filling and emptying modeling $[3,28]$, while investigating also the fundamental aspect of combustion and friction deterioration during transients [12].

Professor Henein's research group at the Wayne State University pioneered in the late eighties the study concerning engine starting based on phenomenological in-cylinder modeling $[29,30]$. Later, they included detailed fuel droplets and film evaporation sub-models $[31,32]$. The simulations incorporated, for the first time, analytical, per ${ }^{\circ} \mathrm{CA}$ friction equations developed in house $[33,34]$. Recently, they reported a transient diesel engine simulation code [35] with emphasis on torsional vibrations.

The research group of Professor Rakopoulos at the National Technical University of Athens (NTUA), Greece, has developed transient operation simulations since the mid nineties. Initially, the model was developed for a single-cylinder, naturally aspirated diesel engine [36-38]. Later, it was validated on a six-cylinder, turbocharged, heavy-duty diesel engine [39]. Care was taken for developing a transient code that takes into account the non-steady-state engine profile during transients. To this aim, the model is a true multi-cylinder one, solving separately and sequentially the algebraic and differential equations for each cylinder; friction is modelled with detailed per degree equations, whereas a fuel injection sub-model is incorporated in order to consider the transient fuel pump operation. The model has been used for an extensive parametric study [40] and sensitivity analysis [41,42], covering, among many other things, various governor configurations [36], while it was also extended to second-law analysis [43-46] and investigation of compressor surging [47] (the latter on a quasi-linear basis).

The research group of Professor Assanis at the University of Michigan has studied transient diesel engine operation [48,49] including starting [50], and focused on whole vehicle simulation and VGT effects [51-53]. The latter was accomplished in partnership with the Universities of lowa, Wayne State and Wisconsin at Madison. The basis for their transient simulation was the single-zone model developed by Assanis and Heywood [54]. The dynamic behavior of the vehicle drive-train was represented by differential equations that described the kinematic and dynamic behavior of the real system, i.e. torque converter, transmission, differential etc, covering up to hybrid truck operation. An extended set of simulations was carried out for truck acceleration or Transient Cycles studies [55-57]. They also investigated the effect of various parameters on the vehicle and engine transient response with emphasis on VGT systems.

A transient model based on experimentally obtained transient heat release rates coupled with 1-D modeling of manifolds operation has been recently developed and validated at the CMT Institute of the University of Valencia, Spain [58-61], and used to investigate improvement in transient response [62], EGR effects [63] and exhaust manifold optimization [64].

Many more models following the filling and emptying [e.g. 65-71], or quasi-linear [e.g. 72-83] approach have been developed. The studies have concentrated on interesting issues such as effect of VGT [84-86], turbocharger match [87], thermal shock in engine structures [88], governor operation [89,90], exhaust emissions [91-99], vehicle cooling system [100], effect of compressor surging [101-107], electrically assisted turbocharging [108-111], vehicle performance [112-116], variable valve timing [117], sequential turbocharging [118] and marine diesel engine applications [119,120].

In recent years, there has been an increasing use of commercial software packages for in-cylinder calculations e.g. GT-Power ${ }^{\circledR}$ [121]. These are based on multi-zone modeling of in-cylinder processes and 1-D modeling of engine manifolds, and have been extended to transient simulations too [122].

Concluding this historical overview, Figure 1 provides a comprehensive list of the number of published papers up to the end of 2005. The authors have tried their best to mention all works published in international journals and well established Conferences (e.g. SAE, ASME, IMechE) requiring full paper reviews. 


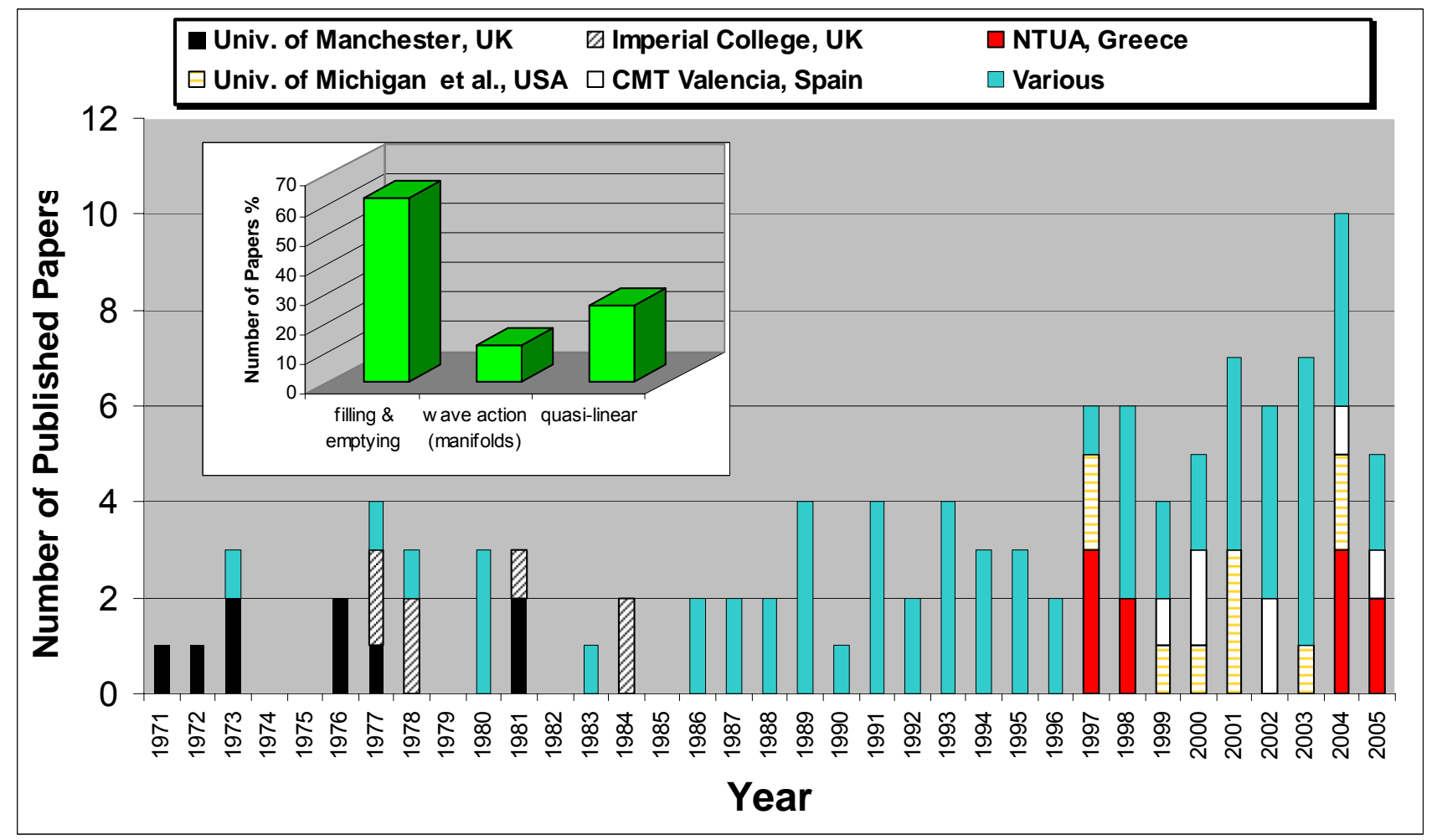

Figure 1. Number of published papers on thermodynamic transient diesel engine simulations in international Journals and well established Conferences (up to the end of 2005)

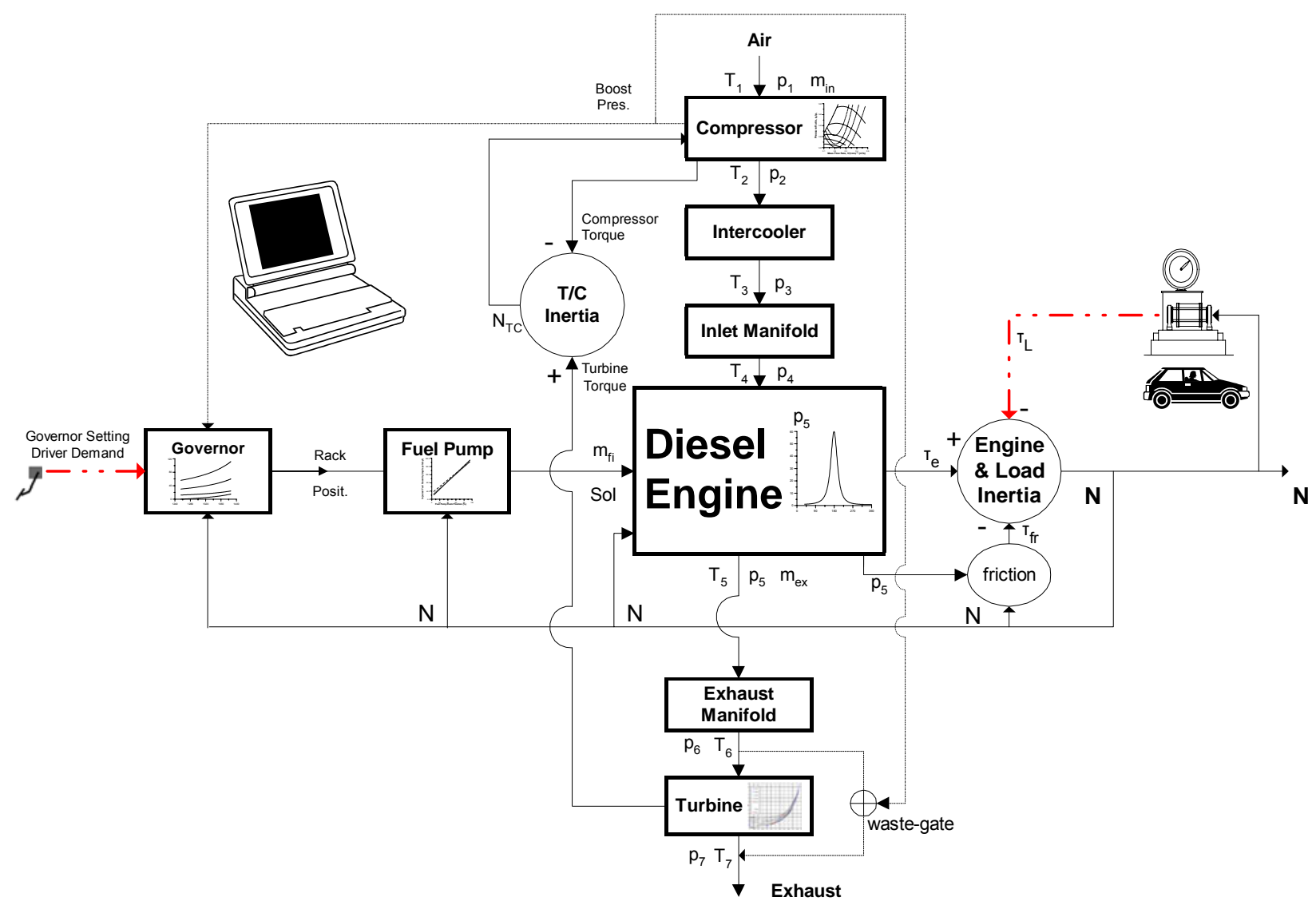

Figure 2. Block diagram of typical simulation code for transient, turbocharged and aftercooled, diesel engine operation 


\section{TRANSIENT SIMULATION ANALYSES}

In general, a simulation model (see, for example, Figure

2) for transient diesel engine operation should:

1. Be composed of high fidelity sub-models covering the operation of all engine subsystems,

2. Give adequate insight into the various engine processes, identifying the effect of key operating parameters,

3. Be flexible and with the minimum need for empirical data,

4. Have limited requirement in execution time,

5. Be modular in order to be able to adopt new subroutines, and

6. Be easily adaptable to different engines/operating conditions.

The studies concerning transient diesel engine simulations are based on a preceding steady-state mathematical-thermodynamic modeling of the processes inside the cylinder and its subsystems. Such models use a combination of analytical and empirical methods to represent the engine components and can be classified according to their degree of complication. Analytically based models tend to focus on a ${ }^{\circ} \mathrm{CA}$ variation of engine variables in considerable detail. On the other hand, empirically based models tend to take a wider view, predicting the mean values or trends of the major engine variables with a subsequent loss of resolution and much shorter run times.

\begin{tabular}{|c|c|c|c|c|c|}
\hline & \multirow[b]{2}{*}{ Linear } & \multirow{2}{*}{$\begin{array}{l}\text { Quasi- } \\
\text { Linear }\end{array}$} & \multicolumn{3}{|c|}{ Non-Linear } \\
\hline & & & $\begin{array}{l}\text { Filling \& } \\
\text { Emptying }\end{array}$ & $\begin{array}{l}\text { Wave- } \\
\text { Action }\end{array}$ & $\begin{array}{c}\text { Multi- } \\
\text { Dimensiona }\end{array}$ \\
\hline $\begin{array}{c}\text { Math. } \\
\text { Complexity }\end{array}$ & Very Low & Low & High & High & Very high \\
\hline Insight & Very Low & Low & Adequate & Adequate & High \\
\hline $\begin{array}{c}\text { Computer } \\
\text { time }\end{array}$ & Negligible & Negligible & Limited & Increased & Very large \\
\hline Adaptability & Medium & Low & Medium & $\begin{array}{l}\text { Medium- } \\
\text { Low }\end{array}$ & Low \\
\hline
\end{tabular}

Table 1. Comparison of specifications and requirements between various modeling approaches

The models used for transient simulations are (see also Table 1):

1. Linear or sampled data modeling using transfer functions ${ }^{2}$.

2. Quasi-linear. Mean value models are practically quasi-linear; their main difference being that they are usually built on physically based sub-models of the engine processes rather than empirical correlations.

3. Filling and emptying models of the zero-dimensional type. These are also termed phenomenological

\footnotetext{
${ }^{2}$ Such models [e.g. 123-125] do not include in-cylinder thermodynamic calculations, and thus will not be reviewed in this paper.
}

since they incorporate scientific principles for the simulations.

4. An extension of the latter with the introduction of wave action modeling for manifolds simulation ${ }^{3}$.

Table A, at the end of the paper, provides a detailed listing of each research group's modeling approach together with details about the engine studied, the transient schedules examined and the parameters investigated.

\section{Comments}

- The majority of transient diesel engine simulations have been carried out on four-stroke, turbocharged engines of medium-high speed. This is due to the dominance of this type of engine in vehicle applications, where the effects of turbocharger lag are most prominent. On the other hand, the naturally aspirated and, especially, the two-stroke engine have been studied scarcely. The same remark holds for Transient Cycles analysis, probably owing to the increased computational time and experimental facilities (e.g. dilution tunnels) needed for validation. An increased interest regarding transient diesel engine simulations is noticed during the last decade.

- Most of the simulations by almost 50 research groups are based on the filling and emptying approach. Quasilinear models offered an interesting alternative in the 70s but the continuously increasing power of the PC systems has limited their use in recent years for control applications. Pure 1-D or multi-dimensional in-cylinder models have not been yet applied owing to the complication and huge computational time required, although their detailed nature would considerably help the delicate task of transient heat release rate predictions.

- All the models used for transient predictions were calibrated against experimental data at steady-state conditions. The majority of them were validated, fairly well, at transient conditions too, mainly for load acceptance and/or acceleration cases. On the other hand, very few experimental data have been made available regarding vehicle operation and operation when the compressor experiences surge.

- Exhaust emissions prediction, although a prosperous field of research for steady-state operation, remains scarce when transient conditions are involved. This is mainly due to the conflict between detailed in-cylinder thermodynamic codes and the necessity to run a large number of engine cycles. On the other hand, a lot of pure experimental approaches dealing with transient (exhaust emissions) measurements have been undertaken in the last 10-15 years. The same holds for

\footnotetext{
${ }^{3}$ One dimensional modeling has also been reported. Kolade et al. [126] attempted a coupling between 1-D and 3-D analysis for fuel injection and combustion that was also used for turbocharger transient response prediction. However, this was not coupled with explicit engine dynamics modules and cannot be classified as pure 'transient' simulation.
} 
studies concerning control strategies development and implementation that are, however, out of the scope of this review.

- The study of starting has focused so far on spark ignition engines and, mainly, experimental investigations. Only a few diesel engine simulation codes have been reported. During the last 15 years, diesel cold starting study was accomplished at the University of Wisconsin-Madison via multidimensional analysis [e.g. 127,128], which allowed more insight into the complicated in-cylinder phenomena without, however, coupling with a dynamic sub-model.

\section{IN-CYLINDER SIMULATION}

\section{QUASI-LINEAR APPROACH}

The basic advantage of quasi-linear modeling lies in its simplicity combined with limited computational requirements. In this approach the elements of the system, i.e. engine cylinder, manifolds etc, are modeled in terms of steady-state and mean value characteristics using empirical correction coefficients, and neglecting the intermittent and non-linear nature of the engine operating cycle. Usually adopted simplifications are $[3,28]$ :

- Accumulation volumes in the system have negligible effect.

- Mean values are used for engine and manifolds pressures and temperatures.

- The engine output is related to fuel input via empirical equations or tabulated steady-state data. For example, Ledger and Walmsley [14] applied a linear relation for the indicated mean effective pressure (imep) provided that the air supply was sufficient for satisfactory combustion

$$
\text { imep }=a_{1} m_{f i}
$$

For air-fuel ratios lower than a critical value, a correction coefficient (termed relative thermal efficiency) was introduced to account for non-linearity between imep and injected fuel quantity $\mathrm{m}_{\mathrm{fi}}[17-19]$.

Jensen et al. [77] studying a small turbocharged diesel engine developed the following relation for the indicated efficiency

$$
\eta_{\text {ind }}=\left(a_{2}+a_{3} N+a_{4} N^{2}\right)\left(1-a_{5} \Phi^{a_{6}}\right)
$$

The indicated torque can then be estimated as the product of injected fuel mass, fuel lower heating value and indicated efficiency.
For the volumetric efficiency needed in order to estimate the air mass flowrate, Younes et al. [94] derived an empirical relation for their engine under study

$$
\eta_{\text {vol }}=a_{7}+a_{8} N+a_{9} N^{2}
$$

On the other hand, Berglund $[78,79]$ used tabulated data of brake torque vs. speed and fueling, derived at steadystate conditions. Jennings et al. [75] and Rackmil et al. $[89,90]$ followed the same approach but applied a correction coefficient to account for transient discrepancies, and a time lag, of the order of $100^{\circ} \mathrm{CA}$, to account for system delays. Winterbone [3] estimated this delay at $120^{\circ} \mathrm{CA}$.

- An empirical equation is applied for estimating the exhaust gas temperature, $T_{e x}$ at turbine inlet. This is defined from the inlet manifold temperature, $T_{\text {inl }}$, adding a temperature rise factor to it, to account for combustion effects $[3,5,17]$

$$
\Delta \mathrm{T}_{\text {st }}=\frac{\mathrm{a}_{10}}{1+1 / \Phi}, \mathrm{T}_{\text {ex }}=\mathrm{T}_{\text {inl }}+\left(1-\mathrm{e}^{\mathrm{a}_{11} \mathrm{t}}\right) \Delta \mathrm{T}_{\mathrm{st}}
$$

with $a_{10}$ a constant depending on injected fuel, engine speed and fuel-air equivalence ratio, and $a_{11}$ a time constant depending on the exhaust manifold configuration.

In order to account for other delays during transients, i.e. extra heat loss to the cooling system, higher frictional losses, and system thermal storage effects, Benson et al. [19,3] arbitrarily reduced both engine power and temperature rise by a further $5 \%$.

It is made obvious that quasi-linear models are heavily dependent on empirical data in order to adjust Equations (1)-(4), or to formulate the steady-state engine maps. However, the non-linear nature of the engine characteristics makes linear interpolation of data unreliable, especially in regions outside of those where the experimental data is available. Moreover, such experimental data are unavailable for low loads/engine speeds, where the most demanding transient tests commence. Quasi-linear modeling plausibly fails to fulfil the second, third and sixth modeling specification mentioned above. A thorough discussion concerning their limitations can be found in $[3,17]$.

\section{FILLING AND EMPTYING APPROACH}

In these models the engine and its subsystems are represented as a series of control volumes, linked by valves or orifices that interchange mass, heat and work. The ideal gas law and the principles of mass and energy conservation are applied to predict engine performance. Gas properties are computed using polynomial relations of temperature and pressure. The computational step is quite small, i.e. $1^{\circ} \mathrm{CA}$ or even less, during which quasisteady conditions are assumed for the thermodynamic properties. 
The filling and emptying, zero-dimensional models that were used as a basis for the simulation of diesel engine transient performance were almost exclusively singlezone ones, i.e. treating the cylinder contents as a uniform mixture. This approach combines satisfactory accuracy with limited computer code execution time. It leaves, however, unanswered the question about the development and prediction of exhaust emissions which is nowadays a key issue. For the latter, a solution was attempted by two-zone [93], or multi-zone models [95,97-99], with moderate success.

\section{Combustion}

When it comes to combustion modeling the usual approach is the application of a semi-empirical, physically based heat release rate law, the accuracy of which has been confirmed under steady-state conditions. This is accomplished either by matching simulated and measured pressure diagrams or by direct match between predicted heat release rates and elaborated ones from steady-state pressure diagrams. Particularly as regards multi-zone modeling, detailed submodels for spray penetration, droplet evaporation, air-fuel mixing etc are also taken into account. The universally accepted premixed-diffusion combustion models are usually applied in the form of simple Wiebe functions [129], or using its alternative and more complex version of Watson [130] or Woschni-Anisits [131], or the more fundamental Whitehouse-Way approach [132], or in the form of Arrhenius equations in multi-zone models. Great care has to be taken, in this case, for modifications needed in order to take into account the peculiarities of transient combustion, which the steady-state modeling cannot predict. The constants in the semi-empirical heat release models should not assume constant values during each transient event ${ }^{4}$, particularly when extreme load changes, and thus fuelair equivalence ratios are involved.

Recently, in order to by-pass the inherently complicated prediction of heat release during transients, some researches extrapolated the heat release rate from previously recorded experimental pressure diagrams during transient tests [e.g. 133,134]. These curves can afterwards be fed in the form of look-up tables [135] or using artificial neural network techniques [136] into the simulation code predicting other transient operations. Of course, no actual modeling is involved here, although this inverse, experimentally oriented technique can prove quite instructive in understanding engine processes.

A fundamental aspect of transient operation lies in the discrepancies when compared to the respective steadystate operation (i.e. for the same speed, fuel pump rack position and air flow). Murayama et al. [137], by studying

\footnotetext{
${ }^{4}$ For example, constant burn duration for each transient cycle is usually assumed when applying the Watson combustion model.
}

the accelerating behavior of a single-cylinder, naturally aspirated, IDI diesel engine, found that

- owing to rapid and considerable changes in fueling, instantaneous torsional deformations in the driving system of the fuel injection pump took place, leading to an incomplete combustion, which the steady-state combustion modeling was unable to predict,

- a retardation of the dynamic injection timing was also noticed, which was correlated to injected fuel mass change, as is illustrated in Figure 3. Moreover, fuel injection pressure was suspected to increase (proportionally) faster than boost pressure.

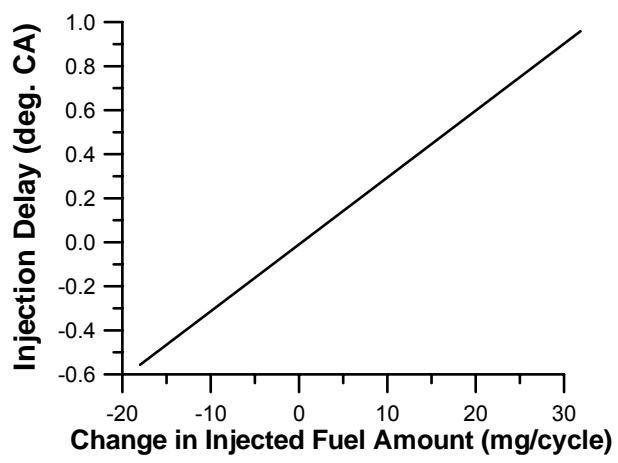

Figure 3. Change in dynamic fuel injection timing due to the deformation of the injection pump driving system resulting from changes in the amount of injected fuel [adapted from [137])

Harndorf and Kuhnt [138], summarizing other off-design phenomena during the early transient cycles, identified: a) an influence in mixture formation and ignition delay due to air-deficiency caused by turbocharger lag, b) a change in the average fuel droplet diameter caused by lower density and swirl, which led to increased jet penetration in comparison to the respective steady-state operating conditions, c) the lower end gas and wall temperatures in combination with a higher amount of end gas resulted in an increased ignition delay and hard combustion course, during the early cycles where the turbocharger lag is more prominent (confirmed also in [133]).

Winterbone and Tennant [12] working on a six-cylinder, turbocharged diesel engine found that the combustion process was somehow deteriorated after a load increase. This differentiation in transient combustion development has also been confirmed by other researchers, and, particularly as regards NOx emissions, by Cui et al. [99].

Unfortunately, transient thermodynamic modeling is not always capable of capturing the above mentioned deteriorations in combustion. One reason may be the possible inability of the empirical combustion models to predict engine performance at very low air-fuel ratios (less than unity). Another one is their inability to take into 
account phenomena of fuel accumulation that are usually experienced during the initial cycles of a turbocharged diesel engine transient cycle. For the latter a quasi- or multi-dimensional modeling would be required. One major inaccuracy lies in a usually adopted simplification, i.e. the assumption of constant combustion coefficients during transients. To overcome these burdens, many empirical approaches have been attempted:

- Benson and Whitehouse [5] proposed that the constant, $\mathrm{K}$ in the (dominant) preparation rate equation of the Whitehouse-Way model, be correlated with the Sauter mean diameter (SMD) of the fuel droplets through a formula of the type

$$
\mathrm{K} \propto \frac{1}{\mathrm{SMD}^{\mathrm{C}}}
$$

This approach was adopted, for example, by Rakopoulos and Giakoumis [40] during transient calculations, using an SMD correlation proposed by Hiroyasu et al. [139], accounting for variations in fueling, and compression and injection pressures.

- Betz and Woschni [140], extending a previous correlation by Woschni and Anisits [131], proposed a correction equation for the burn duration in order for the Wiebe functions to be applicable in the region of less than unity air-fuel ratios,

$$
\Delta \varphi_{\text {burn }}=\Delta \varphi_{\text {burn,o }}\left(\frac{\Phi}{\Phi_{o}}\right)^{0.6}\left(\frac{\mathrm{N}}{\mathrm{N}_{\mathrm{o}}}\right)^{0.5} \eta_{\mathrm{u}}^{0.6}
$$

with $\eta_{\mathrm{u}}$ the energy conversion rate that equals, at most, $1 / \Phi$ for $\Phi>1$, and 1 for $\Phi \leq 1$. This relation was developed for a DI diesel engine of medium swirl, operating at medium engine speed.

- Assanis et al. [141] proposed and validated a new ignition delay correlation, valid under transient conditions, which unlike the usually applied Wolfer one [4], incorporates the fuel-air equivalence ratio, $\Phi$. This ignition delay formula gave satisfactory results, mainly for medium to high engine speeds. It can then be incorporated in the widely adopted Watson combustion model. The same approach (i.e. incorporation of the effect of $\Phi$ ) had already been theoretically investigated by Rakopoulos and Giakoumis [38], concerning the preparation constant, $\mathrm{K}$, of the Whitehouse-Way model. Currently, the effect of $\Phi$ is also investigated concerning ignition delay calculations. This is applied to the activation constant, 'act', in the reaction rate equation of the Whitehouse-Way model,

$$
\text { act }=\operatorname{act}_{\mathrm{o}} \cdot\left(\frac{\Delta \Phi}{\Phi_{\mathrm{o}}}\right)^{\mathrm{c}}
$$

To summarize, in combustion modeling lies one of the most significant weaknesses of filling and emptying transient modeling. On the one hand, the semi-empirical models fail to capture all the details of complicated combustion during transients, despite the effort for correction coefficients. For the inverse heat release modeling approach, on the other hand, an extended set of sophisticated and costly transient tests has to be undertaken in order for the model to be able to predict other transient scenarios for the same engine and in the vicinity of the same engine speed. This fact limits and puts in question the actual process of the model's predictive capability.

A slightly different approach, being in the middle of quasi-linear and filling and emptying modeling, has been also adopted [55,57,114,115]. Here, a ${ }^{\circ} \mathrm{CA}$ based thermodynamic code was used to generate a steadystate, multi-dimensional, look-up engine torque map. The latter is used in the dynamic simulation of vehicle performance. This approach is, mainly, chosen for limiting computational time, particularly as regards Transient Cycles simulation. However, it fails to fully take into account the fundamental aspect of transient operation differentiation from steady-state conditions.

\section{$\underline{\text { Heat Transfer }}$}

As regards heat transfer correlations, the global equations of Annand [142] (including both convective and radiation terms), Woschni [143], Hohenberg [144], Nusselt or Eichelberg [6] have been used. These equations deal with overall, empirical, instantaneous spatially average heat transfer coefficients, generally assumed to be the same for all surfaces and all operating conditions in the engine cylinder. One notable exception here is the transient model by Keribar and Morel [88], who simulated in detail the heat transfer process separately for the piston crown, cylinder liner, cylinder head and valves. This was accomplished using a convective heat transfer submodel based on incylinder flow accounting for swirl, squish and turbulence, and a radiation heat transfer submodel based on soot formation. Keribar and Morel [88] as well as Rakopoulos et al. [37,134] extended the transient analysis to study the special and very interesting phenomenon of thermal shock, i.e. sharp temperature gradients development in the engine structure after a ramp increase in load or fueling, using finite element methods.

Even for the simple case where a uniform wall temperature is assumed for all cylinder surfaces, the thermal inertia of the cylinder wall has to be taken into account. This is accomplished with the use of a heat transfer scheme, based on electrical circuit analogy modeling the temperature distribution from the gas to the cylinder wall up to the coolant $[4,6,7]$. By so doing the cylinder wall thickness, thermal conductivity, diffusivity, and possible insulation schemes are taken into account.

An alternative approach is to use an "hysteresis" (time lag due to thermal inertia) expression to update the wall temperature at each consecutive cycle, which changes as a result of the increase in fueling and/or speed 
$[22,46,98]$. This approach is based on the well known fact that the update of cylinder wall temperature is notably delayed compared to changes in fueling.

\section{ENGINE SUBSYSTEMS}

In the following Sections, the most important modeling aspects will be reviewed regarding transient operation of the various engine subsystems. Most of these aspects hold for both quasi-linear and non-linear diesel engine simulations. Although they cannot be classified as engine subsystems, friction and exhaust emissions will be reviewed in this Section too.

Figure 2, presented earlier, shows a typical blockdiagram of a (filling and emptying) transient simulation code for a turbocharged, aftercooled diesel engine fitted with waste-gate and fuel limiting function, which identifies the subsystems interactions. At steady-state conditions the engine speed, $\mathrm{N}$ and the fueling, $\mathrm{m}_{\mathrm{fi}}$ are inputs to the simulation code. At transient conditions, the inputs are the load torque schedule, $T_{L}$ and the governor position/driver demand.

\section{MANIFOLDS SIMULATION - WAVE ACTION MODELING}

At the most simplified level of quasi-linear modeling, both inlet and exhaust manifolds are modeled as no volume components. The exhaust manifold pressure, which equals the turbine inlet pressure is empirically correlated to the inlet pressure and temperature, engine temperature rise (Equation (4)), and mass flow rate. A 'pulse' factor is also introduced for pulse turbocharging effects in the exhaust manifold $[3,74]$.

A more advanced version of quasi-linear modeling has also been reported, in which the filling and emptying approach is adopted for manifolds simulation [e.g. $47,83]$. Here, the ideal gas law and the first-law of thermodynamics are applied, taking into account the manifold volume and the heat loss from the (exhaust) manifold walls $[3,4,68]$.

On the other hand, most of the researchers who simulated in-cylinder processes with the filling and emptying modeling technique have extended this approach to the manifolds operation too.

However, the gas flow in the exhaust manifold of a diesel engine is markedly unsteady, resulting in the propagation of pressure waves that may affect engine performance if the exhaust pipes are long enough and the valve overlap period substantial. The influence of the unsteady flow waves' propagation is more intense in the case of pulse turbocharged engines. Here, the issue of the inlet and, mainly, exhaust gas interactions with the engine turbocharger is more prominent.

The pressure wave travel time in the exhaust manifold pipe is given by [13],

$$
\Delta \varphi=\frac{12 \mathrm{LN}}{\alpha}
$$

where $\alpha$ is the sonic velocity and $L$ the equivalent pipe length. For long enough exhaust pipes (e.g. $L=0.80 \mathrm{~m}$ ), $\Delta \varphi=35{ }^{\circ} \mathrm{CA}$, at $2000 \mathrm{rpm}$, which means that a wave action simulation should be applied. However, for shorter lengths, typical in automotive applications, or lower engine speeds, the filling and emptying approach seems to be sufficient.

Wave action models, also termed gas-dynamic, are labelled as non-steady and one dimensional $[3,4,6]$. They provide the solution of the unsteady flow equations in the engine ducts. In the more general case, wave action models are a set of first order non-linear, nonhomogenous and hyperbolic partial differential equations of mass, energy, and momentum conservation using the ideal gas law. They are solved by the method of characteristics or by finite differences techniques. Special care has to be paid for accurate modeling of the necessary boundary conditions at the duct ends, e.g. boundary conditions at the cylinder end, at the pipe open end, and at the exhaust system turbine end.

Gas-dynamic models can provide an adequate evaluation of the pulsating flow phenomena, which are of great importance for pulse-turbocharged diesel engines; nonetheless a higher computational time is required.

\section{FRICTION}

For the calculation of friction inside the cylinder, the typical approach consists of the use of mean fmep equations $[4,6,7,145]$, i.e.

$$
\text { fmep }=\alpha+\beta p_{\max }+\gamma \bar{u}_{\text {pist }}+\delta \bar{u}_{\text {pist }}^{2}
$$

where $p_{\max }$ is the peak cylinder pressure calculated at the previous engine cycle, $\bar{u}_{\text {pist }}$ is the mean piston speed, and $\alpha, \beta, \gamma$ and $\delta$ are constants derived after calibration against experimental data at steady-state conditions (some of the constants may equal zero for certain engines). Consequently, friction torque is assumed constant during a cycle with its values differentiating only from engine cycle to cycle. This approach may be suitable for quasi-linear modeling, but not for ${ }^{\circ} \mathrm{CA}$ based ones. This is due to the fact that friction torque varies significantly during the $720^{\circ} \mathrm{CA}$ of an engine cycle $[4,6,7,33,34]$. Its magnitude compared to brake torque is not negligible, particularly at low loads where the most demanding transient events commence. Its modeling remains difficult owing to the interchanging character of lubrication (boundary, mixed, hydrodynamic) and the large number of components, i.e. piston rings, loaded bearings etc, which cannot be easily isolated, experimentally investigated, and studied separately even at steady-state conditions. 
With the notable exceptions from only five research groups $[29,30,39-41,44,45,69,88,146]$, friction modeling in transient simulation codes has always, in the past, been used in the form of 'mean fmep' relations, remaining constant for every degree crank angle in each cycle in the model simulation. This may be attributed to the fact that friction does not affect the heat release rate (and thus the interior engine 'indicating' properties and exhaust emissions) but only the crankshaft energy balance; the latter one being, nonetheless, essential for correct transient predictions. Detailed friction (as well as blow-by) simulations are met in starting models [29,30], as these losses are particularly pronounced during cold start engine conditions.

The sensitivity of transient operation predictions to friction modeling errors was first investigated by Watson [24]. He showed that a (rather exaggerated) $50 \%$ overestimation in friction torque could lead to an almost equal increase in predicted final engine speed drop. He also proposed application of Equation (9) at each computational step, rather than at each cycle.

Rakopoulos and Giakoumis $[39,40]$ incorporated the Rezeka-Henein model in a transient simulation code, and compared the results with the usual fmep approach. They showed that mean fmep modeling could underestimate engine speed response by up to $12 \%$ for a turbocharged, heavy-duty diesel engine.

Recently, Rakopoulos and Giakoumis [41] incorporated the more fundamental Taraza et al. [34] friction model. By so doing, they were able to study the development of friction components during transients. Unlike the rather empirical Rezeka and Henein approach, which suffers from the need of many constants and correction coefficients, the Taraza et al. model is based on fundamental friction analysis. Here, the total amount of friction is divided into four parts, i.e. piston rings assembly, loaded bearings, valve train and auxiliaries, whereas such interesting parameters as the oil temperature can be taken into account as regards their effects on transient response.

A typical example from this work is illustrated in Figure 4a. The transient profiles given correspond to a $10-70 \%$ load increase for a six-cylinder, turbocharged, heavyduty diesel engine. The two speed curves corresponding to $90^{\circ} \mathrm{C}$ oil temperature almost coincide, only until cycle 15 , when the main change in fueling occurs, a fact leading to differentiations in gas pressures and consequently in the profile of friction torque and thus engine speed. The mean fmep curve results differ by $5 \%$ as regards both maximum and final engine speed drop from the analytical ones (for an engine-load setup with a very high moment of inertia). Similar results hold for the other engine and turbocharger properties. In this Figure, the case with an oil temperature of $60^{\circ} \mathrm{C}$ is also depicted, only for the Taraza et al. model [34], which includes such parameters' effect in its equations. Lower oil temperature results in increased viscosity and consequently increased piston rings assembly friction, eventually leading to increased total friction torque and thus greater engine speed drops.

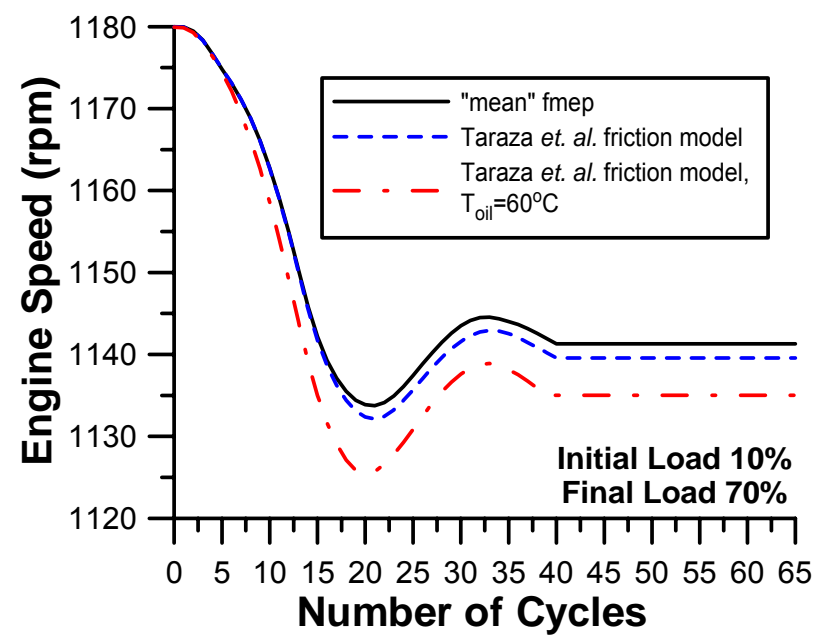

Figure $4 \mathrm{a}$. Effect of friction modeling on the prediction of transient engine operation for warm engine $\left(T_{\text {oil }}=90^{\circ} \mathrm{C}\right)$

In Figure $4 \mathrm{~b}$ the variation of total friction torque during the first and the last cycle of the previous transient load increase of $10-70 \%$ are given for warm engine operation, compared to the mean fmep results of Equation (9). The last cycle has a much fuller friction torque diagram, despite the somewhat lower final engine speed, originating from greater pressures inside the cylinder owing to the increased loading. As it is shown, the constant fmep assumption significantly underestimates friction torque for almost $180^{\circ} \mathrm{CA}$ (around firing TDC), a fact explaining the smaller speed drops observed in Figure 4a.

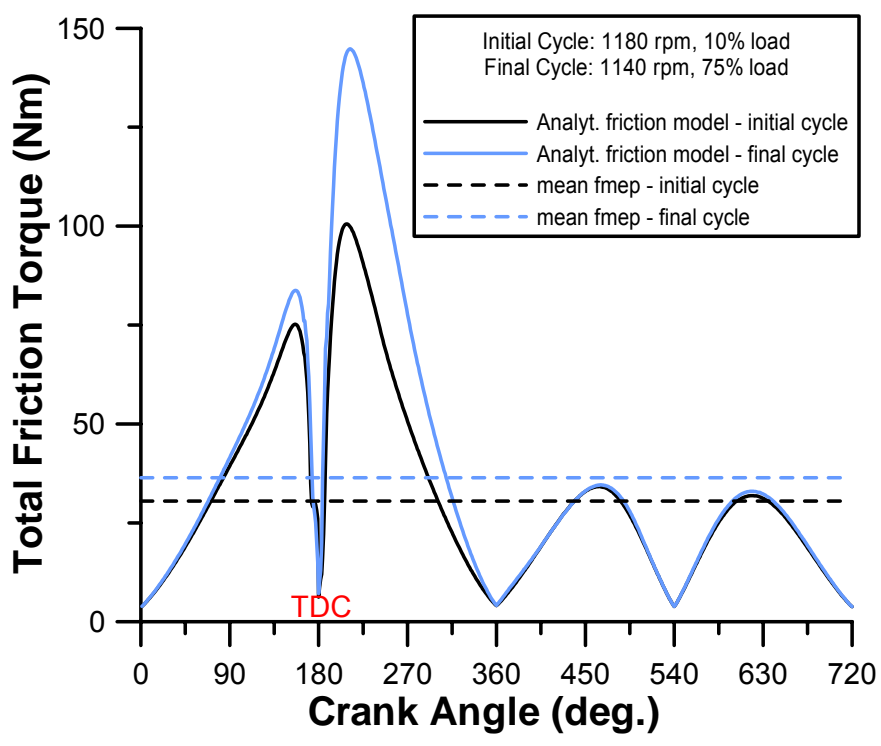

Figure 4b. Mean and detailed fmep development at the initial and final cycles of an engine transient event 


\section{TURBOCHARGER}

The mathematical representation of compressor and turbine characteristics is necessary to calculate the interaction between turbocharger and diesel engine. The majority of transient diesel engine simulations, either quasi-linear or filling and emptying, have adopted the use of compressor and turbine performance characteristics, as provided by the manufacturer or measured in-house. These give the interdependence between isentropic efficiency, $\eta_{\text {is }}$, pressure ratio, $r$, mass flow rate, $\dot{\mathrm{m}}$ and rotational speed $\mathrm{N}_{\mathrm{TC}}$ [13], i.e.

$$
\eta_{\text {isc }}, r_{C}=f_{C}\left(\dot{m}_{C}, N_{T C}\right)
$$

for the compressor, and

$$
\dot{\mathrm{m}}_{\mathrm{T}}=\mathrm{f}_{\mathrm{T}}\left(\mathrm{r}_{\mathrm{T}}, \frac{\mathrm{u}}{\mathrm{c}_{\mathrm{o}}}\right)
$$

for the turbine, with $\left(u / c_{0}\right)_{T}$ the turbine blade to speed ratio.

Jensen et al. [77] modeled the compressor through the use of the dimensionless head and flow rate parameters that were fitted to data provided by the manufacturer. An alternative approach is to simulate the turbocharger turbine as a series of converging-diverging nozzles placed at the exit of the exhaust system in contact with the atmosphere. The equivalent nozzle area of the turbine is obtained from its experimental mass flow rate and pressure ratio values.

In the conventional interpolation approach, turbomachinery maps are digitized and entered into the simulation in a tabular form or in the form of (for example) second-order polynomials. At a particular step in the cycle simulation, the tables or polynomials are interpolated in a two dimensional fashion to calculate two unknown map variables from two known variables. Rakopoulos and Giakoumis [40] reported that no difference in the predictions from a single-zone model was observed, if this computational step was less than $20^{\circ} \mathrm{CA}$.

While this interpolation technique is very straightforward to implement, there are some difficulties associated with its use in transient engine simulations [24,147], i.e.

1. The non-linear nature of compressor and turbine characteristics makes linear interpolation of data in look-up tables somewhat unreliable in regions outside of those where the experimental data are available,

2. Experimental data are usually unavailable for low rotor speed/low pressure ratios,

3. Commencement of a transient test from a zero or very small load means that the compressor practically operates with a pressure ratio less than unity, a fact complicating the situation a lot,
4. Small changes in pressure correspond in much greater changes in mass flow rate in the compressor map,

5. Obtaining accurate turbine efficiency data is another one well acknowledged problem, with general correlations usually applied that are based on the turbine blade to speed ratio,

6. The assumption of quasi-steady flow inside the turbo-machinery is a major simplification too.

All in all, it is highly uncertain that the operating points of the compressor and turbine during a transient event follow their steady-state map values. To this aim, Fink et al. [148] proposed a "flattening" of compressor curves during transient operation by using a differential equation, which takes into account the compressor through-flow time. The use of 1-D turbocharger modeling would help here, but it would significantly increase the complexity and the PC execution time of the developed code.

In recent years, an increased interest in variable geometry turbines (VGT) is observed, since these can improve transient response and fuel consumption. However, the variations between the maps corresponding to different vane positions in the VGT are non-linear, owing to the fact that the swing blade tip position relative to the rotor tip changes with the blade angle. The alternative technique, that has been applied by some researchers [e.g. 53,86 ], is to utilize artificial neural network to capture the properties of the fixed or variable geometry turbine in the whole operating range with only one compact function. The modeling process includes construction of the network of the appropriate architecture, and training of the network on the digitized turbo-machinery characteristics. Like any interpolation technique, this is more accurate when working within the boundaries of the training data; extrapolation should be avoided. Accuracy is also enhanced by increasing the amount of training data presented.

For the turbocharger transient operation, the following differential equation describes the energy balance on its shaft:

$$
\eta_{\mathrm{mTC}} \dot{\mathrm{W}}_{\mathrm{T}}-\left|\dot{\mathrm{W}}_{\mathrm{C}}\right|=\mathrm{G}_{\mathrm{TC}} \frac{\mathrm{d} \omega_{\mathrm{TC}}}{\mathrm{dt}}
$$

where $\dot{W}_{C}$ and $\dot{W}_{T}$ are the instantaneous values for the compressor and turbine power, respectively, and $\eta_{\mathrm{mTC}}$ is the turbocharger mechanical efficiency that is mainly a function of its speed [13].

When present, the waste gate valve should also be simulated, as for example in Refs $[67,84]$. The same holds for the intercooler that is usually modeled via its steady-state thermal effectiveness, being, mainly, a function of charge air mass flow [13]. 


\section{FUEL PUMP}

One of the most important parts that influence the combustion process and thus the indicated pressure, transient response and exhaust emissions, is the fuel injection system. The amount of fuel injected per cycle and cylinder, $\dot{\mathrm{m}}_{\mathrm{fi}}$, in the majority of the transient simulations so far, is found by applying the steady-state fuel pump curves at the instantaneous values of engine speed, $\mathrm{N}$, and fuel pump rack position, h, for every transient cycle, i.e.

$$
\dot{m}_{f i}=f(h, N)
$$

Such curves are shown in Figure $5 a$ for a typical turbocharged and aftercooled, heavy-duty diesel engine, without fuel limiting function. Most researchers assume that these curves hold true for transient conditions too, perhaps by imposing a time delay [14,98]. Cui et al. [99] applied linear, steady-state approximations for the injection timing, duration and injection pattern into the transient simulation code.

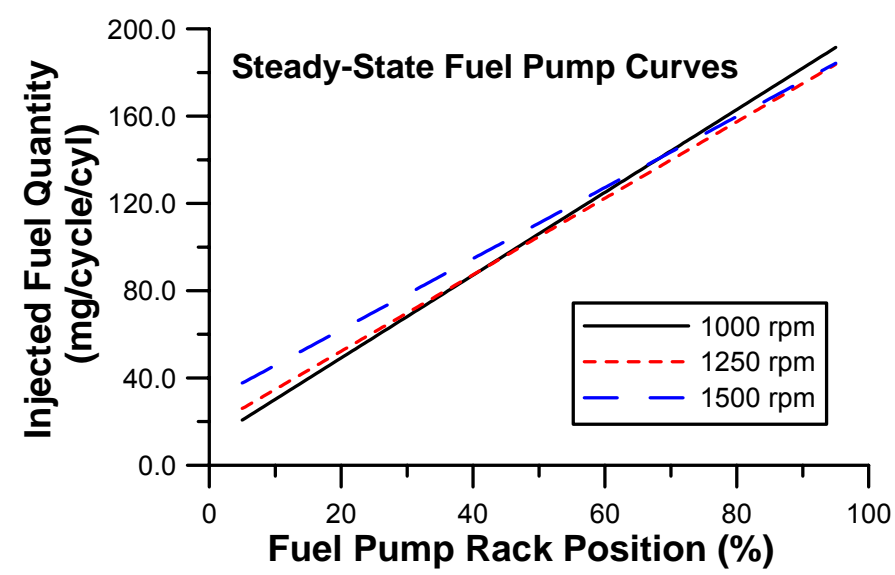

Figure 5a. Typical steady-state fuel pump curves for a diesel engine without fuel limiting function

However, the fuel pump experiences a transient operation of its own during the engine's dynamic conditions. This results in a differentiation in the amount of injected fuel per cylinder compared to the one under 'similar' steady-state conditions (same engine speed and fuel pump rack position). Watson [24] showed that a $3 \%$ underestimation of maximum fuel delivery, for a $0-90 \%$ load acceptance transient case, was enough to predict that the engine will stall, whereas no stall occurs if the 'correct' fuel pump characteristics are used.

In order to overcome the unreliable assumption of steady-state fuel pump operation, Rakopoulos and Giakoumis incorporated a mathematical fuel injection model into their transient simulation code $[39,40,42]$. This model takes into account the delivery valve and injector needle motion. The unsteady gas flow equations are solved using the method of characteristics, providing the dynamic injection timing as well as the duration and the rate of injection for each cylinder at each transient cycle. The obvious advantage here is that the transient operation of the fuel pump is also taken into account. This is mainly accomplished through the fuel pump residual pressure value, which is built up together with the other variables during the transient event. The results when applying the detailed fuel pump model, in contrast to the steady-state curves, are highlighted in Figure $5 \mathrm{~b}$ for a $10-70 \%$ load increase. A difference of the order of $8 \%$ is observed in the lowest engine speed, and consequently in the other engine properties.

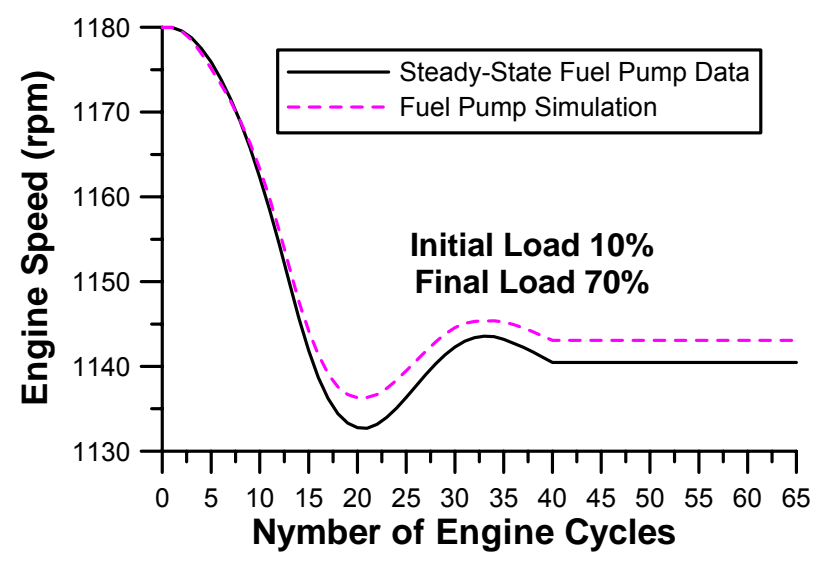

Figure 5b. Effect of fuel pump modeling on the predictions of transient engine operation

\section{GOVERNOR}

The basic function of the governor is to control the engine speed. It carries out this task by determining fueling that is consistent with current engine operating conditions and requested changes in desired engine speed. Typical auxiliary functions of the governor are fuel limiting and load regulation.

Rakopoulos et al. [36] have modeled several governor sensing elements and feedbacks; they coupled the analysis with a comprehensive, filling and emptying transient simulation code for a single cylinder, naturally aspirated, diesel engine.

Rackmil et al. [89] discuss extensively the modeling of an electro-hydraulic governor used for (quasi-linear) transient simulations, equipped with buffer system bypass, compensation cut-off, load regulation and fuel limiting capabilities.

Unfortunately, in most of the cases data for the governors are not readily available, so that in practice it is often difficult to model the governor based entirely on its physics. In order to find the instantaneous fuel pump rack position, $z$, which is initiated by the governor clutch movement, during transient operation, a differential 
equation is thus applied. This incorporates the effect of the centrifugal force of the ball weights, spring force, damping etc of the various governor elements.

Winterbone et al. [28] and Shamsi [74] used a first order differential equation for a proportional governor,

$$
\dot{\mathrm{z}}=\frac{1}{\mathrm{t}_{1}}\left[\mathrm{c}_{1}\left(\mathrm{~N}_{\mathrm{D}}-\mathrm{N}\right)+\mathrm{c}_{1}-\mathrm{z}\right]
$$

Watson and Marzouk [20] applied the following secondorder relation,

$$
c_{3} \ddot{z}+c_{4} \dot{z}+\left(1+c_{5} y\right)\left(z+c_{6} y\right)-c_{7} \omega^{2} z=c_{8}\left(\omega^{2}-\omega_{D}^{2}\right)
$$

Rakopoulos and Giakoumis $[39,40]$ used the following equation,

$$
\frac{d^{2} z}{d \varphi^{2}}=c_{9} \frac{d z}{d \varphi}+c_{10} z+c_{11} z \omega^{2}+c_{12} \omega^{2}+c_{13}
$$

where $y$ is the governor control lever position, and index $D$ corresponds to the demand value. All the $c_{i}(i=1-13)$ constants in the previous equations are derived after calibration against experimental data under transient conditions, so that there is no actual predictive capability here. Other, similar, equations can be found in $[3,84,93,103,116]$.

The most profound accessory included in the governor is the fuel limiting module. This function limits the maximum fuel delivery according to the current boost pressure. By so doing, it helps diminishing extensive smoke emissions during turbocharger lag at the expense of speed droop and recovery time (poorer vehicle driveability). The usual inputs to this module are the turbocharger boost pressure and/or the air mass flowrate. This is especially important during full load acceleration, when turbocharger lag may cause the engine to operate with much lower boost pressures than normally experienced under corresponding steady-state conditions. In modern applications this function is incorporated in the engine electronic control unit. Typical results regarding the effect of fueling control are available in $[20,24,52,90]$.

\section{ENGINE DYNAMICS}

The updated values of crankshaft rotational speed and angular acceleration during transients are derived from the conservation of energy principle applied on the total system (engine-load). For quasi-linear models, this procedure is applied once per cycle or per firing interval using the respective mean torque values. When a filling and emptying modeling is involved, it can be applied at each degree crank angle.

For the case where the stiffness of the crankshaft is taken into account, the following two equations hold [149], with reference to Figure 6,

$$
\begin{gathered}
T_{e}(\varphi)-T_{f r}(\varphi)-T_{S}(\varphi)-T_{D}(\varphi)=G_{e} \frac{d \omega}{d t}+\frac{1}{2} \frac{\partial G_{e}}{\partial \varphi} \omega^{2} \\
T_{S}(\varphi)+T_{D}(\varphi)-T_{L}\left(\varphi_{L}\right)=G_{L} \frac{d \omega_{L}}{d t}
\end{gathered}
$$

Here, $G_{e}=G_{e}(\varphi)$ and $G_{L}$ are the engine and load mass moments of inertia respectively and $\mathrm{T}_{\mathrm{e}}$ is the engine torque including gas, inertia and (the usually negligible) gravitational forces contribution. The latter is mostly dependent on correct combustion modeling,

$$
T_{e}(\varphi)=\left[p_{5}(\varphi) \cdot S_{\text {pist }} \cdot R_{1}(\varphi)+F_{\text {in }}(\varphi)+F_{g r}(\varphi)\right] r
$$

$$
u_{\text {pist }}=r \omega\left\{\sin \varphi\left[1+\frac{\lambda=r / L}{\left(1-\lambda^{2} \sin ^{2} \varphi\right)^{1 / 2}}\right]\right\}=r \omega R_{1}(\varphi)
$$
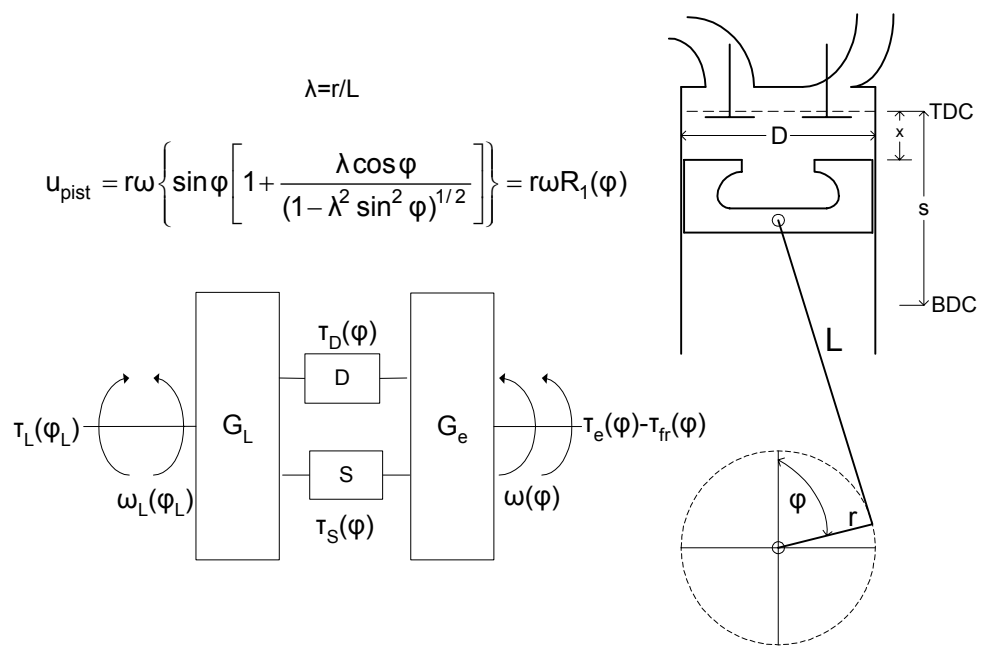

Figure 6. Schematic arrangement of engine-load dynamic system for crankshaft equations analysis

The inertia force depends on the instantaneous piston acceleration $[36,38,50,69]$. In the above relation, $p_{5}(\varphi)$ is the instantaneous cylinder pressure (see also Figure 2), $S_{\text {pist }}=\pi D^{2} / 4$ is the piston cross section area, and $R_{1}(\varphi)=u_{\text {pist }} / r \omega$, with $u_{\text {pist }}$ the instantaneous piston velocity $[4,36]$. Also, $T_{\mathrm{fr}}$ is the friction torque, $\mathrm{T}_{S}(\varphi)=\mathrm{C}_{S}\left(\varphi-\varphi_{L}\right)$ is the torsional stiffness torque, with $\mathrm{c}_{\mathrm{s}}$ the stiffness coefficient, $T_{D}(\varphi)=C_{D}\left(\omega-\omega_{L}\right)$ is the damping torque, with $C_{D}$ the damping coefficient, and $T_{L}$ is the load torque that is approximated by the following relation,

$$
\mathrm{T}_{\mathrm{L}}\left(\varphi_{\mathrm{L}}\right)=\mathrm{k}_{1}+\mathrm{k}_{2} \omega_{\mathrm{L}}^{\mathrm{s}}
$$

For a linear load-type (i.e. electric brake, generator) $s=1$, for a quadratic load-type (i.e. hydraulic brake, fixed pitch propeller, vehicle aerodynamic resistance) $s=2$, with $k_{1}$ the speed-independent load term (e.g. road slope). In general, Equation (19) is valid under steady-state conditions. Hodgson and Raine [150], who modeled the dynamic behavior of a hydraulic dynamometer, proved that deviations during transients are to be expected 
when large speed changes (more than $500 \mathrm{rpm}$ ) are involved.

Ceasu et al. [35] applied an even more detailed energy balance, taking into account all possible crankshaft deformations between pulley, each cylinder of a fourcylinder, DI diesel engine, and flywheel. This eventually led to a system of six differential equations. However, no data are available, as regards the effect of such detailed crankshaft modelings on the predicted engine-load response during transients.

In most cases, the crankshaft can be assumed as sufficiently rigid $\left(\varphi=\varphi_{L}\right)$ and the engine inertia constant. Hence, the energy balance equation reads

$$
T_{e}(\varphi)-T_{f r}(\varphi)-T_{L}(\varphi)=\left(G_{e}+G_{L}\right) \frac{d \omega}{d t}
$$

In the special case of starting, Equation (20) becomes

$$
T_{\text {start }}+T_{e}(\varphi)-T_{f r}(\varphi)-T_{L}(\varphi)=\left(G_{e}+G_{L}\right) \frac{d \omega}{d t}
$$

where $T_{\text {start }}=d_{1} e^{d_{2} N}$ is the starter motor torque [29].

As regards the connecting rod, this is usually modeled as equivalent to two-lumped masses concentrated at its ends. Rakopoulos and Giakoumis [36,38] modeled the connecting rod as a rigid body experiencing reciprocating and rotating, at the same time, movement. By so doing, they took into account the rod's complex movement and incorporated its angular velocity and acceleration. They also considered the effect of the crank angular acceleration in the rod's movement, providing a more accurate value for the instantaneous inertia force $F_{\text {in }}$ needed in Equation (18). This, however, resulted in a very modest differentiation in the results obtained from the simulation.

\section{EXHAUST EMISSIONS}

Transient simulation codes involving exhaust emissions prediction with multi-zone models are extremely few, concentrating mainly on nitrogen oxides. In the few models incorporating exhaust emissions calculations, the extended Zel'dovich mechanism [151] was adopted for NOx, and the Hiroyasu model [152] as regards soot emissions prediction.

Figure 7a shows typical predicted and experimental NOx emissions from a four-cylinder, turbocharged, DI diesel engine transient after a load increase. The discrepancies observed may be attributed to either (combustion) modeling or experimental inaccuracies. The latter holds true, since a very high response chemiluminescence analyzer is required. Appropriate regression techniques must be also applied.

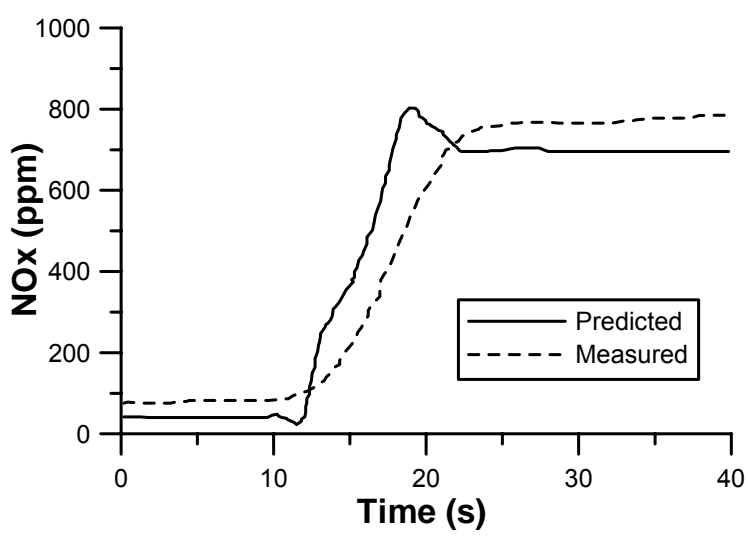

Figure 7a. Comparison between predicted and measured NOx emissions under engine load acceptance (adapted from [98])

Bazari [95] reached the conclusion that NO formation under transient operation can be closely correlated to that of its mass specific levels for the equivalent steady speed, which is a function of engine speed and rack position. On the other hand, the difference observed between transient and steady-state mass specific combustible emissions was very big.

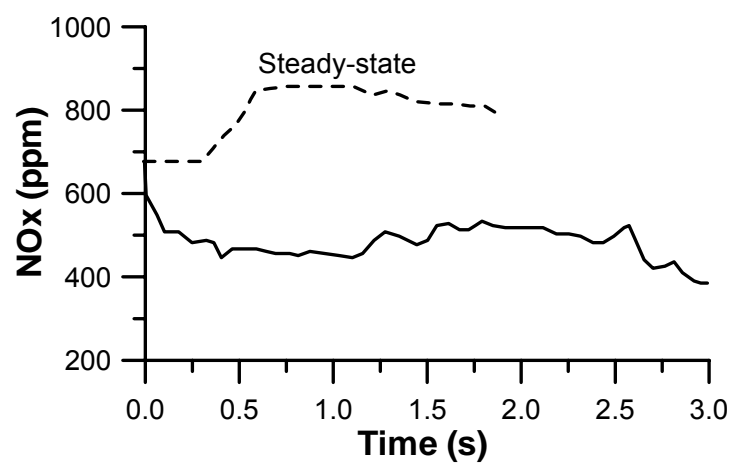

Figure $7 \mathrm{~b}$. NOx prediction for turbocharged diesel engine acceleration from 1100 to $2200 \mathrm{rpm}$ (adapted from [99])

Cui et al. [99] worked on a turbocharged, DI diesel engine of 1.30 It displacement per cylinder. They showed that the NOx emission law under transient conditions was complicated and differing with operating conditions. They found that NOx emissions do not deteriorate during all transient acceleration or load acceptance processes. NOx emissions are lower than those of corresponding steady-state conditions during acceleration and load acceptance processes with relatively high load. On the other hand, they are higher than those of corresponding steady-state ones during transient processes with low load. A typical result from their study is reproduced in Figure $7 \mathrm{~b}$, corresponding to acceleration from 1100 to $2200 \mathrm{rpm}$, with load torque increasing from 250 to $637 \mathrm{Nm}$. The respective steady- 
state NOx emissions are also provided in this figure, for the sake of comparison.

Owing to the obvious limitations of quasi-linear and single-zone modeling as regards exhaust emissions prediction, many researchers incorporated empirical approaches in their models. Such a simple relation for transient soot emissions, on a Celesco smokemeter, was given in $[3,27,74]$. This gave satisfactory results for the acceleration of a six-cylinder, turbocharged diesel engine,

$$
\text { Smoke }=b_{1} A F R^{b_{2}}
$$

Watson [22] used the following correlation for a sixcylinder, turbocharged, DI diesel engine,

$$
\frac{\text { Smoke }}{(\text { Smoke })_{\text {ref }}}=b_{3}\left(\frac{N}{N_{\text {ref }}}\right)^{b_{4}}\left(\frac{\Phi}{\Phi_{\text {ref }}}\right)^{b_{5}} \exp \left[b_{6} \frac{(1-\beta)}{\left(1-\beta_{\text {ref }}\right)}\right]
$$

with $\beta$ the premixed burning fraction [130].

Younes et al. [94] incorporated in their quasi-linear code the following relation for the Bosch smoke number (BSN) of a four-cylinder, turbocharged, diesel engine,

$$
\mathrm{BSN}=\mathrm{b}_{7}\left(\frac{\dot{\mathrm{m}}_{\mathrm{air}}}{\dot{\mathrm{m}}_{\mathrm{fi}}}\right)_{8} \mathrm{~b}^{3}+\mathrm{b}_{9} \mathrm{~N}^{2}+\mathrm{b}_{10} \mathrm{~N}+\mathrm{b}_{11} \dot{\mathrm{m}}_{\text {air }}+\mathrm{b}_{12}
$$

and a similar one for $\mathrm{HC}$ emissions.

Rakopoulos and Giakoumis [39] found the following BSN relation more appropriate for their engine studied,

$$
\mathrm{BSN}=\mathrm{b}_{13} \mathrm{e}^{\mathrm{b}_{14} \mathrm{AFR}}
$$

Jiang and Van Gerpen [91] developed the following equation for estimating the rate of particulate emissions during the EPA transient cycle,

$$
\mathrm{P}_{\text {rate }}=\mathrm{b}_{15}+\mathrm{b}_{16} \Phi+\mathrm{b}_{17} \Phi^{2}+\mathrm{b}_{18} \Phi^{3}+\mathrm{b}_{19} \Phi^{4}
$$

For all the above mentioned equations, constants $b_{i}(i=1$ 19) were derived using experimental data at steadystate conditions for various engine speeds and loads; they gave overall moderately satisfactory results.

A different approach was followed by Brace et al. [96], who applied neural network techniques on steady-state data to predict transient exhaust emissions from a quasilinear model.

Watson and Alimoradian [92], on the other hand, attempted exhaust emissions prediction during vehicle acceleration using steady-state engine emission maps, extended to include the effect of torque and speed derivatives. This feature was incorporated in a simplified transient model based exclusively on steady-state operation.

\section{DISCUSSION}

- From the transient schedules mentioned in the Introduction, the most critical one is No.1, i.e. load acceptance with constant governor setting, as in this case prediction of correct governor position is of utmost importance. This is due to the continuous movement of the fuel pump rack during the transient test (see also 'multi-cylinder' modeling discussion, later in this Section). Consequently, most of the examples in the next Sections will focus on this transient case. One of its common variations, i.e. load change under constant engine speed, is modeled more easily since no engine dynamics are involved. On the other hand, engine acceleration is usually more easily predicted, as here the rack lies at its maximum position during most of the transient test. Moreover, during acceleration, speed increases rapidly, thus limiting turbocharger lag effects compared to load acceptance cases. Prediction of Transient Cycles is a most demanding case owing to the interchanging character of transient schedules and, particularly, to the long duration involved.

- The most notable effect of transient turbocharged diesel engine operation is the turbocharger lag. This is pronounced with the continuous increase in engine rating, and it is usually realized with the increased black smoke emissions. During transients, the air-fuel ratio that produces excessive smoke is much lower than the one that is yielded at maximum engine torque, especially for low engine speeds. Turbocharger lag is caused because of the lack of mechanical connection between turbocharger compressor and engine crankshaft. Consequently, the power delivered to the turbine must first accelerate the turbocharger shaft in order for the compressor to be able to produce the increased boost pressure.

Moreover, despite the increased amount of fuel injected in the cylinders, the transfer of energy through the exhaust manifold air-gas columns slows things down. The use of fuel limiters complicates things even more, by delaying the increase in the injected fuel quantity. Other related delays concern the heat loss to the cylinder and exhaust manifold walls, and the acceleration of the rotating masses.

'Single-' vs. 'multi-cylinder' approach - This is discussed separately, as it is considered a fundamental modeling aspect. At steady-state operation the performance of each cylinder is essentially the same, due to the constant position of the governor clutch resulting in the same amount of fuel being injected per cycle. Under transient operation, however, each cylinder experiences different fuelings and air mass flow-rates during the same engine cycle. This happens due to the combined effect of the: a) continuous movement of the fuel pump rack that is initiated by a load or speed change, and b) continuous 


\begin{tabular}{|c|c|c|c|c|c|}
\hline & Simulation section & Usual approach & $\begin{array}{c}\text { Examined-more detailed } \\
\text { approach }\end{array}$ & $\begin{array}{l}\text { Differentiation } \\
\text { in results for } \\
\text { current engine } \\
\text { set up }\end{array}$ & $\begin{array}{c}\text { Computational time } \\
\text { burden }\end{array}$ \\
\hline 1 & $\begin{array}{l}\text { Cylinder wall } \\
\text { temperature }\end{array}$ & Constant value & $\begin{array}{l}\text { Heat convection- } \\
\text { conduction scheme }\end{array}$ & Negligible & Negligible \\
\hline 2 & $\begin{array}{l}\text { Cylinder-manifolds } \\
\text { interdependence }\end{array}$ & $\begin{array}{l}\text { Single-cylinder } \\
\text { approach }\end{array}$ & $\begin{array}{l}\text { "Pure" multi-cylinder } \\
\text { approach }\end{array}$ & $7.5 \%$ & Considerable \\
\hline 3 & Fuel injection & $\begin{array}{l}\text { Steady-state fuel } \\
\text { pump curves }\end{array}$ & $\begin{array}{l}\text { Fuel pump - injector } \\
\text { mechanism model }\end{array}$ & $8 \%$ & Very small \\
\hline 4 & Dynamometer & $\begin{array}{l}\text { Steady-state } \\
\text { curve }\end{array}$ & $\begin{array}{c}\text { Transient modeling of } \\
\text { brake }\end{array}$ & None * & small \\
\hline 5 & Exhaust manifold & $\begin{array}{l}\text { Filling and } \\
\text { emptying }\end{array}$ & Method of characteristics & $<3 \%$ ** & Considerable \\
\hline 6 & Friction & "mean" fmep & Modeling per deg. CA & $6 \%$ & Negligible \\
\hline 7 & $\begin{array}{c}\text { Differentiation of } \\
\text { transient from steady- } \\
\text { state }\end{array}$ & No compensation & $\begin{array}{l}\text { "Deterioration" of friction- } \\
\text { combustion rates, } \\
\text { Eq. (28) }\end{array}$ & $>10 \%$ & None \\
\hline
\end{tabular}

Table 2. Comparison between usual and more advanced approaches for filling and emptying modeling: Summary of the differentiation in results and of the computational time burden induced (engine studied is a six-cylinder, turbocharged and aftercooled diesel engine, with a speed range of $1000-1500$ rpm, coupled to a hydraulic brake, with relatively high total mass moment of inertia)

change of the turbocharger compressor operating point. As regards speed changes only the first cycles are practically affected. However, when load changes are investigated, significant variations can be experienced throughout the whole transient cycle. The usual approach, here, is the solution of the governing equations for one cylinder and the subsequent use of suitable phasing images of this cylinder's behavior. This approach was first introduced by Watson $[20,22]$ and was widely adopted for limiting the computational time. Unlike this, Rakopoulos and Giakoumis [39,40,42] developed a true multi-cylinder engine model. In this model, all the governing differential and algebraic equations are solved individually for every one cylinder of the six-cylinder engine under study, resulting in (significant) differentiations in both fueling and air mass flow-rates for each cylinder during the same cycle of a transient event. This approach has, of course, the drawback of increasing the computational time almost linearly to the number of cylinders involved.

Figure 8 is a typical illustration of the results obtained by comparing the 'single-cylinder' to the 'multi-cylinder' engine modeling approach, on a six-cylinder, turbocharged and aftercooled, heavy-duty diesel engine. For the examined transient case of $10-70 \%$ load increase (cf. Figures $4 a$ and $5 b$ ), the pressure diagrams of the first and the last in firing order cylinders are depicted for cycle No 5 and No 15. Cylinder pressures can assume up to $5 \%$ greater values when the first and the last in firing order cylinders are under investigation. This differentiates accordingly the performance of each cylinder. Similarly, all other properties that depend on the fueling rate are also differentiated from cylinder to cylinder during the same transient cycle, thus affecting the whole engine transient response.

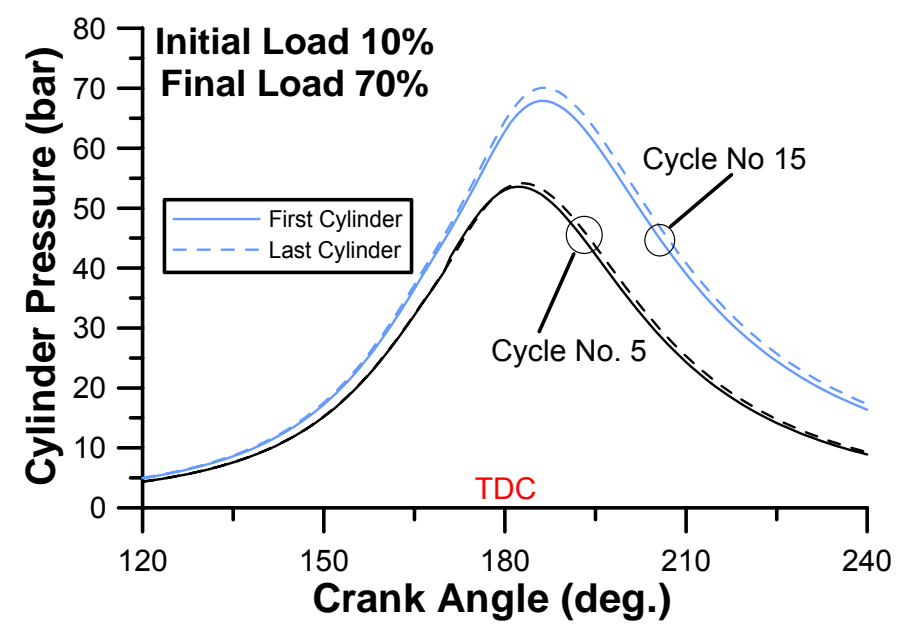

Figure 8. Effect of multi-cylinder modeling on the predictions of transient engine operation 
In recent years, commercial software packages (e.g. Matlab/Simulink) have been used as the modeling environment for transient codes. Such packages, which operate in a lumped manner, give the ability to interconnect various engine subsystems modules, e.g. cylinders, manifolds, compressors and turbines. Thus, they provide the basis for a true multi-cylinder simulation.

- Deterioration of friction - According to Winterbone and Tennant [12], rapid changes in loading lead to instantaneous, though considerable, deflections of the crankshaft due to great accelerations-decelerations, resulting in an increase of transient mechanical friction. Winterbone and Loo [26] applied the following equation for the correction of fmep during transient operation

$$
\mathrm{fmep}_{\mathrm{tr}}=\mathrm{fmep}_{\mathrm{st}}\left[1+0.0025\left(\mathrm{~N}_{\mathrm{D}}-\mathrm{N}\right)\right]
$$

where fmep $_{\mathrm{st}}$ is the corresponding steady-state fmep from Equation (9), $N$ the current engine speed and $N_{D}$ the demand speed.

Rakopoulos and Giakoumis [38,40] proposed the following correlation for the transient case,

$$
\mathrm{T}_{\mathrm{fr}}(\varphi)_{\text {trans }}=\mathrm{T}_{\mathrm{fr}}(\varphi)\left[1+\mathrm{c}_{\mathrm{fr}} \frac{\varepsilon(\varphi)}{\varepsilon_{\max }}\right]
$$

where the instantaneous value for the total friction torque, $\mathrm{T}_{\mathrm{fr}}(\varphi)$, is corrected according to the current crankshaft angular acceleration, $\varepsilon(\varphi)$, thus providing the 'real' transient friction torque, $\mathrm{T}_{\mathrm{fr}}(\varphi)_{\text {trans }}$, needed in the energy balance Equation (20). The exact value of coefficient $\mathrm{C}_{\mathrm{fr}}$ needs experimental investigation. In any case, its effect was found to be substantial $[38,42]$.

- Modeling errors - Transient simulation codes suffer from the need to run a large number of engine cycles. This often results in ignoring or over-simplifying specific submodels for the sake of speeding up program execution (quasi-linear modeling being here the most extreme example).

As regards filling and emptying modeling, the present research group has studied a number of these simplifications [42], on a high moment of inertia, turbocharged and aftercooled, heavy-duty diesel engine. It was shown that only the assumptions of constant cylinder wall temperature and steady-state dynamometer curves (for load changes or small speed changes only) are justified.

All the other assumptions can induce a modeling error, which ranges from $5-20 \%$ according to the examined transient schedule and engine-load setup. The results are presented in Table 2, which also includes comments on the imposed burden in PC execution time.
Other associated assumptions that can lead to errors in filling and emptying modeling results are the use of many empirical coefficients and exhaust manifold heat losses. On the contrary, chemical dissociation, turbulence, blowby losses and slider crank mechanism dynamics induce negligible errors.

\section{CASE STUDIES - PARAMETRIC ANALYSIS}

A typical transient event initiated from a load change of $10-80 \%$ of full engine load at constant governor setting is illustrated in Figure 9a, for a heavy-duty, turbocharged and aftercooled, medium-high speed diesel engine of 16.62 It displacement, rated at $235 \mathrm{~kW}$ at $1500 \mathrm{rpm}$. Eight, typical engine and turbocharger variables are depicted here with respect to the engine cycles or time, i.e. engine speed, reduced angular acceleration, fuel pump rack position, peak cylinder pressure, air-fuel ratio, Bosch smoke number (Equation (25)), boost pressure and turbocharger speed.
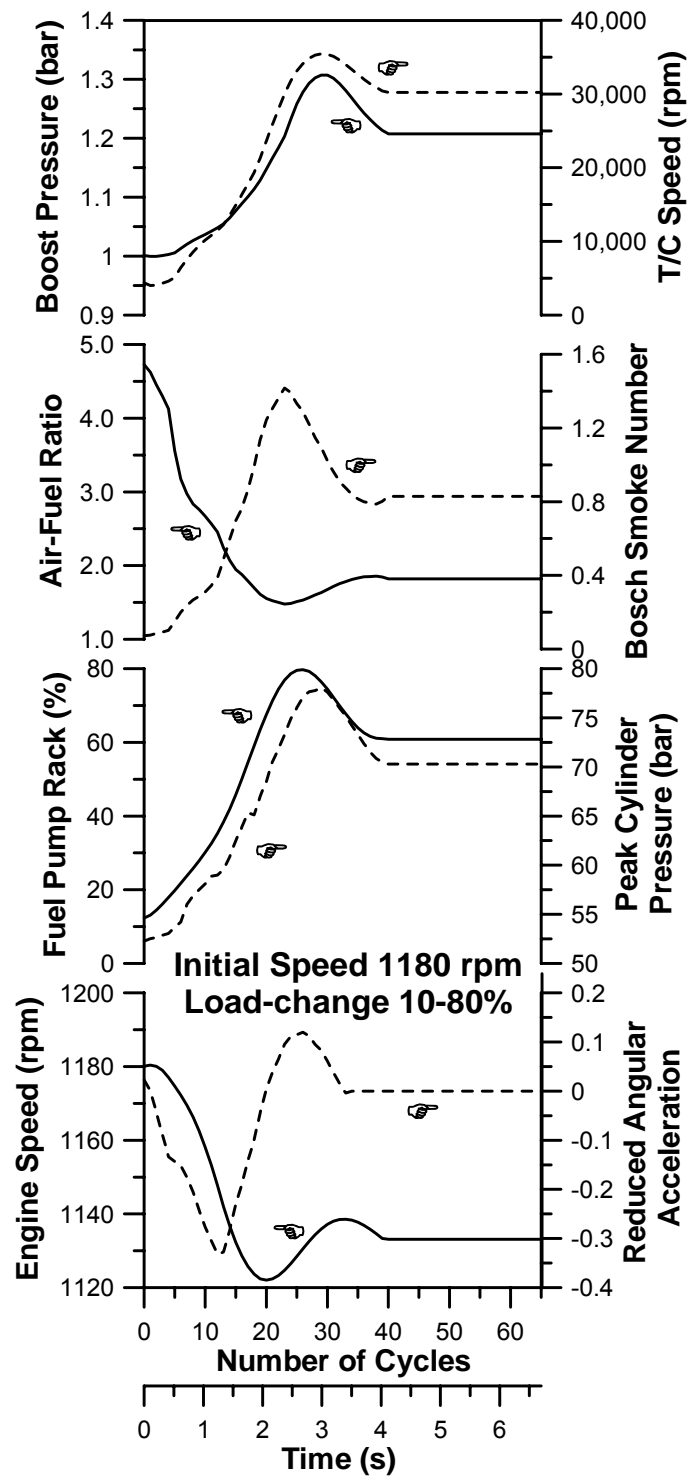

Figure 9a. Prediction of various engine and turbocharger properties development during a transient event after a ramp increase in load 
At the initial condition, the engine and load torques are equal and the air-fuel ratio very high. As soon as the new load is applied (this is accomplished in $0.5 \mathrm{~s}$ ), the engine speed drops because the load torque becomes considerably greater than its engine counterpart. This leads to a movement of the governor sensing element which, in turn, shifts the fuel pump rack towards a position of more fueling. During the early cycles (where the energy deficit is greatest), the highest values of crankshaft deceleration occur. With the gradual increase in fueling, the cylinder pressure increases and the airfuel ratio decreases. At this point the highest smoke emissions are expected. The lowest engine speed is observed twenty cycles after the application of the load change. Because of the type of load involved (quadratic, $s=2$ in Equation (19)), the drop in speed causes also a drop in load torque, resulting in quicker equilibrium between engine and load. The final equilibrium is achieved after $4 \mathrm{~s}$ or 40 cycles. Compressor boost pressure and turbocharger speed profiles are similar, with the turbocharger lag being obvious in the first cycles of the transient event. The delays involved in the engine and turbocharger response build-up, mentioned in a previous Sub-Section, are best highlighted with the observed phase shift between the minima or maxima of the various properties. The particular engine is fitted with a non-zero speed droop governor, and also possesses a high mass moment of inertia, which slows down the development of the transient event and produces rather limited smoke emissions and angular deceleration. Moreover, the load-change imposed was not a very difficult task for the engine to cope with, as the final load was lower than the maximum one. The successful load acceptance was further supported by the speed dependent load torque. For greater load-changes engine stall might occur, particularly if the engine is fitted with a fuel limiter $[20,24]$.

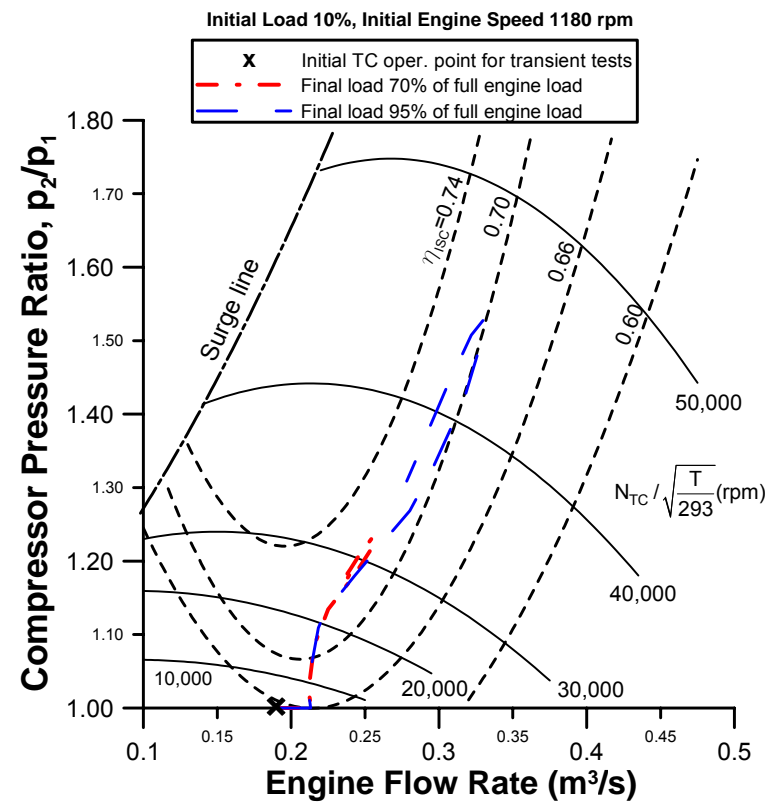

Figure 9b. Depiction of engine transient response on the turbocharger compressor map
Another way of presenting a turbocharged diesel engine transient event is by depicting it on the compressor map. This is presented in Figure 9b, for a $10-70 \%$ and a $10-$ $95 \%$ load increase of the previous engine. This technique has the major disadvantage of ignoring the time scale but can prove quite useful in studying enginecompressor interdependence such as, for example, during surge or when the subject of concern is the matching between engine and turbocharger.

A typical engine acceleration case (speed change owing to governor control lever movement, at constant engine load) is illustrated in Figure 10a for a four-cylinder, turbocharged, IDI diesel engine fitted with a waste-gate valve.

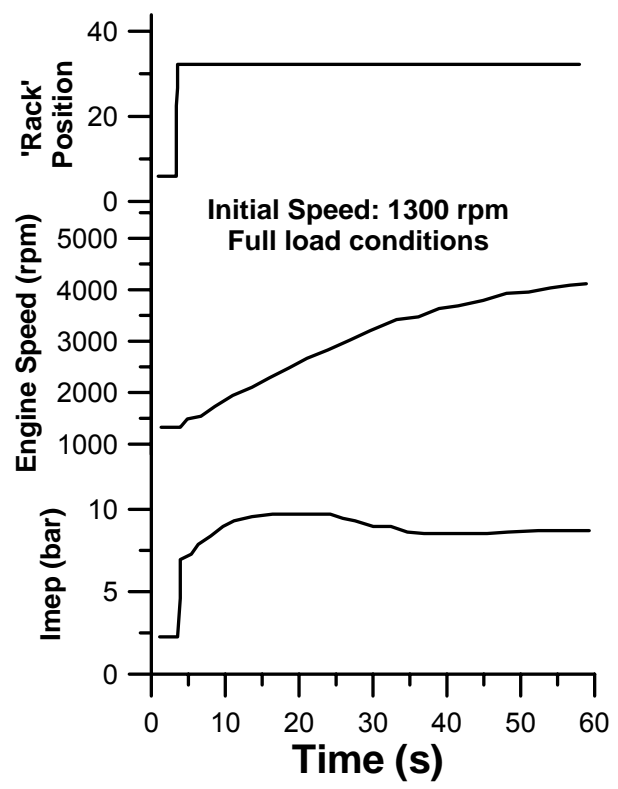

Figure 10a. Prediction of engine and turbocharger properties development during full load acceleration in $4^{\text {th }}$ gear (adapted from [67])

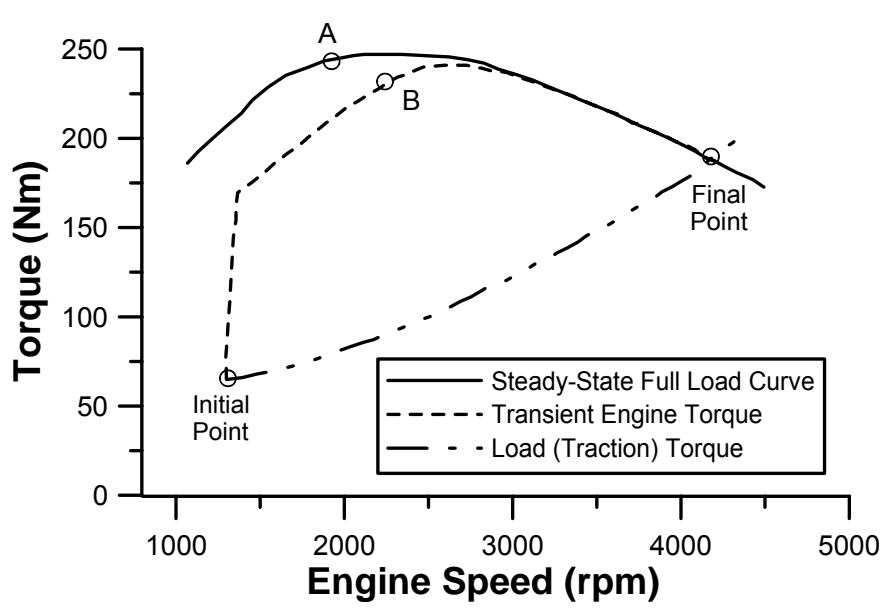

Figure 10b. Curves of steady-state full load torque, transient engine torque and load torque for the vehicle acceleration of Fig. 10a (adapted from [67]). 

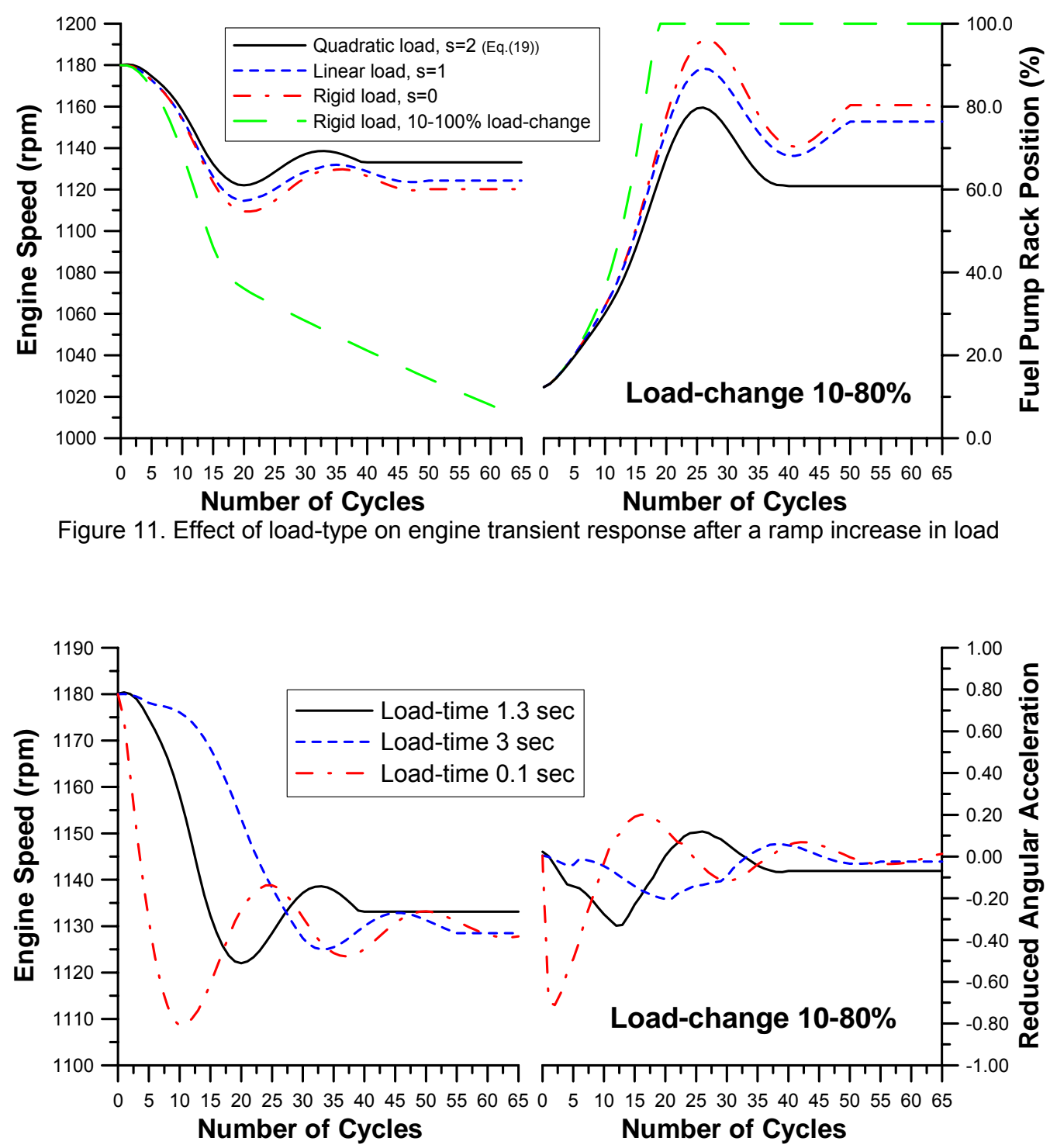

Figure 12. Effect of load-change duration on engine transient response after a ramp increase in load

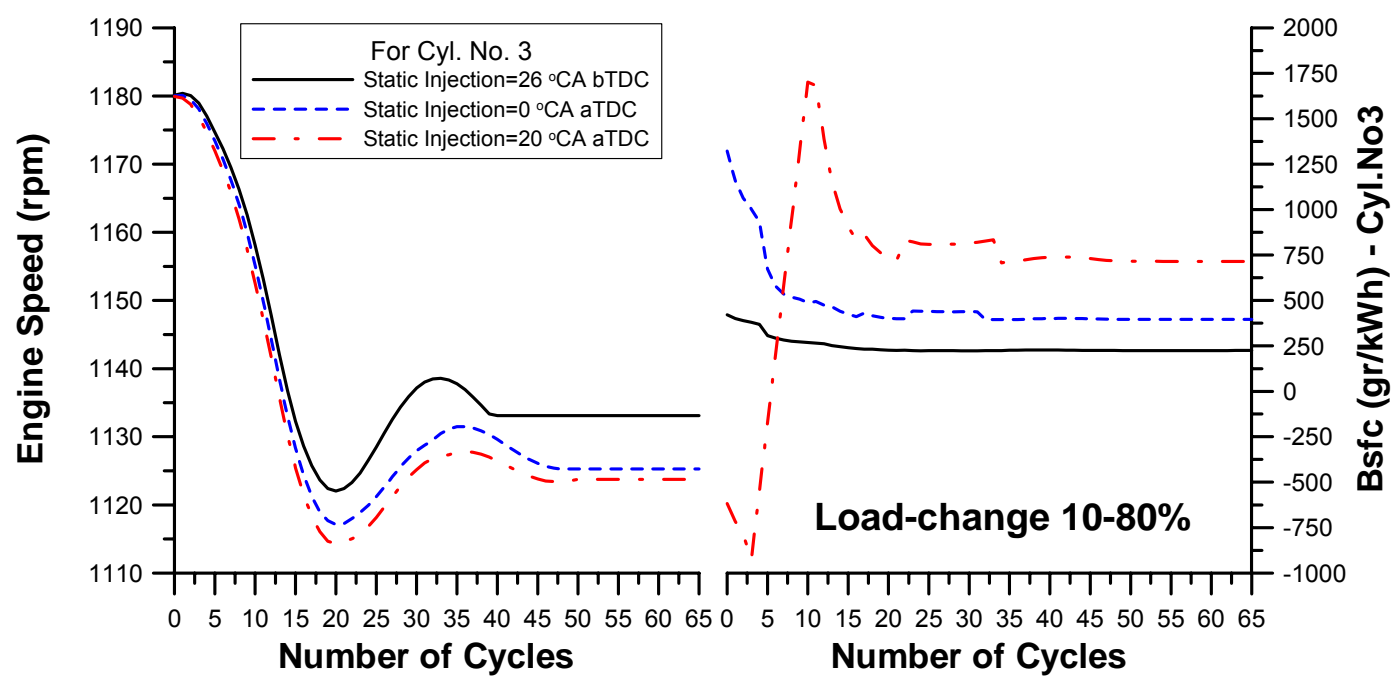

Figure 13. Effect of retarded injection timing for one cylinder of a six-cylinder diesel engine transient response after a ramp increase in load 
Full load acceleration is shown in Figure 10a, typical of vehicles operating in high gear. Here, the governor control lever reached immediately its maximum value helping the build-up of boost pressure, indicated mean effective pressure and so engine speed. Governor modeling is, in such cases, of lesser importance. Unlike the engine of Figure 9a, this one is fitted with a fuel limiting device, the effect of which is highlighted in Figure 10b. Initially (1250 rpm) and following the driver's demand, the transient engine torque increased sharply but afterwards it developed much slower owing to the fuel limiting action initiated by the lag in boost pressure (1300-2750 rpm). A clear difference is also observed between steady-state and transient maximum torques (points $A$ and $B$ respectively) as regards both absolute values and corresponding engine speeds. This was attributed to turbine acceleration, heat losses in the cold exhaust manifold and acceleration of the engine rotating masses.

An extensive parametric study has been conducted by various researchers [e.g. 20-24,36,38,40,62,84,119] as regards load acceptance and acceleration cases. Some of the major conclusions derived are summarized below. These are, mainly, predicted results derived from experimentally validated simulation codes. Some of the parameters effects have been confirmed by experimental works too. Most of the results have been confirmed by more than one research groups. Other configurations that are more design oriented and aim at improving transient response will be discussed in the next Section.

- As it is expected, the intensity of the applied load affects seriously both the speed drop and the recovery period. According to specific cases, engine stall might be experienced for intense load changes, particularly when combined with fuel limiting patterns.

- The type of load involved (rigid, linear or quadratic, Equation (19)) plays a significant role, as speed dependent loads vary favorably during operation, thus contributing to quicker equilibrium. However, a very high load change coupled to a more rigid load-type can lead to engine stall, as it is illustrated in Figure 11 for a sixcylinder, turbocharger and aftercooled, heavy-duty diesel engine.

- The load-time schedule affects significantly the profile of the response but the final equilibrium conditions are more or less unaffected. An instant load application can lead to pulsating recovery as it is depicted in Figure 12, proving also to be very demanding in terms of correct governor simulation.

- An increasing engine moment of inertia slows down the response, reducing the maximum speed drop and the smoke emissions with a simultaneous increase in the recovery time required. The obvious advantage here is the ability of the engine to cope successfully with higher and faster applied load changes.

- The compression ratio plays a secondary role, affecting thermodynamic (e.g. peak cylinder pressure) but not dynamic (e.g. engine speed) properties.
- It is a matter of final load applied and type of load involved for an engine with one problematic cylinder to successfully cope (though with greater speed drop) with a specific load change. This is illustrated in Figure 13, where the static injection timing is delayed for cylinder No 3 of a six-cylinder, turbocharged engine due to some malfunctioning of the fuel pump. Two cases are examined as follows: In the first one the static injection timing is $0^{\circ} \mathrm{CA}$ after TDC and in the second one $20^{\circ} \mathrm{CA}$ after TDC (in the nominal case the static injection timing is $26^{\circ} \mathrm{CA}$ before TDC). Delayed injection reduces considerably the efficiency of the third cylinder thus retarding the whole speed response of the engine. As is revealed from the bsfc sub-diagram, in the early cycles of the $20^{\circ} \mathrm{CA}$ case the third cylinder is motored by the other 5 cylinders. Even though only one of the six cylinders suffered a delayed injection, this was enough for a notable increase in the engine speed droop compared to the nominal case.

- Variation of the cylinder wall temperature during transients has a minimal effect on engine response and final conditions (see also Figure 19 in a following Section). However, the initial wall temperature slightly affects response, with the hot walls being more favorable, as now smaller amounts of exhaust gas energy are lost to cylinder wall heating.

- The same holds true for the exhaust manifold walls with the 'adiabatic' case being the most preferred one. Here, no heating of manifold walls takes place in the early cycles of the transient event, thus helping faster boost pressure build-up. This is shown in Figure 14 that depicts the accelerating behavior of a four-cylinder, turbocharged diesel engine of 2.4 It displacement.

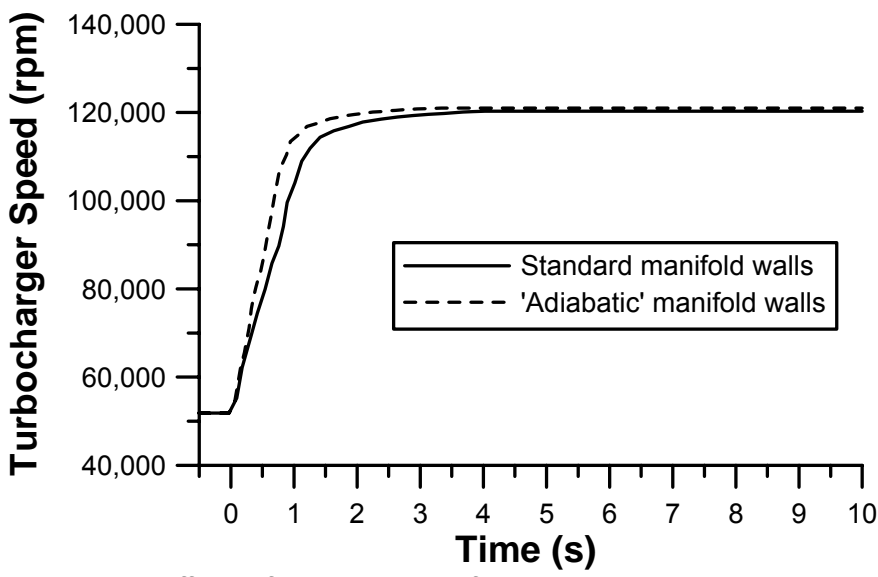

Figure 14. Effect of exhaust manifold insulation on turbocharger acceleration (adapted from [84])

- A smaller turbocharger mass moment of inertia causes faster turbocharger, according to Equation (12), and thus engine response, but it can lead to pulsating engine recovery according to the characteristics of the connected governor. A waste-gate valve may have to be installed in order to avoid extremely high boost pressures at increased loading. Figure 15 highlights the effect of turbocharger moment of inertia on engine 
speed response for a propeller-law acceleration of a highly rated turbocharged diesel engine.

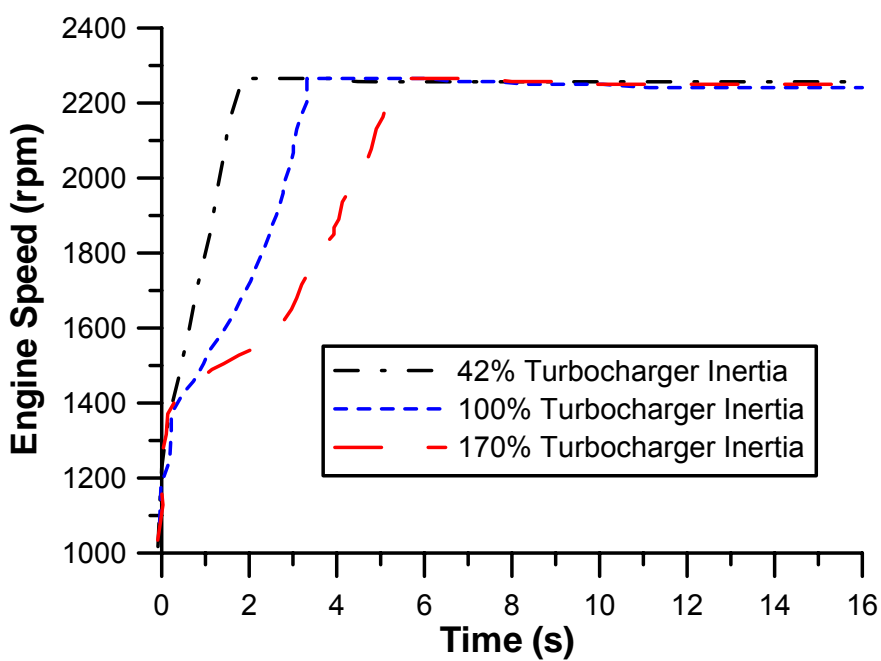

Figure 15. Effect of turbocharger moment of inertia on engine acceleration (adapted from [24])

- Reduced turbocharger frictional losses result in better turbocharger efficiency and, therefore, higher and quicker turbine speeds and boost pressures, as it was also expected from Equation (12).

- Decreased ambient temperature slightly improves boost pressure build-up and speed response owing to the increased inlet air density involved.

- Higher altitude response worsens owing to the decrease in both inlet air density and partial pressure of oxygen.

- Reduced fuel cetane number is mainly responsible for prolonged ignition delay, affecting only marginally the engine acceleration

- Geometrical and technical characteristics of the governor affect the engine response seriously in terms of speed droop and recovery period, as well as whole speed response profile. The effect of each term is sometimes conflicting when comparing speed droop and recovery period diagrams.

- The speed droop is favored when the governor is equipped with a mechanical sensing element, rather than an electrical one (when both have the same equilibrium curves and initial operating points), while the recovery period worsens. On the other hand, two-pulse sensing elements prove even more satisfactory owing to their dependence on the angular acceleration term, which is of great importance during transient operation but may lead to unstable final conditions.

- The (instantaneous) maximum speed droop improves (i.e. it lowers) with higher amplification in the servomechanism though at the expense of final speed instability. It also improves with higher values of the number and mass of flyweights, sensing element spring stiffness and sensing element spring prior tension, which lead to initial conditions close to the maximum spring deformation.

\section{WAYS OF IMPROVING RESPONSE}

Several methods have been studied via transient simulation codes for improving transient response; a lot of them were experimentally validated. Winterbone [3] categorised the methods of improving transient response as either 'passive' ones, i.e. those that do not require a separate energy source, or 'active' ones, i.e. those, which require an external energy source, such as electrical or hydraulic assistance.

Ledger et al. [16] and Winterbone et al. [27-pt.1] proposed a method of air-injection into the centrifugal compressor, studying a six-cylinder turbocharged diesel engine. This resulted in modification of the compressor characteristics, and consequently in an increase in the delivery pressure ratio and mass flow rate, and reduction in the required torque to drive the compressor. Stalling of the engine, when large load increases were applied at low engine speeds, was successfully dealt with by this method, although movement of the surge line to the right was reported.

Winterbone et al. [27-pt.1] investigated also the injection of high pressure oil onto a Pelton wheel fitted to the turbine rotor. This method required more modifications on the existent engine setup than the previous one and its results, although considered as successful, fell short of the air-injection method.

Watson and co-workers modeled various 'passive' methods for improving transient response and identified turbocharger match [21], two-stage turbocharging [25], and the simultaneous use of smaller compressor and turbine casings with a waste-gate valve [24] as promising ones. The latter method, which is nowadays an industry standard, was depicted in Figure 15.

As regards two-stage turbocharging, although the use of two turbochargers increases the total inertia, it was shown that the high pressure turbine could benefit from the low pressure one, thus improving the response of highly rated engines. This was due to the fact that the kinetic energy needed to accelerate the two sets was lower than that for a (larger) single unit. Appropriate compressor matching was also needed to exploit the above benefits, which were more pronounced for load acceptance transients. On the other hand, Saulnier and Guillain [122], studying the accelerating performance of a small automotive engine, identified a drawback of twostage turbocharging, i.e. difficulty to maintain good driveability at low engine speeds for very low cylinder volumes. It was proposed that an electrically assisted turbocharging would be needed in this case. The latter approach seems to gain increased interest in the industry during the last years. Some preliminary results will be reviewed later in this Section. 


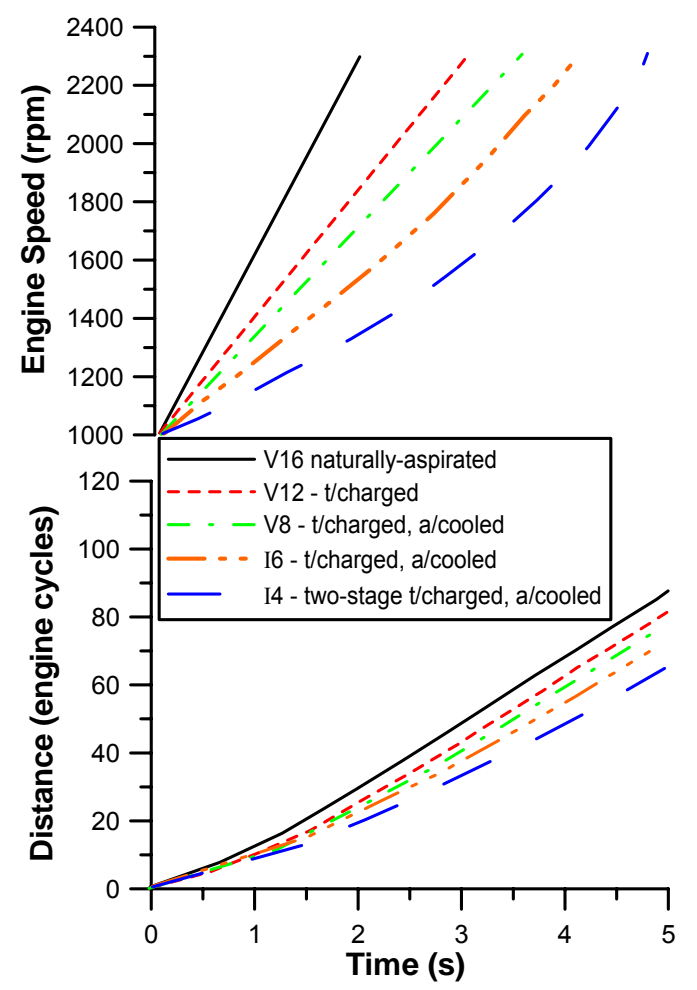

Figure 16. First gear acceleration from 1000 to $2300 \mathrm{rpm}$ and distance covered for 5 engines with different aspiration and turbocharging options, rated at the same power output (adapted from [23])
In a fundamental study [23], Watson investigated several engines, all rated at the same maximum power output but with different number of cylinders and aspirations. Figure 16, from this study, gives an overall comparison of engine acceleration and distance covered in terms of engine cycles. In the case of the naturally aspirated V16 engine, acceleration is almost linear, since full load torque is available almost instantly and the torque curve is relatively flat.

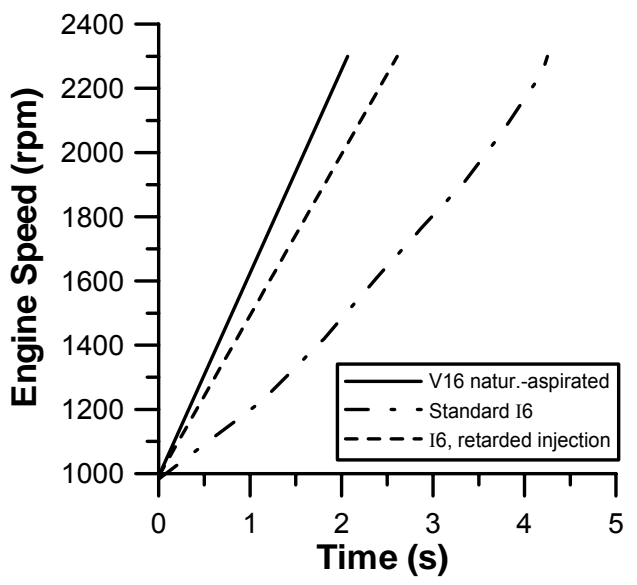

Figure 17. Effect of retarded injection timing in engine acceleration (adapted from [23])

\begin{tabular}{|ccc|}
\hline Configuration adopted & Improvement & Possible side-effects \\
\hline Air-injection into the compressor & Considerable & Considerable system modifications \\
\hline Pelton wheel fitted in turbine rotor & Considerable & Cost \\
\hline Hyperbar turbocharging & $\begin{array}{c}\text { Moderate to } \\
\text { considerable }\end{array}$ & Cost, higher bsfc, complexity \\
\hline Two-stage turbocharging & $\begin{array}{c}\text { Significant at optimum } \\
\text { matching }\end{array}$ & Poor driveability at low engine speeds \\
\hline Variable geometry turbine & Significant & Complicated control strategy \\
\hline Sequential turbocharging & Significant at part loads & $\begin{array}{c}\text { Complexity, cost, possibility of surge when } \\
\text { switching from 1 to 2 turbochargers }\end{array}$ \\
\hline Reduced turbocharger inertia & Significant & Overboosting (need for waste-gate valve) \\
\hline Reduced turbine friction & Moderate & Higher bsfc \\
\hline Retarded injection timing & Moderate to \\
considerable & Higher bsfc \\
\hline Early exhaust valve opening & Moderate to & \\
\hline Exhaust manifold volume & considerable & - \\
\hline Exhaust manifold insulation & Small & - \\
\hline Exhaust manifold tuning & Moderate & - \\
\hline Electrically assisted turbocharging & Considerable & Cost, complicated installation \\
\hline
\end{tabular}

Table 3. Various measures for improving turbine acceleration 
Acceleration of the in-line six- and four-cylinder engines is highly non-linear, largely owing to turbocharger lag. Consequently, the response time of the most highlyrated engine (in-line, four-cylinder, 27.1 bar bmep, twostage turbocharged and aftercooled) is nearly 2.5 times that of the naturally aspirated, while at the same time achieving only $74 \%$ of the distance covered by the V16 engine. Variable geometry turbine, early opening of the exhaust valve and retarded injection timing were identified as viable means for improving response. The latter is illustrated in Figure 17, for $25^{\circ} \mathrm{CA}$ before TDC static injection timing at initial steady-state conditions retarded to $15^{\circ} \mathrm{CA}$ after TDC at start of transient. However, some of the above-mentioned improvements are accomplished at the expense of fuel consumption or smoke emissions. Nonetheless, naturally aspirated engine transient performance could not be surpassed.

Boy [119-pt.2] confirmed the transient improvement owing to air-injection into the compressor, and proposed air-injection directly into the engine cylinders as a more effective technique. The backflow of exhaust gas from exhaust to inlet manifold during turbocharger lag was reduced in the case of smaller valve overlap periods too, for a V18 marine diesel engine assisting turbine acceleration.

Rakopoulos et al. [40] studied, among other things, the exhaust manifold volume and configuration and found that this can markedly affect the engine and turbocharger response after a ramp increase in load, leading even to unsteady and pulsating operation if a very small manifold volume is chosen. On the other hand, a large manifold volume (as in constant pressure turbocharging) slows down the response, since the amount of gas which has to be 'accelerated' is much larger now. This significantly enhances turbocharger lag, and it is usually met in ships where the vessel's acceleration takes considerably more time than the engine's.

Assanis and co-workers [53,56] confirmed the importance of VGT systems, for various combinations of engine-vehicle accelerations including the very interesting case of Transient Cycles, as it will be highlighted in a next Section.

Banisoleiman et al. [153] used the Watson-Marzouk [20] transient simulation code and studied the transient improvement through inlet manifold tuning, using either ram pipe or Cser-Helmholtz resonators. The results, which were mostly based on experimental study, were quite promising, although the positive aspects could not apply to all engine operating conditions and transient schedules.

Investigating ways for faster turbine acceleration, Zellbeck et al. [108] compared the performance of an electrically assisted turbocharging to a VGT turbine, and a 'nominal' turbocharger fitted with a waste gate. The former one was able to improve vehicle acceleration from $40-80 \mathrm{~km} / \mathrm{h}$ in $6^{\text {th }}$ gear up to $20 \%$ compared to the nominal case. This was significantly more than the $11 \%$ improvement from the VGT.

Panting et al. [109] investigated theoretically the improvement in transient performance of a four-cylinder turbocharged diesel engine using a motor-generator of varying power. The results were encouraging and most beneficial the greater the power of the motor-generator. However, more complex fueling strategies would have to be employed. It was suggested that the performance would benefit from the assist motor operation at low speeds, even at steady-state conditions.

Katrašnik et al. [110,111] studied the improvement in transient response of a six-cylinder, turbocharged diesel engine, rated at $162 \mathrm{KW}$ at $2400 \mathrm{rpm}$, via the use of an electrically assisted turbocharging system too. This proved satisfactory as long as the electric motor possesses high torque to mass moment of inertia ratio.

Table 3 summarizes several of the measures for improving engine transient response as were analyzed by various researches in the past 35 years. This table should be considered as a general guideline, since the actual effect depends on current engine-load setup, initial conditions and magnitude of speed or load change.

\section{SPECIAL CASES}

\section{SECOND-LAW}

Rakopoulos and Giakoumis studied the transient operation also from the second-law perspective $[43,44,154]$, i.e. using the term of availability. Availability (or exergy) of a system in a given state is defined as the maximum reversible work that can be produced through interaction of the system with its surroundings as it reaches thermal, mechanical and chemical equilibrium.

The availability balance equations were applied to the turbocharged diesel engine and all its subsystems, on a ${ }^{\circ} \mathrm{CA}$ basis [155]. For the engine cylinder it holds (index 4 corresponds to inlet manifold conditions and $5 j$ to the $j$-th engine cylinder - see also Figure 2),

$$
\frac{d A_{j}}{d \varphi}=\frac{\dot{m}_{4 j} b_{4 j}-\dot{m}_{5 j} b_{5 j}}{6 N}-\frac{d A_{w}}{d \varphi}-\frac{d A_{L}}{d \varphi}+\frac{d A_{f}}{d \varphi}-\frac{d l}{d \varphi}
$$

with $\dot{\mathrm{m}}_{4 \mathrm{j}}$ the incoming flow rate from the inlet manifold and $\dot{m}_{5 j}$ the outgoing one to the exhaust manifold for the cylinder $\mathrm{j}$, according to the first-law analysis; $\frac{d A_{w}}{d \varphi}=\left(p_{5 j}-p_{o}\right) \frac{d V}{d \varphi}$ is the availability term for work transfer with $p_{5 j}$ the instantaneous cylinder pressure, 
$\frac{d A_{L}}{d \varphi}=\frac{d Q_{L}}{d \varphi}\left(1-\frac{T_{O}}{T_{5 j}}\right)$ is the availability term for the heat transfer to the cylinder walls with $T_{5 \mathrm{j}}$ the instantaneous (uniform) cylinder temperature and $\mathrm{dA}_{\mathrm{f}} / \mathrm{d} \varphi$ is the availability term for the injected fuel. The term

$$
b=h-T_{o} s-\sum_{i} x_{i} \mu_{i}^{0}
$$

corresponds to the flow availability of the cylinder gas with $x_{i}$ the mole fraction of species $i$ in the mixture and $\mu_{i}^{o}$ the chemical potential of species $i$ at the true dead state (i.e., when there exists thermal, mechanical and chemical equilibrium with the environment). The term $\mathrm{dl} / \mathrm{d} \varphi$ in Equation (29) is the rate of irreversibility production within the cylinder, which consists mainly of the combustion term, while inlet-valve throttling and mixing of the incoming air with the cylinder residuals contribute a little. Similar expressions were derived for the second-law operation of manifolds, turbocharger and aftercooler [155].

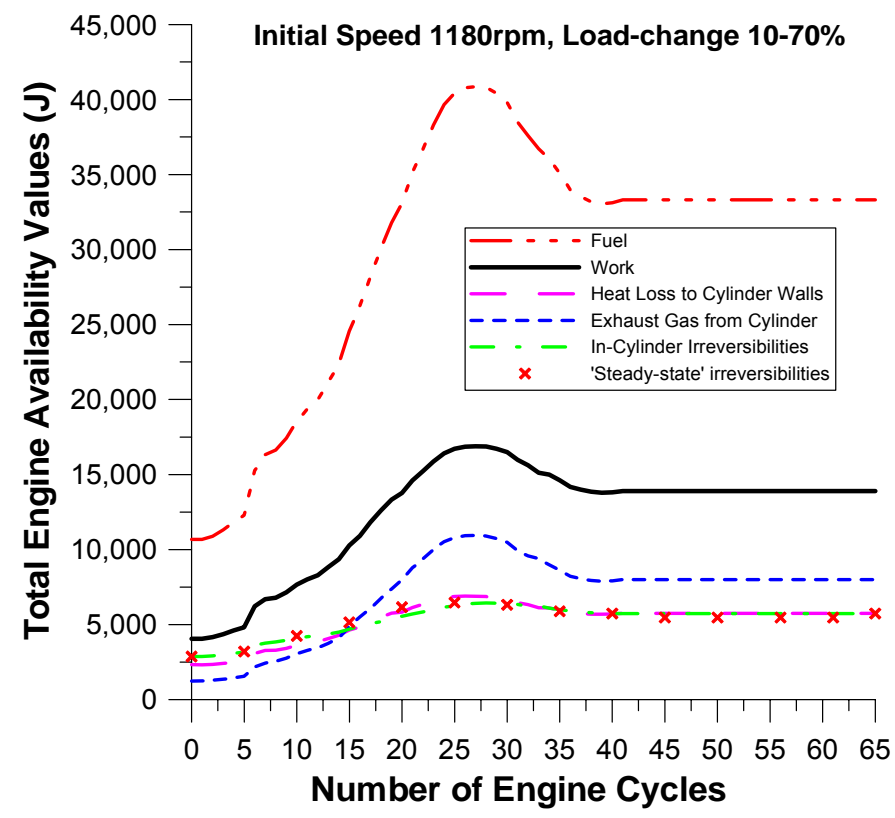

Figure 18. In-cylinder, second-law terms development during a transient event after a ramp increase in load

A typical example of second-law application to diesel engine transient operation is given in Figure 18 for a sixcylinder, turbocharged and aftercooled, diesel engine of 16.62 It displacement, producing $235 \mathrm{~kW}$ at $1500 \mathrm{rpm}$, and for a load increase of $10-70 \%$ at constant governor setting [44,154]. The response of all the in-cylinder exergy terms, viz. work, heat loss to the walls, exhaust gas and irreversibilities are illustrated as a function of the engine cycles. All of these terms are cumulative values $(\mathrm{J})$ over each cycle (for all cylinders of the engine). The exergy term for work and heat loss to the walls increase with the increase in fueling as a function of the engine cycles, because of increases in the charge temperature resulting from increases of the injected fuel quantity and accompanying fuel-air equivalence ratios. Similar results hold for the exhaust gas from the cylinder term (ranging from $12.5 \%$ at initial conditions to maximum $27.5 \%$ of the fuel availability) and for the irreversibilities term (ranging from 25\% at initial conditions to $15 \%$ at final conditions of the fuel availability). The contribution of combustion to the total irreversibilities was computed around 95\%. In Figure 18 a comparison is also included between transient and some intermediate 'steady-state' irreversibilities terms (i.e. steady-state irreversibilities at the engine speed and fueling of the corresponding transient cycles). A difference up to $11 \%$ at the $20^{\text {th }}$ cycle is observed highlighting the different evolution profile of transient combustion irreversibilities compared to steady-state operation.

Rakopoulos and Giakoumis performed an extensive parametric study too $[45,46]$. It was made obvious that a significant amount of work potential is available during transient operation (after a ramp increase in load), the exploitation of which could increase the total engine efficiency. The following were revealed from the parametric study:

- The general profile of the second-law properties transient response depend on the respective first-law ones, since the second-law properties are evaluated using first-law data.

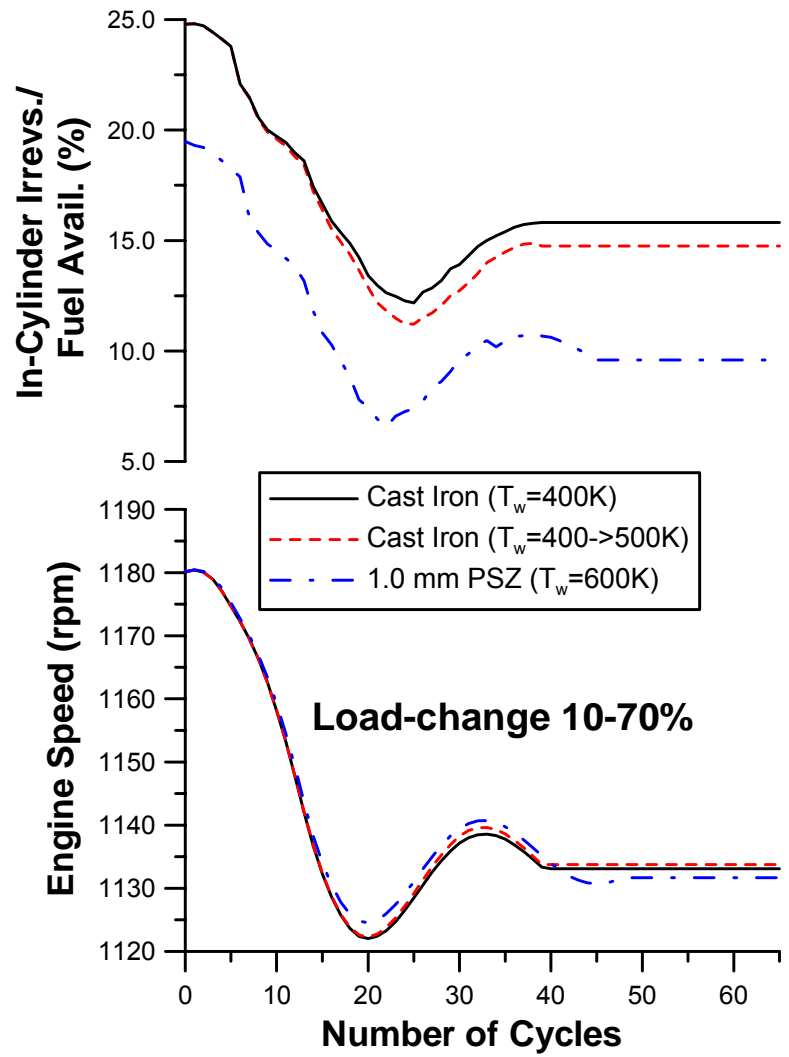

Figure 19. Effect of cylinder wall insulation on the second-law diesel engine transient performance after a ramp increase in load 
- All the parameters that lead to slow engine speed recovery (large exhaust manifold volume, or high turbocharger mass moment of inertia, or high engine mass moment of inertia) result in similarly slow turbocharger recovery, increased fuel injected quantities and thus decreased in-cylinder irreversibilities and increased exhaust gas from cylinder or to ambient availability (reduced to the fuel availability). They are, therefore, favorable from the second-law perspective, since they increase the potential for work recovery, during the transient event, for example using a bottoming cycle.

- The effect of the cylinder wall insulation (temperature) [46], for transient operation after a ramp increase in load, was also studied, as it can be seen in Figure 19. Special reference was paid to the low heat rejection ("adiabatic") case, represented here by a 1.0 $\mathrm{mm}$ plasma spray zirconia (PSZ) coating applied on the cylinder walls. As it can be seen in Figure 19, the response of the transient first-law properties remains almost unaffected by the applied wall temperature schedule. However, the engine second-law terms, including the various irreversibilities are greatly affected especially when a low heat rejection cylinder wall is chosen. This conclusion best pinpoints the difference in the results given by the two thermodynamic laws and it is in accordance with the steady-state results of previous researchers.

- The effect of the aftercooler effectiveness on the engine first-law transient response is similarly minimal, whereas the second-law terms are significantly affected.

\section{COMPRESSOR SURGE}

For optimal matching between the engine and the (VGT) turbocharger, the whole compressor operating region needs to be exploited. As a result, under steady-state conditions, the maximum torque engine operating line on the compressor map is often located close to the compressor surge line. Although the surge margin is usually adequate under steady-state conditions, when the engine operates under dynamic conditions, there are certain cases (especially for engine operation close to full load), in which the turbocharger compressor may be driven beyond its surge limit. For example, very fast load changes from high to low and again to high load, or turbocharger dirt, or switch from 1 to 2 turbochargers ${ }^{5}$ may lead to compressor surge.

Diesel engine transient simulation when the compressor operates in the surge region has been studied rarely [47,101-107]. In order to accomplish this task, representation of the compressor characteristics to the

\footnotetext{
${ }^{5}$ The sequential turbocharging technique, i.e. sequential use of two or more turbochargers, is met in marine applications in order to improve part load performance of highly-rated engines. Swain [118] published early transient data (albeit for a truck diesel engine) using a simplified engine code. Benvenuto and Campora [120] applied a two-zone thermodynamic model on a V18, four-stroke, marine diesel engine. Chesse, Tauziat and co-workers [102-104] investigated one possible side-effect of sequential turbocharging, i.e. compressor surge when switching from 1 to 2 turbochargers, for V12, V16 and V20 marine diesel engines.
}

left of the surge line is required. To obtain the unstable region of the compressor performance map, a simple method for estimating the complete compressor characteristics is usually adopted [47] that is based on the available steady region ones.

A typical, extreme engine operation case, which caused compressor surging, is illustrated in Figure 20a. Initially, the engine was running at full load and $1200 \mathrm{rpm}$. Then, the load was rapidly reduced to $10 \%$ and very soon it was increased again to $80 \%$. The relevant predicted compressor parameters are shown in Figure 20b. Firstly, the engine speed was increased owing to the load decrease. Thus, the engine airflow was increased too and the compression system operating point moved towards the choke region. After that, the engine load was increased again, causing the rapid drop of engine speed, which reached almost the value of $800 \mathrm{rpm}$. At that moment $(0.6 \mathrm{sec})$, compressor surging started, as the compressor operating point was driven beyond the surge line. As the engine speed governor responded in order to meet the demand of $1200 \mathrm{rpm}$ at $80 \%$ load, more fuel mass was injected into the engine cylinders, the engine brake torque was increased, the engine speed followed that increase and consequently the engine air flow was increased too. Thus, shortly after 0.7 sec, the compression system operating point moved back again into the stable compressor region.

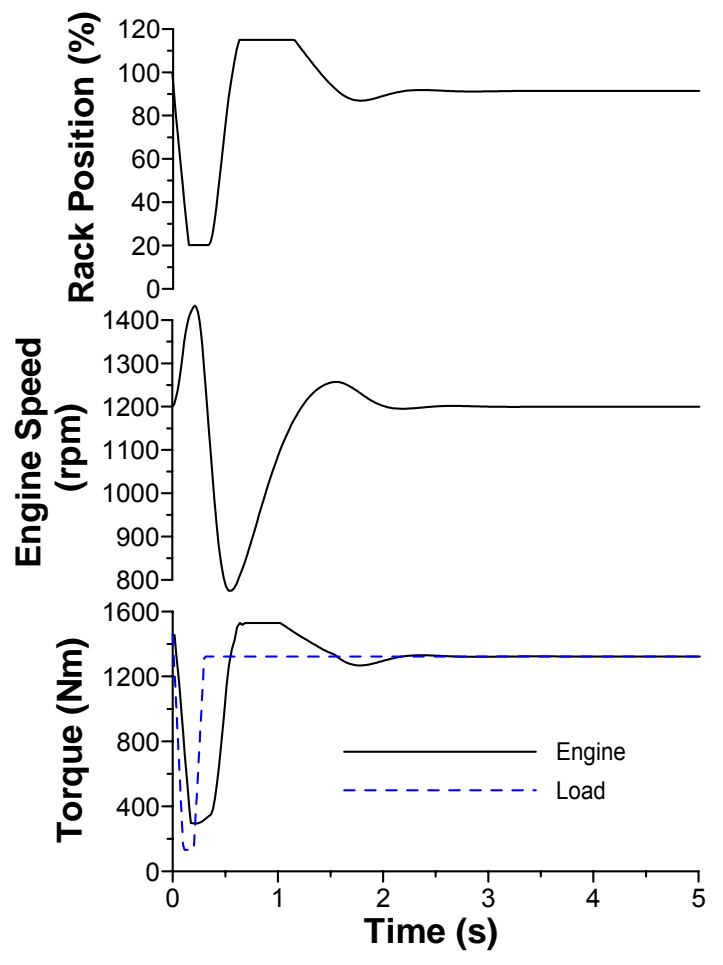

Figure 20a. Engine transient behavior for a $100-10-80 \%$ load-change schedule

As shown in Figure 20b, during the compressor surging the torque absorbed by the compressor impeller rapidly 
varied, mainly because of the air flow reversals. In this way, severe torsional loadings were introduced to the turbocharger shaft. So, it is evident that such air flow, inlet manifold pressure and turbocharger shaft torque oscillations can harmfully affect both the engine and turbocharger operation. In the examined case, compressor surging lasted only approximately $0.25 \mathrm{sec}$, and therefore it could not practically affect the engine safe running. However, if compressor surging continuously occurs, the engine and turbocharger safe running can be adversely affected.
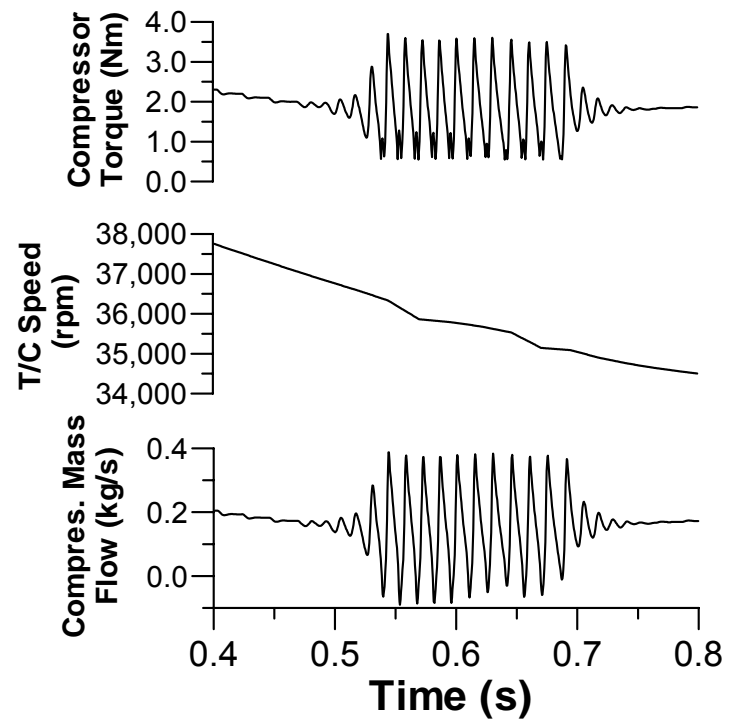

Figure 20b. Turbocharger compressor transient behavior for a 100-10$80 \%$ load-change schedule

For the engine to avoid operation under compressor surge, everything that can limit speed drop is helpful, i.e. increasing engine moment of inertia (this has a negative impact on fast speed response), or decreasing turbocharger moment of inertia, or increased governor gain constant $\mathrm{C}_{2}$ in Equation (14) (although this may lead to pulsating engine recovery), or decreased load change duration.

\section{VEHICLE PERFORMANCE}

Simulations of the whole vehicle performance were first coupled with transient engine simulation code by Winterbone et al. [3,27-pt.2], who provided basic equations for modeling the engine-gearbox-wheel drivetrain and gave some preliminary results, incorporating smoke emissions. The engine output was absorbed by the various resistances to truck motion, or in acceleration.

Figure 21 is a typical result from this modeling for a sixcylinder, turbocharged diesel engine of 11.32 It displacement, rated at $175 \mathrm{~kW}$ at $1800 \mathrm{rpm}$, mounted on a 32 tonne truck, and for upward gear changes schedule commencing from still-stand. Satisfactory validation with experimental measurements was also reported. For those, the dynamometer load simulated the acceleration torque and the road resistance. As was expected, the effect of turbocharger lag is here less prominent than in the load acceptance case (Figure 9a). This is due to the fact that the acceleration of the engine helps the build-up of boost pressure. A similar simulation approach was adopted in the following years by other researchers regarding vehicle acceleration and gear change simulation [e.g. 26,63,93,116].

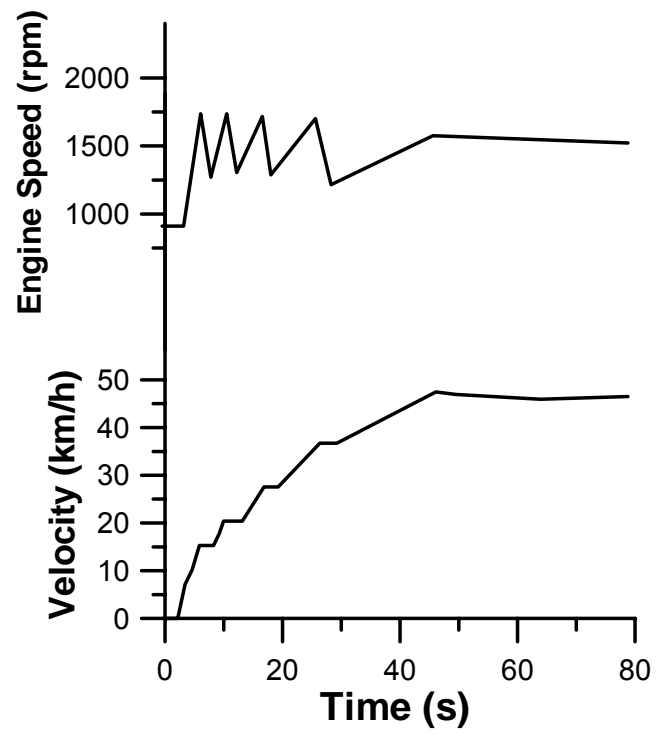

Figure 21. Truck vehicle velocity and engine speed development for an upward gear shift schedule commencing from still stand (adapted from [27-pt.2])

A more detailed and comprehensive approach for vehicular transient performance studies was adopted by Jennings et al. [75] and Ciesla and Jennings's modular, quasi-linear [113], and Assanis and co-workers' [52,53] filling and emptying models. For the vehicle model, nonlinear, 3-D multi-body kinematics and dynamics models were developed in longitudinal and heave directions, covering several subsystems, i.e. torque converter, transmission, inter-axle differential and front and rear driveline, wheels/tyres, axles, suspensions and body of the vehicle. One of the main difficulties of such studies is the appropriate link between the engine simulation module with the multi-body vehicle dynamics module. The difficulty arises because of the different time steps required for the solution of the differential equations in each module. The engine module requires a time step of the order of one ${ }^{\circ} \mathrm{CA}$, which is much too small for the vehicle dynamics. The fully integrated wheeled vehicle simulation was then used to study several combinations of engine, driveline and vehicle modules.

A typical result from these studies is given in Figure 22 [53]. Here, the hard acceleration $(0-60 \mathrm{mph})$ of a truck equipped with fixed geometry turbine is compared to the one with a VGT. The vehicle is initially at still-stand, with 
brakes applied and the engine idling at $700 \mathrm{rpm}$. At $\mathrm{t}=3$ seconds, the brakes are released and the driver demand is increased to the maximum value. Vehicle and engine parameters are tracked until the vehicle reaches $60 \mathrm{mph}$. The comparison of output parameters calculated for the engine with the conventional and VGT turbocharger are shown in this Figure, regarding engine speed development. It is obvious that the turbocharger lag can be significantly limited with the VGT coupled to a performance-oriented control strategy. The latter closes down the blades as long as the boost level is below the target, thus significantly increasing the rate of rotor acceleration after a sudden increase of engine load. Faster build-up of pressure allows injection of more fuel without the danger of causing excessive smoke. The resulting higher levels of transient engine torque with VGT reduce the time from launch to the first gear as well as the total acceleration time.

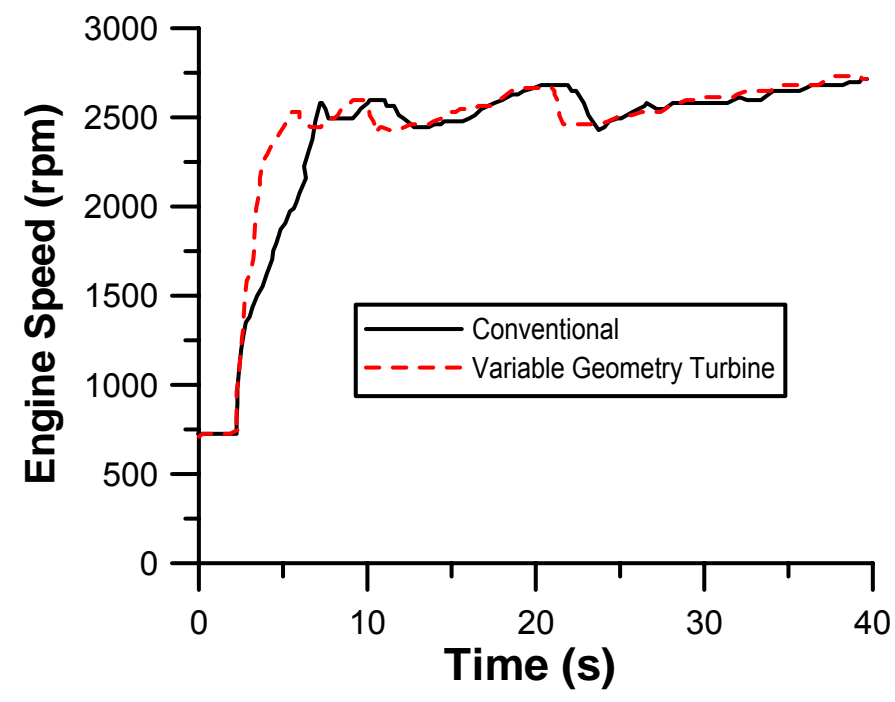

Figure 22. Effect of VGT on engine speed development during full power acceleration from 0-60 miles per hour (adapted from [53])

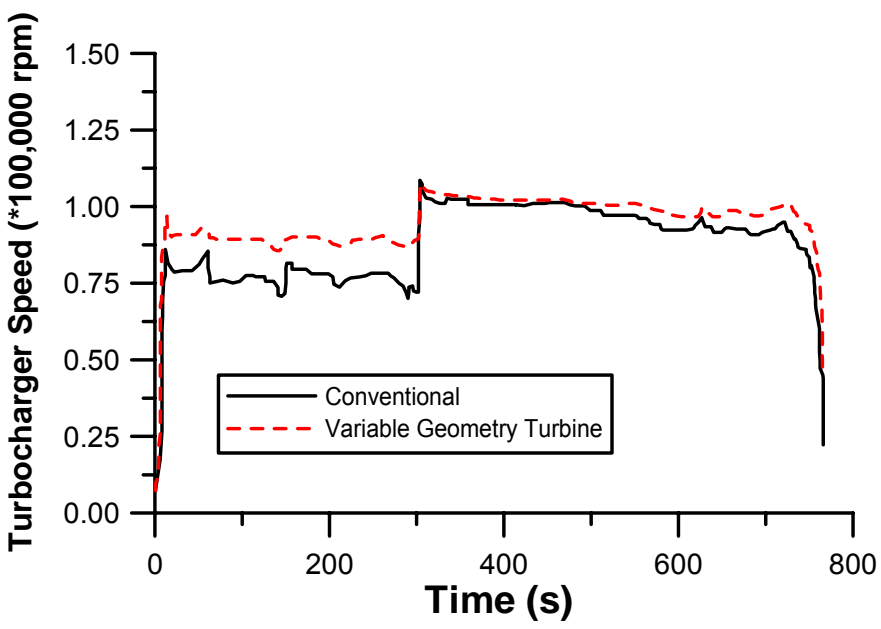

Figure 23. Effect of VGT on turbocharger speed development over the US Highway Driving Cycle (adapted from [53])
The previous analysis is extended in Figure 23 for a (highway driving) Transient Cycle. The application of VGT with a performance oriented control strategy affects primarily the filling of engine with fresh charge. The turbocharger with the VGT is kept at almost constant speed during the whole driving cycle, and consequently the variations of the pressure in the intake manifold with engine load are very small. This produces a favorable reduction in the fuel-air ratio during the first part of the driving cycle and a slight reduction of fuel-air ratio during the high speed/high load part of the cycle, including the peak at the 300-second interval. This reduction in fuelair ratio illustrates the potential of the VGT to adapt to varying operating conditions and allows better control of cycle parameters that are important for combustion efficiency and emissions [53].

\section{SUMMARY-CONCLUSIONS-FUTURE WORK}

- The transient response of compression ignition engines forms a significant part of their operation and it is of critical importance, owing to the often non-optimum performance involved as regards turbocharged engines. Moreover, the launch of emission directives, in the form of Transient Cycles, have directed engine manufacturers to deal with overall (vehicles') transient performance, since it is well established that the transient operation contributes much more to the total amount of emissions than the corresponding steady-state one.

- The most notable effect of transient turbocharged diesel engine operation is the turbocharger lag, which is caused by the lack of mechanical connection between turbocharger compressor and engine crankshaft. Consequently, the power delivered to the turbine must first accelerate the turbocharger shaft in order for the compressor to be able to produce increased boost pressure. The way the energy is transferred through the exhaust manifold, the use of fuel limiters, and the heat losses to the cylinder and exhaust manifold walls are few of the reasons for delaying transient response.

- The majority of transient diesel engine simulations are based on the filling and emptying approach, which combines adequate insight into the relevant phenomena and requires limited computational time. Quasi-linear models are met often, owing to the low computational time required that makes them ideal for real time simulations. Four-stroke turbocharged engines of medium-high speed have been in the focal point of research in the last 35 years, due to their dominance in vehicle applications, where the effects of turbocharger lag are most prominent.

- Transient diesel engine simulation has not yet adequately been diversified from steady-state/linear approximations, the most notable ones being the fuel pump and turbocharger modeling. Moreover, the simulations often fail to give insight into the highly complicated combustion performance during the early cycles of the transient event, despite the application of correction equations and coefficients. In combustion 
modeling lies one of the most significant weaknesses of the transient simulations applied so far. Quasi- or multidimensional modeling would be required, but these are, for the time being, prohibited owing to the high computational time involved. Detailed friction, fuel pump and multi-cylinder modeling were identified as important aspects for more accurate transient simulation.

- A lot of fundamental and parametric studies that were carried out have shed light into the basic engine and turbocharger variables development, and identified several means of improving response, such as decreased turbocharger inertia or VGT. Unfortunately, some of the proposed measures are effective for a limited engine operating range, e.g. tuned manifolds. Other measures, such as retarded injection timing or early opening of exhaust valves, conflict with important engine specifications (exhaust emissions or fuel consumption).

- The simulations have been extended to special cases of transient operation, such as whole vehicle performance, cold starting, turbocharger compressor surging and, recently, second-law analysis. By so doing new interesting aspects of diesel engine transient performance have been provided.

- Reliable study of pollutants emissions during transient operation via the use of suitable models is the most important objective for the future. Its accomplishment is, for the moment, limited, due to the high computational time required for the analysis of hundreds of cycles. Fortunately, experimental investigations of transient operation and computational power of personal computers both flourish during the last years, forming a sound basis for an even more successful investigation of dynamic engine operation in the near future.

\section{ACKNOWLEDGEMENT}

The authors would like to thank Assistant Professor D.C. Kyritsis with University of Illinois at Urbana-Champaign for his kind assistance with literature gathering.

\section{REFERENCES}

1. European Commission for Environmental and Transport Issues: http://www.europa.eu.int/comm/ environment/air/legis.htm\#transport

2. http://www.dieselnet.com/standards/cycles/

3. Horlock, J.H. and Winterbone, D.E., eds, The Thermodynamics and Gas Dynamics of Internal Combustion Engines, Vol.II, Clarendon Press, Oxford, 1986.

4. Heywood, J.B., Internal Combustion Engine Fundamentals, McGraw-Hill, New York, 1988

5. Benson, R.S. and Whitehouse, N.D., Internal Combustion Engines, Pergamon Press, Oxford, 1979.

6. Stone, R., Introduction to Internal Combustion Engines, London, MacMillan, $3^{\text {rd }}$ ed., 1999.

7. Ferguson, C.R., Internal Combustion Engines, Wiley, New York, 1986.
8. Rakopoulos, C.D. and Hountalas, D.T., "Development and Validation of a 3-D Multi-Zone Combustion Model for the Prediction of DI Diesel Engines Performance and Pollutants Emissions", SAE Paper No. 981021, SAE Transactions, Journal of Engines, Vol. 107, pp. 1413-1429, 1998.

9. Rakopoulos, C.D., Rakopoulos, D.C., Giakoumis, E.G. and Kyritsis, D.C., "Validation and Sensitivity Analysis of a Two Zone Diesel Engine Model for Combustion and Emissions Prediction", Energy Conversion and Management, Vol. 45, No. 9-10, pp. 1471-1495, 2004.

10. Rakopoulos, C.D., Hountalas, D.T., Rakopoulos, D.C. and Giakoumis, E.G., "Experimental Heat Release Rate Analysis in Both Chambers of an Indirect Injection Turbocharged Diesel Engine at Various Load and Speed Conditions", SAE Paper No. 2005-01-0926.

11. Rakopoulos, C.D., Antonopoulos, K.A., Rakopoulos, D.C. and Giakoumis, E.G., "Investigation of the Temperature Oscillations in the Cylinder Walls of a Diesel Engine with Special Reference to the Limited Cooled Case", Energy Research, Vol. 28, No. 11, pp. 977-1002, 2004.

12. Winterbone, D.E. and Tennant, D.W.H., "The Variation of Friction and Combustion Rates During Diesel Engine Transients", SAE Paper No. 810339, 1981.

13. Watson, N. and Janota, M.S., Turbocharging the Internal Combustion Engine, MacMillan, London (Chapters 12 and 15), 1982.

14. Ledger, J.D. and Walmsley, S., "Computer Simulation of a Turbocharged Diesel Engine Operating Under Transient Load Conditions", SAE Paper No. 710177, 1971.

15. Ledger, J.D., Benson, R.S. and Whitehouse, N.D., "Dynamic Modeling of a Turbocharged Diesel Engine", Institution of Mechanical Engineers, Conference on "Engine Performance Modeling", London, 1972.

16. Ledger, J.D., Benson, R.S. and Furukawa, H., "Improvement in Transient Performance of a Turbocharged Diesel Engine by Air Injection into the Compressor", SAE Paper No. 730665, 1973.

17. Benson, R.S., Ledger, J.D., Whitehouse, N.D. and Walmsley, S., "Comparison of Experimental and Simulated Transient Responses of a Turbocharged Diesel Engine", SAE Paper No. 730666, 1973.

18. Winterbone, D.E., Benson, R.S., Closs, G.D. and Mortimer, A.G., "A Comparison Between Experimental and Analytical Transient Test Results for a Turbocharged Diesel Engine", Proceedings of the Institution of Mechanical Engineers, Vol. 190, pp. 267-276, 1976.

19. Benson, R.S., Winterbone, D.E. and Shamsi, S.S., "A Real-Time Analogue Computer Simulation of a Turbocharged Diesel Engine", ASME Paper No. 76WA/DGP-1, 1976.

20. Watson, N. and Marzouk, M., "A Non-Linear Digital Simulation of Turbocharged Diesel Engines Under 
Transient Conditions", SAE Paper No. 770123, 1977.

21. Marzouk, M. and Watson, N., "Load Acceptance of Turbocharged Diesel Engines", Institution of Mechanical Engineers, Conference on "Turbocharging and Turbochargers", Paper C54/78, London, 1978.

22. Watson, N., "Dynamic Turbocharged Diesel Engine Simulator for Electronic Control System Development", ASME Transactions, Journal of Dynamic Systems Measurement and Control, Vol. 106, No.1, pp. 27-45, 1984.

23. Watson, N., "Eliminating Rating Effects on Turbocharged Diesel Engine Response", SAE Paper No. 840134, 1984.

24. Watson, N., "Transient Performance Simulation and Analysis of Turbocharged Diesel Engines", SAE Paper No. 810338, 1981.

25. Watson, N., Marzouk, M. and Baazaari, Z., "An Evaluation of Two Stage Turbocharging for Efficient High-Output Diesel Engines", ASME Energy Technology Conference \& Exhibition, Houston, TX, Paper No. 78-DGP-2, 1978.

26. Winterbone, D.E. and Loo, W.Y., "A Dynamic Simulation of a Two-Stroke Turbocharged Diesel Engine", SAE Paper No. 810337, 1981.

27. Winterbone, D.E., Benson, R.S., Mortimer, A.G., Kenyon, P. and Stotter, A., "Transient Response of Turbocharged Diesel Engines: Pt. 1 - A Comparison of Two Methods of Improving Response, Pt. 2 Application to a Heavy Truck: A Study of the Dynamic Performance of the Engine", SAE Paper No. 770122, 1977.

28. Winterbone, D.E., Thiruarooran, C. and Wellstead, P.E., "A Wholly Dynamic Model of a Turbocharged Diesel Engine for Transfer Function Evaluation", SAE Paper No. 770124, 1977.

29. Gardner, T.P. and Henein, N.A., "Diesel Starting: A Mathematical Model", SAE Paper No. 880426, 1988.

30. Liu, H.-Q, Chalhoub, N.G. and Henein, N., "Simulation of a Single Cylinder Diesel Engine under Cold Start Conditions using Simulink", ASME Transactions, Journal of Engineering for Gas Turbines and Power, Vol. 123, pp. 117-124, 2001.

31. Liu, H.-Q., Henein, N. and Bryzik, W., "Simulation of Diesel Engines Cold Start", SAE Paper No. 2003-010080, 2003.

32. Zhong, L., Henein, N.A., Liu, H. and Bryzik, W., "A Mathematical Model for the Cranking Period in the Cold Start of Diesel Engines", IMECE2003, ASME International Mechanical Engineering Congress, November 2003, Washington, DC, Paper No. IMECE2003-43990, 2003.

33. Rezeka, S.F. and Henein, N.A., "A New Approach to Evaluate Instantaneous Friction and its Components in Internal Combustion Engines", SAE Paper No. 840179, 1984.

34. Taraza, D., Henein, N. and Bryzik, W., "Friction Losses in Multi-Cylinder Diesel Engines", SAE Paper No. 2000-01-0921.
35. Ceasu, R., Taraza, D., Henein, N.A. and Bryzik, W., "A Generic, Transient Model of a Turbocharged, Multi-Cylinder, Common-Rail Diesel Engine", Proc. ICES2005, ASME I.C.E. Division, Spring Technical Conference, Chicago, IL, Paper No. ICES20051021, 2005.

36. Rakopoulos, C.D., Giakoumis, E.G. and Hountalas, D.T., "The Effect of Governor Technical Characteristics and Type on the Transient Performance of a Naturally Aspirated IDI Diesel Engine", SAE Paper No. 970633, SAE Transactions, Journal of Engines, Vol. 106, pp. 905-922, 1997.

37. Rakopoulos, C.D., Hountalas, D.T., Mavropoulos, G.C. and Giakoumis, E.G., 1997, "An Integrated Transient Analysis Simulation Model Applied in Thermal Loading Calculations of an Air-Cooled Diesel Engine under Variable Speed and Load Conditions", SAE Paper No. 970634, SAE Transactions, Journal of Engines, Vol. 106, pp. 923939, 1997.

38. Rakopoulos, C.D. and Giakoumis, E.G., "Simulation and Analysis of a Naturally Aspirated, Indirect Injection Diesel Engine under Transient Conditions Comprising the Effect of Various Dynamic and Thermodynamic Parameters", Energy Conversion and Management, Vol. 39, pp. 465-484, 1998.

39. Rakopoulos, C.D., Giakoumis, E.G. and Hountalas, D.T. "Experimental and Simulation Analysis of the Transient Operation of a Turbocharged, MultiCylinder IDI Diesel Engine", Energy Research, Vol. 21, pp. 317-332, 1998.

40. Rakopoulos, C.D., Giakoumis, E.G., Hountalas, D.T. and Rakopoulos, D.C., "The Effect of Various Dynamic, Thermodynamic and Design Parameters on the Performance of a Turbocharged Diesel Engine Operating under Transient Load Conditions", SAE Paper No. 2004-01-0926.

41. Rakopoulos, C.D. and Giakoumis, E.G., "Prediction of Friction Development during Transient Diesel Engine Operation Using a Detailed Model", International Journal of Vehicle Design, 2006 (in press).

42. Rakopoulos, C.D. and Giakoumis, E.G., "Sensitivity Analysis of Transient Diesel Engine Simulation", Proceedings of the Institution of Mechanical Engineers, Part D, Journal of Automobile Engineering, Vol. 220, pp. 89-101, 2006.

43. Rakopoulos, C.D. and Giakoumis, E.G., "Simulation and Exergy Analysis of Transient Diesel-Engine Operation", Energy-The International Journal, Vol. 22, No. 9, pp. 875-886, 1997.

44. Rakopoulos, C.D. and Giakoumis E.G., "Availability Analysis of a Turbocharged Diesel Engine Operating under Transient Load Conditions", Energy-The International Journal, Vol. 29, pp. 1085-104, 2004.

45. Rakopoulos, C.D. and Giakoumis, E.G., "Parametric Study of Transient Turbocharged Diesel Engine Operation from the Second-Law Perspective", SAE Paper No. 2004-01-1679. 
46. Rakopoulos, C.D. and Giakoumis, E.G., "The Influence of Cylinder Wall Temperature Profile on the Second-Law Diesel Engine Transient Response", Applied Thermal Engineering, Vol. 25, No. 11/12, pp. 1779-1795, 2005.

47. Rakopoulos, C.D., Michos, C.N. and Giakoumis, E.G., "Study of the Transient Behavior of Turbocharged Diesel Engines Including Compressor Surging Using a Linearized Quasi-Steady Analysis", SAE Paper No. 2005-01-0225.

48. Zhang, G., Filipi, Z.S. and Assanis, D.N., "A Flexible, Reconfigurable, Transient Multi-Cylinder Diesel Engine Simulation for System Dynamics Studies", Mechanics Based Design of Structures and Machines, Vol. 25, No. 3, pp. 357-378, 1997.

49. Assanis, D.N., Atreya, A, Borgnakke, C., et al., "Development of a Modular, Transient Multi-Cylinder Diesel Engine Simulation for System Performance and Vibration Studies", Proceedings ASME-ICE Spring Technical Conference, Vol. 28-1, Fort Collins, CO, April 27-30, 1997.

50. Filipi Z.S. and Assanis, D.N., "A Non-Linear Transient Single-Cylinder Diesel Engine Simulation for Predictions of Instantaneous Engine Speed and Torque", ASME Transactions, Journal of Engineering for Gas Turbines and Power, Vol. 123, pp. 951-959, 2001.

51. Assanis, D., Bryzik, W., Chalhoub, N., Filipi, Z., et al., "Integration and Use of Diesel Engine, Driveline and Vehicle Dynamics Models for Heavy Duty Truck Simulation", SAE Paper No. 1999-01-0970.

52. Assanis, D., Filipi, Z., Gravante, S., Grohnke, D., Gui, X., Louca, L., Rideout, G., Stein, J. and Wang, Y., "Validation and Use of SIMULINK Integrated, High Fidelity, Engine-In-Vehicle Simulation of the International Class VI Truck", SAE Paper No. 200001-0288.

53. Filipi, Z., Wang, Y. and Assanis, D., "Effect of Variable Geometry Turbine (VGT) on Diesel Engine and Vehicle System Transient Response", SAE Paper No. 2001-01-1247.

54. Assanis, D.N. and Heywood, J.B., "Development and Use of a Computer Simulation of the Turbocompounded Diesel System for Engine Performance and Component Heat Transfer Studies", SAE Paper No. 860329, 1986.

55. Lin, C.-C., Filipi, Z., Wang, Y., Louca, L., Peng, H., Assanis, D. and Stein, J., "Integrated, Feed-Forward Hybrid Electric Vehicle Simulation in SIMULINK and its Use for Power Management Studies", SAE Paper No. 2001-01-1334.

56. Filipi, S., Wang, Y. and Assanis, D., "Variable Geometry Turbine (VGT) Strategies for Improving Diesel Engine In-Vehicle Response: A Simulation Study", International Journal of Heavy Vehicle Systems, Vol. 11, No. 3/4, pp. 303-326, 2004.

57. Lin, C.-C., Filipi, Z., Louca, L., Peng, H., Assanis, D. and Stein, J., "Modeling and Control of a MediumDuty Hybrid Electric Truck", International Journal of
Heavy Vehicle Systems, Vol. 11, Nos 3/4, pp. 349370, 2004.

58. Payri, F., Reyes, E. and Serrano, JR, "A Model for Load Transients of Turbocharged Diesel Engines", SAE Paper No. 1999-01-0225.

59. Payri, F., Galindo, J. and Serrano, J.R., "Variable Geometry Turbine Modeling and Control for Turbocharged Diesel Engines Transient Operation", Proc. Thiesel 2000 Conference on "Thermo- and Fluid Dynamic Processes in Diesel Engines", Valencia, pp. 173-189, 2000.

60. Benajes, J., Lujan, J.M., Bermudez, V. and Serrano, J.R. "Modelling of Turbocharged Diesel Engines in Transient Operation. Part 1: Insight into the Relevant Physical Phenomena", Proceedings of the Institution of Mechanical Engineers, Part D, Journal of Automobile Engineering, Vol. 216, No. 5, pp. 431441, 2002.

61. Payri, F., Benajes, J., Galindo, J. and Serrano, J.R., "Modelling of Turbocharged Diesel Engines in Transient Operation. Part 2: Wave action Models for Calculating the Transient Operation in a High Speed Direct Injection Engine", Proceedings of the Institution of Mechanical Engineers, Part D, Journal of Automobile Engineering, Vol. 216, No. 6, pp. 479493, 2002.

62. Benajes, J., Luján, J.M. and Serrano, J.R., "Predictive Modeling Study of the Transient Load Response in a Heavy-Duty Turbocharged Diesel Engine", SAE Paper No. 2000-01-0583.

63. Serrano, J.R., Climent, H., Arnau, F.J. and Traumat, G., "Global Analysis of the EGR Circuit in a HSDI Diesel Engine in Transient Operation", SAE Paper No. 2005-01-0699.

64. Galindo, J., Luján, J.M., Serrano, J.R., Dolz, V. and Guillain S., "Design of an Exhaust Manifold to Improve Transient Performance of a High-Speed Turbocharged Diesel Engine", Experimental Thermal and Fluid Science, Vol. 28, pp. 863-875, 2004.

65. Goyal, M.R., "Simulation of a Turbocharged Diesel Engine to Predict the Transient Response", ASME Paper No. 78-DGP-11, 1978.

66. Zellbeck, H. and Woschni, G., "Prediction of the Transient Response of Turbocharged Diesel Engines“, Motortechnische Zeitschrift, Vol. 44, No. 3, pp. 81-86, 1983 (in German).

67. Woschni, G., Doll, M. and Spindler, W., "Simulation of the Stationary and Transient Performance of Small High Speed Car Diesel Engines", Motortechnische Zeitschrift, Vol. 52, pp. 468-477, 1991 (in German).

68. Kao, M. and Moskwa, J.J., "Turbocharged Diesel Engine Modeling for Nonlinear Engine Control and State Estimation", ASME Transactions, Journal of Dynamic Systems Measurement and Control, Vol. 117, No. 1, pp. 20-30, 1995.

69. Zweiri, Y.H., Whidborne, J.F. and Seneviratne, L.D., "Detailed Analytical Model of a Single-Cylinder Diesel Engine in the Crank Angle Domain", Proceedings of the Institution of Mechanical 
Engineers, Part D, Journal of Automobile Engineering, Vol. 215, No. 11, pp. 1197-1216, 2001.

70. Anguita, D., Rivieccio, F., Canova, M., Casoli, P. and Gambarotta, A., "A Learning-Machine Based Method for the Simulation of Combustion Process in Automotive I.C. Engines", Proc. ICES03, Spring Technical Conference of the ASME I.C.E. Division, Salzburg, Austria, Paper No. ICES2003-682, 2003.

71. Breuer, S., "Simulation and Analysis of the Transient Behaviour of a Turbocharged Common Rail Diesel Engine", THIESEL Conference on Thermo- and Fluid Dynamic Processes in Diesel Engines, Valencia, 2004.

72. Bowns, D.E., Cave, P.R., Hargreaves, M.R.O. and Wallace, F.J., "Transient Characteristics of Turbocharged Diesel Engines", Institution of Mechanical Engineers, Conference on Engine Performance Modelling, London, 1973.

73. Ghuman, A.S., Iwamuro, M.A. and Weber, H.G., "Turbocharged Diesel Engine Simulation to Predict Steady-State and Transient Performance", ASME Paper No. 77-DGP-5, 1977.

74. Shamsi, S.S., "Development of a Real-Time Digital Computer Simulation of a Turbocharged Diesel Engine", SAE Paper No. 800521, 1980.

75. Jennings, M.J., Blumberg, P.N. and Amann, R.W., "A Dynamic Simulation of the Detroit Diesel Electronic Control System in Heavy Duty Truck Powertrains", SAE Paper No. 861959, 1986.

76. Hendricks, E., "Mean Value Modeling of Large Turbocharged Two-Stroke Diesel Engines", SAE Paper No. 890564, 1989.

77. Jensen, J.P., Kristensen, A.F., Sorensen, S.C., Houbak, N. and Hendricks, E., "Mean Value Modeling of a Small Turbocharged Diesel Engine", SAE Paper No. 910070, 1991.

78. Berglund, S., "A Model of Turbocharged Engines as Dynamic Drivetrain Members", SAE Paper No. 933050, 1993.

79. Berglund, S., "Comparison Between Measured and Simulated Transients of a Turbocharged Diesel Engine", SAE Paper No. 942323, 1994.

80. Dekker, H.J. and Sturm, W.L., "Simulation and Control of a HD Diesel Engine Equipped with New EGR Technology", SAE Paper No. 960871, 1996.

81. Isermann, R., Sinsel, S. and Schaffnit, J., "Modeling and Real-Time Simulation of Diesel Engines for Control Design", SAE Paper No. 980796, 1998.

82. Canova, M., "Development and Validation of a Control-Oriented Library for the Simulation of Automotive Engines", International Journal of Engine Research, Vol. 5, No. 3, pp. 219-228, 2004.

83. Chung, N., Kim, S. and Sunwoo, M., "Nonlinear Dynamic Model of a Turbocharged Diesel Engine", SAE Paper No. 2005-01-0017.

84. Schorn, N., Pischinger, F. and Schulte, H., "Computer Simulation of Turbocharged Diesel Engines Under Transient Conditions", SAE Paper No. 870723, 1987.
85. Bartsch, P., Prenninger, P., and Allmer, I., "Transient Performance Optimization of Turbocharged Engines by Means of Gas Exchange Simulations," Institution of Mechanical Engineers, Int. Conference on "Turbocharging and Air Management Systems", Paper C554/016, pp. 237-251, London, 1998.

86. Jung, M., Ford, R.G., Glover, K., Collings, N., Christen, U. and Watts, M.J., "Parameterization and Transient Validation of a Variable Geometry Turbocharger for Mean-Value Modeling at Low and Medium Speed-Load Points", SAE Paper No. 200201-2729.

87. Bozza, F., Nocera, R., Senatore, A. and Tuccilo, R., "Theoretical and Experimental Investigation of the Matching Between an I.C.E. and a Turbocharger", SAE Paper No. 901601, 1990.

88. Keribar, R. and Morel, T., "Thermal Shock Calculations in I.C. Engines", SAE Paper No. 870162, 1987.

89. Rackmil, C.I., Blumberg, P.N., Becker, D.A., Schuler, R.R. and Garvey, D.C., "A Dynamic Model of a Locomotive Diesel Engine and Electrohydraulic Governor", ASME Transactions, Journal of Engineering for Gas Turbines and Power, Vol. 110, pp. 405-414, 1988.

90. Rackmil, C.I. and Blumberg, P.N., "Dynamic Simulation of a Turbocharged/Intercooled Diesel Engine with Rack-Actuated Electronic Fuel Control System", SAE Paper No. 890394, 1989.

91. Jiang, Q. and Van Gerpen, J.H., "Prediction of Diesel Engine Particulate Emission During Transient Cycles", SAE Paper No. 920466, 1992.

92. Watson, H.C. and Alimoradian, B., "A Transient Engine Mapping Model for Analysing and Predicting Fuel Consumption and Emissions", Institution of Mechanical Engineers, European Automobile Engineers Cooperation 2nd Int. Conference on "New Developments in Powertrain and Chassis Engineering", pp. 27-36, Strasburg, 1989.

93. Qiao, J., Dent, J.C. and Garner, C.P., "Diesel Engine Modeling under Steady and Transient Conditions Using a Transputer Based Concurrent Computer", SAE Paper No. 922226, 1992.

94. Younes, R. Champoussin, J.C. and Liazid, A., "Modeling of Turbocharged Diesel Engine for Optimal Control", Entropie, Vol. 174/175, pp. 31-42, 1993 (in French).

95. Bazari, Z., "Diesel Exhaust Emissions Prediction Under Transient Operating Conditions", SAE Paper No. 940666, 1994.

96. Brace, C.J., Deacon, M., Vaughan, N.D., Charlton, S.J. and Burrows, C.R., "Prediction of Emissions from a Turbocharged Passenger Car Diesel Engine Using a Neural Network", Institution of Mechanical Engineers, 5th Int. Conference on "Turbocharging and Turbochargers", Paper C484/046, London, 1994.

97. Bazari, Z., Smith, L.A., Banisoleiman, K. and French, B.A., "An Engineering Building Block Approach to Engine Simulation with Special 
Reference to New Application Areas", Institution of Mechanical Engineers, 3rd Int. Conference on "Computers in Reciprocating Engines and Gas Turbines", Paper C499/017/96, London, 1996.

98. Chan, S.H., He, Y. and Sun, J.H., "Prediction of Transient Nitric Oxide in Diesel Exhaust", Proceedings of the Institution of Mechanical Engineers, Part D, Journal of Automobile Engineering, Vol. 213, No. 4, pp. 327-339, 1999.

99. Cui, Y., Deng, K. and Wu, J., "A Modeling and Experimental Study of Transient NOx Emissions in Turbocharged Direct Injection Diesel Engines", Proceedings of the Institution of Mechanical Engineers, Part D, Journal of Automobile Engineering, Vol. 218, pp. 535-541, 2004.

100. Pirotais, F., Bellettre J., Le Corre, O., Tazerout, M., De Pelsemaeker, G. and Guyonvarch, G., "A Diesel Engine Thermal Transient Simulation: Coupling Between a Combustion Model and a Thermal Model", SAE Paper No. 2003-01-0224.

101. Skopil, M. and Bulaty, T., "Calculation of Compressor Surge with Unsteady Flow Model", Institution of Mechanical Engineers, 6th Int. Conference on "Turbocharging and Air-Management Systems”, Paper C554/018, pp. 219-225, 1998.

102. Tauzia, X. Hetet, J.F., Chesse, P., Grosshans, G. and Mouillard L., "Computer Aided Study of the Transient Performances of a Highly Rated Sequentially Turbocharged Marine Diesel Engine", Proceedings of the Institution of Mechanical Engineers, Part A, Journal of Power and Energy, Vol. 212, No. 3., pp. 185 - 196, 1998.

103. Chesse, P., Hetet, J.-F., Tauzia X., Roy, P. and Inozu, B., "Performance Simulation of Sequentially Turbocharged Marine Diesel Engines with Applications to Compressor Surge", ASME Transactions, Journal of Engineering for Gas Turbines and Power, Vol. 122, pp. 562-569, 2000.

104. Chesse, P., Tauzia, X., Hetet, J.-F., Grosshans, G., "Simulation of Dynamical Behavior of Sequentially Turbocharged High Output Diesel Engine", Comptes Rendus de l'Académie des Sciences - Series IIB Mechanics-Physics-Astronomy, Vol. 328, No. 3, pp. 193-198, 2000 (in French).

105. Theotokatos, G. and Kyrtatos, N.P., "Diesel Engine Transient Operation with Turbocharger Compressor Surging", SAE Paper No. 2001-01-1241.

106. Theotokatos, G. and Kyrtatos, N.P., "Analysis of a Large Two-Stroke Marine Diesel Engine Transient Behavior during Compressor Surging", Institution of Mechanical Engineers, 7th Int. Conference on "Turbochargers and Turbocharging", Paper C602/005, London, 2002.

107. Theotokatos, G. and Kyrtatos, N.P., "Investigation of a Large High- Speed Diesel Engine Transient Behavior Including Compressor Surging and Emergency Shutdown", ASME Transactions, Journal of Engineering for Gas Turbines and Power, Vol. 125, No. 2, pp. 580-589, 2003.
108. Zellbeck, H., Friedrich, J. and Berger, C., "Electrically Assisted Turbocharging as a New Boosting Concept", Motortechnische Zeitschrift, Vol. 60, No. 6, pp. 386-391, 1999 (in German).

109. Panting, J., Pullen, K.R. and Martinez-Botas, R.F., "Turbocharger Motor-Generator for Improvement of Transient Performance in an Internal Combustion Engine", Proceedings of the Institution of Mechanical Engineers, Part. D, Journal of Automobile Engineering, Vol. 215, No. 3, pp. 369-383, 2001.

110. Katrašnik, T., Rodman, S., Trenc, F., Hribernik, A. and Medica, V., "Improvement of the Dynamic Characteristic of an Automotive Engine by a Turbocharger Assisted by an Electric Motor", ASME Transactions, Journal of Engineering for Gas Turbines and Power, Vol. 125, pp. 590-595, 2003.

111. Katrašnik, T., Medica, V. and Trenc, F., "Analysis of the Dynamic Response Improvement of a Turbocharged Diesel Engine Driven Alternating Current Generating Set", Energy Conversion and Management, Vol. 46, No. 18/19, pp. 2838-2855, 2005.

112. Jenny, E., Hansel, J. and Mayer, A., "The Transient Behavior of Supercharged Passenger Car Diesel Engines Fitted with Particulate Traps", SAE Paper No. 890171, 1989.

113. Ciesla, C.R. and Jennings, M.J., "A Modular Approach to Powertrain Modeling and Shift Quality Analysis", SAE Paper No. 950419, 1995.

114. Woschni, W., Schwartz, C. and Zeilinger, K., "Simulation of the Transient Behavior of Vehicles with Diesel Engine", Motortechnische Zeitschrift, Vol. 56, No. 4, pp. 206-211, 1995 (in German).

115. Ertl, C., Kranawetter, E. and Stütz, W., "Simulation of the Dynamic Behavior of Diesel Engines with Electronic Management System", Motortechnische Zeitschrift, Vol. 58, No. 10, pp. 612-618, 1997 (in German).

116. Bi, X., Han, S., Ma, Z. and Liu, X., "Transient Modeling for Heavy Tracked Vehicle Performance and Fuel Consumption under Accelerating Conditions", SAE Paper No. 2002-01-0630.

117. Charlton, S.J., Stone, C.R., Leonard, H.J., Elliot, C., Newman, M.J., "Transient Simulation of a Highly Turbocharged Diesel Engine with Variable Valve Timing", Proceedings of the Institution of Mechanical Engineers, Int. Conference on "Computers in Engine Technology", pp. 149-160, Cambridge, 1991.

118. Swain, E., "Diesel Engine Transient Performance Prediction During Sequential Turbocharging Operations", Institution of Mechanical Engineers, Int. Conference on "Experimental and Predictive Methods in Engine Research and Development", Paper C465/012, Birmingham, pp. 123-131, 1993.

119. Boy, P. "Investigation of Several Influences on the Dynamic Performance of Medium-Speed Marine Diesel Engine, Pt. 1: Calculation Model", Motortechnische Zeitschrift, Vol. 41, pp. 343-348, 1980, "Pt. 2: Influences of Different Factors on the 
Dynamic Performance“, Motortechnische Zeitschrift, Vol. 41, pp. 491-496, 1980 (in German).

120. Benvenuto, G. and Campora, U., "Dynamic Simulation of a High Performance Sequentially Turbocharged Marine Diesel Engine", International Journal of Engine Research, Vol. 3, No. 3, pp. 115125, 2002.

121. Keribar, R., Ciesla, C.R. and Morel, T., "Engine/Powertrain/Vehicle Modeling Tool Applicable to All Stages of the Design Process", SAE Paper No. 2000-01-0934.

122. Saulnier, S. and Guillain, S., "Computational Study of Diesel Engine Downsizing Using Two-Stage Turbocharging", SAE Paper No. 2004-01-0929.

123. Bowns, D.E., "The Dynamic Transfer Characteristics of Reciprocating Engines", Proceedings of the Institution of Mechanical Engineers, Vol. 185, No. 16, pp. 185-201, 1970-71.

124. Backhouse, R. and Winterbone, D.E., "Dynamic Behaviour of a Turbocharged Diesel Engine", SAE Paper No. 860453, 1986.

125. Tsai, S.-C. and Goyal, M.R., "Dynamic Turbocharged Diesel Engine Model for Control Analysis and Design", SAE Paper No. 860455, 1986.

126. Kolade, B., Morel, T. and Kong, S.-C., "Coupled 1D/3-D Analysis of Fuel Injection and Diesel Engine Combustion", SAE Paper No. 2004-01-0928.

127. Gonzalez, M.A., Borman, G.L. and Reitz, R.D., "A Study of Diesel Cold Starting Using Both Cycle Analysis and Multidimensional Calculations", SAE Paper No. 910180, 1991.

128. Ayoub, N.S. and Reitz, R.D., "Multidimensional Modeling of Fuel Composition Effects on Combustion and Cold-Starting in Diesel Engines", SAE Paper No. 952425, 1995.

129. Wiebe, I., "Halbempirische Formel für die Verbrennungsgeschwindigkeit", Verlag der Akademie der Wissenschaften der UdSSR, Moscow, 1967.

130. Watson, N., Pilley, A.D. and Marzouk, M., "A Combustion Correlation for Diesel Engine Simulation", SAE Paper No. 800029, 1980.

131. Woschni, G. and Anisits, F., "Eine Methode zur Vorausberechnung der Änderung des Brennverlaufs mittelschnelllaufender Dieselmotoren bei geänderten Betriebsbedingungen", Motortechnische Zeitschrift, Vol. 34, No. 4, pp. 106-115, 1973.

132. Whitehouse N.D. and Way, R.G.B., "Rate of Heat Release in Diesel Engines and its Correlation with Fuel Injection Data", Proceedings of the Institution of Mechanical Engineers, Vol. 184, Part 3J, pp. 17-27, 1969-70.

133. Assanis, D.N., Filippi, Z.S., Fiveland, S.B. and Syrimis, M., "A Methodology for Cycle-By-Cycle Transient Heat Release Analysis in a Turbocharged Direct Injection Diesel Engine", SAE Paper No. 2000-01-1185.

134. Rakopoulos, C.D., Hountalas, D.T. and Mavropoulos, G.C., "Modeling the Structural
Thermal Response of an Air-Cooled Diesel Engine Under Transient Operation Including a Detailed Thermodynamic Description of Boundary Conditions", SAE Paper No. 981024, 1998.

135. Galindo, J., Bermúdez, V., Serrano, J.R. and López, J.J., "Cycle To Cycle Diesel Combustion Characterisation During Engine Transient Operation", SAE Paper No. 2001-01-3262.

136. Galindo, J., Luján, J.M., Serrano, J.R., and Hernández, L., "Combustion Simulation of Turbocharger HSDI Diesel Engines During Transient Operation Using Neural Networks", Applied Thermal Engineering, Vol. 25, pp. 877-898, 2005.

137. Murayama, T., Miyamoto, N., Tsuda, T., Suzuki, M. and Hasegawa, S., "Combustion Behaviors Under Accelerating Operation of an IDI Diesel Engine", SAE Paper No. 800966, 1980.

138. Harndorf, H. and Kuhnt, H.-W., "Improvement of Transient Behavior of Turbocharged Diesel Engines Through Additional Air Injection in the Turbocharger", Motortechnische Zeitschrift, Vol. 56, No. 1, pp. 20-28, 1995 (in German).

139. Hiroyasu, H., Kadota, T. and Arai, M., "Development and Use of a Spray Combustion Modeling to Predict Diesel Engine Efficiency and Pollutant Emissions", Bulletin of the Japan Society of Mechanical Engineers, Vol. 26, pp. 569-576, 1983.

140. Betz, A. and Woschni, G, "Energy Conversion Rate and Rate of Heat Release of Turbocharged Diesel Engines Under Transient Conditions“, Motortechnische Zeitschrift, Vol. 47, Nos 7/8, pp. 263-267, 1986 (in German).

141. Assanis, D.N., Filipi, Z.S., Fiveland, S.B. and Syrimis, M., "A Predictive Ingition Delay Correlation under Steady-State and Transient Operation of a Direct Injection Diesel Engine“, ASME Transactions, Journal of Engineering for Gas Turbines and Power, Vol. 125, pp. 450-457, 2003.

142. Annand, W.J.D., "Heat Transfer in the Cylinders of Reciprocating Internal Combustion Engines", Proceedings of the Institution of Mechanical Engineers, Vol. 177, pp. 983-90, 1963.

143. Woschni, G., "A Universally Applicable Equation for the Instantaneous Heat Transfer Coefficient in the Internal Combustion Engine", SAE Paper No. 670931, 1967.

144. Hohenberg, G.F., "Advanced Approaches for Heat Transfer Calculations", SAE Paper No. 790825, 1979.

145. Ciulli, E., "A Review of Internal Combustion Engine Losses Pt. 2: Studies for Global Evaluations", Proceedings of the Institution of Mechanical Engineers, Part D, Journal of Automobile Engineering, Vol. 207, No. 3, pp. 229-240, 1993.

146. Tuccilo, R., Arnone, L., Bozza, F., Nocera, R. and Senatore, A., "Experimental Correlations for Heat Release and Mechanical Losses in Turbocharged Diesel Engines", SAE Paper No. 932459, 1993. 
147. Moraal, P. and Kolmanovksy, I.V., "Turbocharger Modeling for Automotive Control Applications", SAE Paper No. 1999-01-0908.

148. Fink, D. A., Cumpsty, N. A. and Greitzer, E. M., "Surge Dynamics in a Free-Spool Centrifugal Compressor System", ASME Transactions, Journal of Turbomachinery, Vol. 114, pp. 321-329, 1992.

149. Drakunov, S., Rizzoni, G. and Wang, Y.-Y., "OnLine Estimation of Indicated Torque in IC Engines Using Nonlinear Observers", SAE Paper No. 950840, 1995.

150. Hodgson, P. G. and Raine, J. K., "Computer Simulation of a Variable Fill Hydraulic Dynamometer. Pt. 2: Steady State and Dynamic Open Loop Performance", Proceedings of the Institution of Mechanical Engineers, Part C, Vol. 206, No. 1, pp. 49-56, 1992.

151. Lavoie, G. A., Heywood, J. B. and Keck, J. C. "Experimental and Theoretical Study of Nitric Oxide Formation in Internal Combustion Engines", Combustion Science and Technology, Vol. 1, pp. 313-326, 1970.

152. Hiroyasu, H. and Kadota, T., "Models for Combustion and Formation of Nitric Oxide and Soot in Direct Injection Diesel Engines", SAE Paper No. 760129, 1976.

153. Banisoleiman, K., Smith, L.A. and French, B.A., "The Interaction of Diesel Engine Turbocharging and Tuned Inlet Manifold Systems Under Steady State and Transient Operation", Proceedings of the Institution of Mechanical Engineers, Part A, Journal of Power and Energy, Vol. 205, pp. 269-281, 1991.

154. Rakopoulos, C.D. and Giakoumis, E.G., "Comparative First- and Second-Law Parametric Study of Transient Diesel Engine Operation", Energy-The International Journal, Vol. 32, 2006 (in press).

155. Rakopoulos, C.D. and Giakoumis, E.G., "SecondLaw Analyses Applied to Internal Combustion Engines Operation", Progress in Energy and Combustion Science, Vol. 32, pp. 2-47, 2006.

\section{NOMENCLATURE}

$\begin{array}{ll}\text { A } & \text { availability (exergy), J } \\ \text { b } & \text { flow availability, J/kg } \\ \text { F } & \text { force, N } \\ \text { G } & \text { mass moment of inertia, } \mathrm{kg} \mathrm{m}^{2} \\ \text { h } & \text { fuel pump rack position, \% } \\ \text { I } & \text { irreversibilities, J } \\ \text { L } & \text { length, } \mathrm{m} \\ \text { m } & \text { mass, } \mathrm{kg} \\ \mathrm{N} & \text { engine speed, rpm } \\ \text { p } & \text { pressure, bar } \\ \mathrm{Q} & \text { heat, J } \\ \mathrm{r} & \text { pressure ratio, or crank radius, } \mathrm{m} \\ \mathrm{S} & \text { surface, } \mathrm{m}^{2} \\ \mathrm{~T} & \text { temperature, } \mathrm{K} \\ \mathrm{t} & \text { time, } \mathrm{S} \\ \mathrm{u} & \text { speed, } \mathrm{m} / \mathrm{s}\end{array}$

$\begin{array}{ll}\dot{W} & \text { power, } \mathrm{J} / \mathrm{s} \\ \mathbf{x} & \text { mole fraction } \\ \mathrm{z} & \text { governor position, } \mathrm{mm} \text { or } \%\end{array}$

\section{GREEK SYMBOLS}

$\begin{array}{ll}\Delta \varphi & \text { crank angle duration } \\ \varepsilon & \text { angular acceleration, } \mathrm{s}^{-2} \\ \eta & \text { efficiency, \% } \\ \mu & \text { chemical potential, } \mathrm{J} / \mathrm{kg} \\ \mathrm{T} & \text { torque, } \mathrm{Nm} \\ \varphi & \text { crank angle } \\ \Phi & \text { fuel-air equivalence ratio } \\ \omega & \text { angular velocity, } \mathrm{s}^{-1}\end{array}$

\section{SUBSCRIPTS}

$\begin{array}{ll}\text { O } & \text { initial or reference conditions } \\ \text { C } & \text { compressor } \\ \text { D } & \text { demand or damping } \\ \text { e } & \text { engine } \\ \text { ex } & \text { exhaust } \\ \text { fi } & \text { fuel injected } \\ \text { fr } & \text { friction } \\ \mathrm{g} & \text { gas } \\ \text { gr } & \text { gravitational } \\ \text { in } & \text { inertia } \\ \text { is } & \text { isentropic } \\ \text { L } & \text { load, or loss } \\ \text { S } & \text { stiffness } \\ \text { st } & \text { steady-state } \\ \text { T } & \text { turbine } \\ \text { TC } & \text { turbocharger } \\ \text { tr } & \text { transient } \\ \text { W } & \text { work }\end{array}$

\section{ABBREVIATIONS}

${ }^{\circ} \mathrm{CA}$ degree(s) crank angle

1-D/3-Done-dimensional/three-dimensional

AFR air-fuel ratio

BDC bottom dead centre

bmep brake mean effective pressure, bar

bsfc brake specific fuel consumption

DI direct injection

EVO exhaust valve opening

$f \&$ filling and emptying

fmep friction mean effective pressure, bar

IDI indirect injection

imep indicated mean effective pressure, bar

rpm revolutions per minute

Sol start of injection

TDC top dead centre

VGT variable geometry turbine 


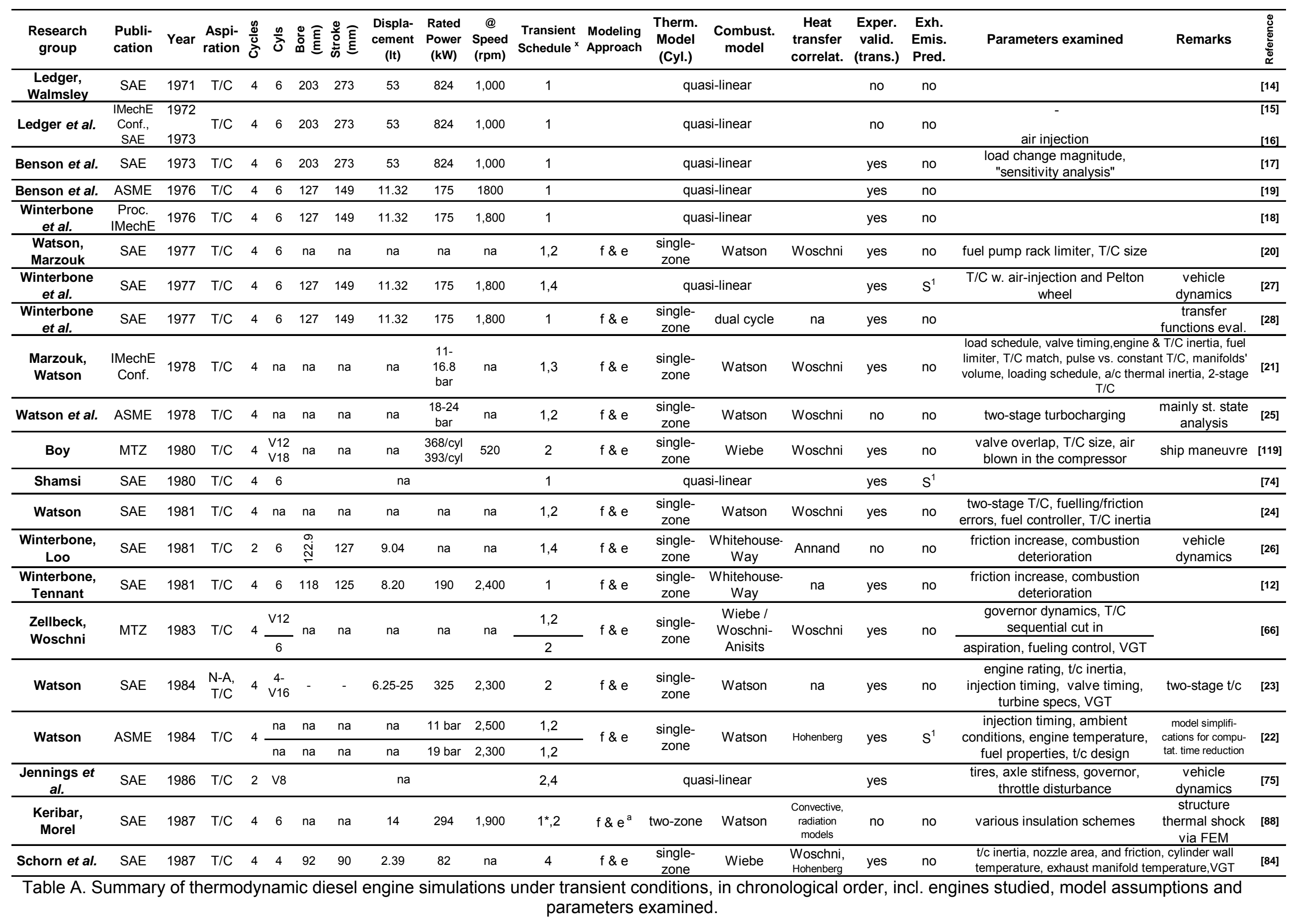




\begin{tabular}{|c|c|c|c|c|c|c|c|c|c|c|c|c|c|c|c|c|c|c|c|c|}
\hline $\begin{array}{l}\text { Research } \\
\text { group }\end{array}$ & $\begin{array}{l}\text { Publi- } \\
\text { cation }\end{array}$ & Year & $\begin{array}{l}\text { Aspi- } \\
\text { ration }\end{array}$ & $\frac{0}{\frac{0}{0}}$ & $\frac{n}{d}$ & ڤั) & 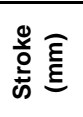 & $\begin{array}{c}\text { Displa- } \\
\text { cement } \\
\text { (It) }\end{array}$ & $\begin{array}{c}\text { Rated } \\
\text { Power } \\
\text { (kW) }\end{array}$ & $\begin{array}{c}\text { @ } \\
\text { Speed } \\
\text { (rpm) }\end{array}$ & $\begin{array}{l}\text { Transient } \\
\text { Schedule }^{x}\end{array}$ & $\begin{array}{l}\text { Modeling } \\
\text { Approach }\end{array}$ & $\begin{array}{l}\text { Therm. } \\
\text { Model } \\
\text { (Cyl.) }\end{array}$ & $\begin{array}{c}\text { Combust. } \\
\text { model }\end{array}$ & $\begin{array}{c}\text { Heat } \\
\text { transfer } \\
\text { correlat. }\end{array}$ & $\begin{array}{l}\text { Exper. } \\
\text { valid. } \\
\text { (trans.) }\end{array}$ & $\begin{array}{l}\text { Exh. } \\
\text { Emis. } \\
\text { Pred. }\end{array}$ & Parameters examined & Remarks & 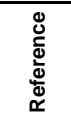 \\
\hline $\begin{array}{c}\text { Gardner, } \\
\text { Henein }\end{array}$ & SAE & 1988 & $\mathrm{~N}-\mathrm{A}$ & 4 & 1 & 95 & 95 & 0.67 & na & na & 6 & $f \& e^{a}$ & $\begin{array}{l}\text { single- } \\
\text { zone }\end{array}$ & Watson & Hohenberg & yes & no & & & [29] \\
\hline Rackmil et al. & ASME & 1988 & $\mathrm{~T} / \mathrm{C}$ & 2 & 8 & na & na & na & na & 900 & 1,2 & \multicolumn{4}{|c|}{ quasi-linear } & no & no & & governors & [89] \\
\hline Hendricks & SAE & 1989 & $\mathrm{~T} / \mathrm{C}$ & 2 & 6 & na & na & na & 10,000 & 100 & $1,1^{*}$ & \multicolumn{4}{|c|}{ quasi-linear } & yes & no & & & {$[76]$} \\
\hline Jenny et al. & SAE & 1989 & $\mathrm{~T} / \mathrm{C}$ & 4 & 4 & na & na & 2.0 & na & na & 4 & \multicolumn{4}{|c|}{ quasi-linear } & yes $^{b}$ & no & $\begin{array}{c}\text { Comprex®, VGT, patriculate } \\
\text { traps }\end{array}$ & $\begin{array}{c}\text { vehicle } \\
\text { dynamics }\end{array}$ & [112] \\
\hline $\begin{array}{l}\text { Rackmil, } \\
\text { Blumberg }\end{array}$ & SAE & 1989 & $\mathrm{~T} / \mathrm{C}$ & 4 & 6 & na & na & na & na & 2,200 & 1,2 & \multicolumn{4}{|c|}{ quasi-linear } & no & no & closed and open loop control & & [90] \\
\hline Tuccilo et al. & SAE & $\begin{array}{l}1990 \\
1993 \\
\end{array}$ & $\mathrm{~T} / \mathrm{C}$ & 4 & 4 & na & na & 1.37 & 55.6 & 4,500 & 2 & $\begin{array}{l}f \& e \\
f \& e^{a}\end{array}$ & $\begin{array}{l}\text { single- } \\
\text { zone }\end{array}$ & Watson & Annand & no & no & $\mathrm{t} / \mathrm{c}$ match & & $\begin{array}{c}{[87]} \\
{[146]}\end{array}$ \\
\hline Jensen et al. & SAE & 1991 & $\mathrm{~T} / \mathrm{C}$ & 4 & 4 & 76.5 & 86.4 & 1.59 & 50 & 4000 & $1^{*}, 2$ & \multicolumn{4}{|c|}{ quasi-linear } & yes & no & & & [77] \\
\hline $\begin{array}{l}\text { Woschni et } \\
\text { al. }\end{array}$ & MTZ & 1991 & $\mathrm{~T} / \mathrm{C}$ & 4 & 5 & 92.4 & 90.9 & 3.05 & na & na & 2 & $f \& e$ & $\begin{array}{l}\text { single- } \\
\text { zone }\end{array}$ & $\begin{array}{l}\text { Woschni- } \\
\text { Anisits }\end{array}$ & Woschni & yes & no & & $\begin{array}{l}\text { 2-D engine map } \\
\text { from } f \& \text { e code }\end{array}$ & {$[67]$} \\
\hline $\begin{array}{l}\text { Jiang, Van } \\
\text { Gerpen }\end{array}$ & SAE & 1992 & $\mathrm{~T} / \mathrm{C}$ & 4 & 4 & $\begin{array}{l}0 \\
\stackrel{2}{0} \\
\stackrel{0}{\circ}\end{array}$ & 127 & 4.52 & na & na & 5 & $f \& e$ & $\begin{array}{l}\text { single- } \\
\text { zone }\end{array}$ & $\begin{array}{l}\text { modified } \\
\text { Watson }\end{array}$ & Annand & yes & Part. $^{2}$ & & & [91] \\
\hline Qiao et al. & SAE & 1992 & $\mathrm{~N}-\mathrm{A}$ & 4 & 4 & 93.7 & 90.5 & 2.50 & na & na & 2 & $f \& e$ & two-zone & Watson & Woschni & yes & NOx & & vehicle dynam. & [93] \\
\hline Younes et al. & Entropie & 1993 & $\mathrm{~T} / \mathrm{C}$ & 4 & 4 & 86 & 89 & 2.07 & 65 & 4,250 & 2 & \multicolumn{4}{|c|}{ quasi-linear } & yes & $\mathrm{S}^{1}, \mathrm{HC}^{1}$ & & & [94] \\
\hline Berglund & SAE & $\begin{array}{l}1993 \\
1994 \\
\end{array}$ & $\mathrm{~T} / \mathrm{C}$ & 4 & & & & na & & & $\begin{array}{c}4 \\
1^{*}\end{array}$ & \multicolumn{4}{|c|}{ quasi-linear ** } & $\begin{array}{l}\text { no } \\
\text { yes }\end{array}$ & no & & $\begin{array}{c}\text { vehicle } \\
\text { dynamics }\end{array}$ & $\begin{array}{l}{[78]} \\
{[79]}\end{array}$ \\
\hline Bazari & SAE & 1994 & $\mathrm{~T} / \mathrm{C}$ & 4 & 6 & 118 & 125 & 8.20 & 220 & 2,400 & 2 & $\begin{array}{c}f \& e \\
\text { w. action }\end{array}$ & $\begin{array}{l}\text { multi- } \\
\text { zone }\end{array}$ & $\begin{array}{c}\text { Nishida- } \\
\text { Hiroyasu } \\
\text { (SAE 890269) }\end{array}$ & Annand & yes & $\begin{array}{l}\mathrm{S}^{1}, \mathrm{HC}^{1} \\
\mathrm{NO}^{1}, \mathrm{CO}\end{array}$ & & & [95] \\
\hline Brace et al. & $\begin{array}{l}\text { IMechE } \\
\text { Conf. }\end{array}$ & 1994 & $\mathrm{~T} / \mathrm{C}$ & 4 & 4 & na & na & 1.80 & na & na & 2 & \multicolumn{4}{|c|}{ quasi-linear } & no & $\begin{array}{l}\text { S, Part., } \\
\text { NOx,HC }\end{array}$ & & neural networks & [96] \\
\hline Kao, Moskwa & ASME & 1995 & $\mathrm{~T} / \mathrm{C}$ & 4 & 6 & na & na & na & na & na & 1 & $f \& e$ & $\begin{array}{l}\text { single- } \\
\text { zone }\end{array}$ & Watson & Eichelberg & no & no & & $\begin{array}{l}\text { quasi-linear } \\
\text { model too }\end{array}$ & [68] \\
\hline $\begin{array}{l}\text { Woschni et } \\
\text { al. }\end{array}$ & MTZ & 1995 & $\mathrm{~T} / \mathrm{C}$ & 4 & 5 & 87 & 84 & 2.50 & na & 4,600 & 4,5 & \multicolumn{4}{|c|}{$\begin{array}{l}\text { 7-D engine map generated from } \mathrm{f} \& \text { e code } \\
\text { (based on Woschni-Anisits comb. model) }\end{array}$} & yes & no & $\begin{array}{c}\text { mechanical supercharging vs. } \\
\text { turbocharging }\end{array}$ & & [114] \\
\hline Bazari et al. & $\begin{array}{l}\text { IMechE } \\
\text { Conf. }\end{array}$ & 1996 & $\mathrm{~T} / \mathrm{C}$ & 4 & 4 & na & na & 1.80 & na & na & 2 & $\begin{array}{c}f \& e \\
\text { w. action }\end{array}$ & $\begin{array}{l}\text { multi- } \\
\text { zone }\end{array}$ & $\begin{array}{c}\text { Nishida- } \\
\text { Hiroyasu } \\
\text { (SAE 890269) }\end{array}$ & Annand & no & $\begin{array}{l}\text { Part., HC, } \\
\text { NOx, CO }\end{array}$ & turbine size & & [97] \\
\hline $\begin{array}{l}\text { Dekker, } \\
\text { Sturm }\end{array}$ & SAE & 1996 & $\mathrm{~T} / \mathrm{C}$ & 4 & na & na & na & 12 & 315 & 2000 & $1^{*}$ & \multicolumn{4}{|c|}{ quasi-linear } & yes & no & EGR, VGT & & [80] \\
\hline Ertl et al. & MTZ & 1997 & $\mathrm{~T} / \mathrm{C}$ & 4 & na & na & na & na & na & na & 4 & \multicolumn{4}{|c|}{$\begin{array}{l}\text { 8-D engine map generated from } \mathrm{f} \& \text { e code } \\
\text { (based on Woschni-Anisits comb. model) }\end{array}$} & yes & no & altitude & & [115] \\
\hline $\begin{array}{l}\text { Rakopoulos, } \\
\text { Giakoumis }\end{array}$ & Energy & 1997 & $\mathrm{~N}-\mathrm{A}$ & 4 & 1 & 76.2 & 111.2 & 0.51 & na & na & 1,2 & $f \& e$ & $\begin{array}{l}\text { single- } \\
\text { zone }\end{array}$ & $\begin{array}{l}\text { Whitehouse- } \\
\text { Way }\end{array}$ & Annand *** & * no & no & $\begin{array}{c}\text { load/speed change magnitude, } \\
\text { heat transfer coeffs }\end{array}$ & 2nd-law & [43] \\
\hline $\begin{array}{l}\text { Rakopoulos } \\
\text { et al. }\end{array}$ & SAE & 1997 & $\mathrm{~N}-\mathrm{A}$ & 4 & 1 & 76.2 & 111.2 & 0.51 & na & na & 1 & $f \& e$ & $\begin{array}{l}\text { single- } \\
\text { zone }\end{array}$ & $\begin{array}{l}\text { Whitehouse- } \\
\text { Way }\end{array}$ & Annand *** & * no & no & $\begin{array}{c}\text { various governor } \\
\text { types/configurations }\end{array}$ & & [36] \\
\hline $\begin{array}{l}\text { Rakopoulos } \\
\text { et al. }\end{array}$ & SAE & 1997 & $\mathrm{~N}-\mathrm{A}$ & 4 & 1 & 85.7 & 82.6 & 0.48 & na & na & 1,2 & $f \& e$ & $\begin{array}{l}\text { single- } \\
\text { zone }\end{array}$ & $\begin{array}{l}\text { Whitehouse- } \\
\text { Way }\end{array}$ & Annand *** & * no & no & & $\begin{array}{l}\text { structural heat } \\
\text { transfer }\end{array}$ & [37] \\
\hline Zhang et al. & MSM & 1997 & $\mathrm{~T} / \mathrm{C}$ & 4 & 6 & 130 & 160 & 12.74 & 350 & 2,100 & 2,3 & $f \& e^{* *}$ & $\begin{array}{l}\text { single- } \\
\text { zone }\end{array}$ & Watson & Nusselt *** & * no & no & $\begin{array}{l}\text { load moment of inertia, governor } \\
\text { strategies, gear ratios }\end{array}$ & & [48] \\
\hline
\end{tabular}

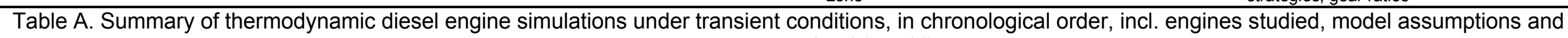
parameters examined (cont'd) 


\begin{tabular}{|c|c|c|c|c|c|c|c|c|c|c|c|c|c|c|c|c|c|c|c|c|}
\hline $\begin{array}{l}\text { Research } \\
\text { group }\end{array}$ & $\begin{array}{l}\text { Publi- } \\
\text { cation }\end{array}$ & Year & $\begin{array}{l}\text { Aspi- } \\
\text { ration }\end{array}$ & $\frac{\mathscr{d}}{\mathrm{d}}$ & $\frac{\infty}{3}$ & $\stackrel{0}{\bar{\emptyset}}$ & 辛灾 & $\begin{array}{l}\text { Displa- } \\
\text { cement } \\
\text { (It) }\end{array}$ & $\begin{array}{c}\text { Rated } \\
\text { Power } \\
\text { (kW) }\end{array}$ & $\begin{array}{c}@ \\
\text { Speed } \\
(\text { rpm) }\end{array}$ & $\begin{array}{l}\text { Transient } \\
\text { Schedule }^{\times}\end{array}$ & $\begin{array}{l}\text { Modeling } \\
\text { Approach }\end{array}$ & $\begin{array}{l}\text { Therm. } \\
\text { Model } \\
\text { (Cyl.) }\end{array}$ & $\begin{array}{l}\text { Combust. } \\
\text { model }\end{array}$ & $\begin{array}{l}\text { Heat } \\
\text { transfer } \\
\text { correlat. }\end{array}$ & $\begin{array}{l}\text { Exper. } \\
\text { valid. } \\
\text { (trans.) }\end{array}$ & $\begin{array}{l}\text { Exh. } \\
\text { Emis. } \\
\text { Pred. }\end{array}$ & Parameters examined & Remarks & 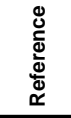 \\
\hline Bartsch et al. & $\begin{array}{l}\text { IMechE } \\
\text { Conf. }\end{array}$ & 1998 & $\mathrm{~T} / \mathrm{C}$ & 4 & 68 & 8 na & na & na & na & na & $1^{*}$ & \multicolumn{4}{|c|}{ AVL Boost $^{\circledR}$ (wave action ${ }^{* *}$ ) } & yes & no & $\begin{array}{l}\text { VGT control strategies, exh. } \\
\text { manifold insulation }\end{array}$ & & [85] \\
\hline Chesse et al. & $\begin{array}{l}\text { IMechE } \\
\text { ASME } \\
\text { C.R.Acad }\end{array}$ & $\begin{array}{l}1998 \\
2000 \\
2000\end{array}$ & $\mathrm{~T} / \mathrm{C}$ & 4 & $\begin{array}{l}\text { V12 } \\
\text { V16 } \\
\text { V20 }\end{array}$ & $\begin{array}{ll}2 & \\
6 & 280 \\
0\end{array}$ & 290 & 13.39/cyl & 325/cyl & 1,050 & $1^{*}$ & $f \& e$ & $\begin{array}{l}\text { single- } \\
\text { zone }\end{array}$ & Wiebe & Woschni & $\begin{array}{l}\text { yes yes } \\
\text { no }\end{array}$ & no & manifolds volumes & $\begin{array}{l}\text { switch from } 1 \text { to } \\
2 \mathrm{~T} / \mathrm{Cs} \text {, } \\
\text { compres. surge }\end{array}$ & $\begin{array}{l}{[102]} \\
{[103]} \\
{[104]}\end{array}$ \\
\hline $\begin{array}{l}\text { Isermann et } \\
\text { al. }\end{array}$ & SAE & 1998 & $\mathrm{~T} / \mathrm{C}$ & 4 & 8 & na & na & na & 420 & na & 4 & \multicolumn{4}{|c|}{$\begin{array}{l}\text { combination of steady-state engine map and } \\
\text { idealized in-cylinder calculations }\end{array}$} & yes & no & & & [81] \\
\hline $\begin{array}{l}\text { Rakopoulos, } \\
\text { Giakoumis }\end{array}$ & $\begin{array}{c}\text { Energy } \\
\text { Convers } \\
\text { Mgmt }\end{array}$ & 1998 & $\mathrm{~N}-\mathrm{A}$ & 4 & 1 & 76.2 & 111.2 & 0.51 & na & na & 1 & $f \& e$ & $\begin{array}{l}\text { single- } \\
\text { zone }\end{array}$ & $\begin{array}{l}\text { Whitehouse- } \\
\text { Way }\end{array}$ & Annand *** & no & no & $\begin{array}{l}\text { load/speed schedule, load-type, } \\
\text { friction and combustion } \\
\text { deterioration, compression ratio, } \\
\text { faulty injection }\end{array}$ & & [38] \\
\hline $\begin{array}{l}\text { Rakopoulos } \\
\text { et al. }\end{array}$ & $\begin{array}{l}\text { Energy } \\
\text { Res. }\end{array}$ & 1998 & $\mathrm{~T} / \mathrm{C}$ & 4 & 6 & 140 & 180 & 16.62 & 236 & 1,500 & 1,2 & $f \& e^{a}$ & $\begin{array}{l}\text { single- } \\
\text { zone }\end{array}$ & $\begin{array}{l}\text { Whitehouse- } \\
\text { Way }\end{array}$ & Annand ${ }^{* * *}$ & yes & $s^{3}$ & & & [39] \\
\hline \multirow{2}{*}{ Assanis et al. } & \multirow{2}{*}{ SAE } & \multirow{2}{*}{1999} & \multirow{2}{*}{$\mathrm{T} / \mathrm{C}$} & \multirow[t]{2}{*}{2} & $\underline{\mathrm{V} 12}$ & 2 na & na & 37.70 & 1,007 & na & 2 & \multirow{2}{*}{$f \& e^{* *}$} & \multirow{2}{*}{$\begin{array}{l}\text { single- } \\
\text { zone }\end{array}$} & \multirow{2}{*}{ Watson } & \multirow{2}{*}{ Nusselt *** } & \multirow{2}{*}{ no } & \multirow{2}{*}{ no } & $\mathrm{T} / \mathrm{C}$ inertia, intercooling & \multirow{2}{*}{$\begin{array}{c}\text { total vehicle } \\
\text { dynamic model }\end{array}$} & \multirow{2}{*}{ [51] } \\
\hline & & & & & 6 & na & na & 12.70 & na & na & 4 & & & & & & & & & \\
\hline Chan et al. & $\begin{array}{c}\text { Proc. } \\
\text { IMechE,D }\end{array}$ & 1999 & $\mathrm{~T} / \mathrm{C}$ & 4 & 4 & 93.7 & 90.5 & 2.50 & 52 & 4,000 & $1^{*}, 2,3$ & $f \& e$ & $\begin{array}{l}\text { multi- } \\
\text { zone }\end{array}$ & $\begin{array}{c}\text { Arrhenius } \\
\text { type }\end{array}$ & Eichelberg & yes & $\mathrm{NOx}^{1}$ & & & [98] \\
\hline Payri et al. & SAE & 1999 & $\mathrm{~T} / \mathrm{C}$ & 4 & 6 & na & na & 10 & na & na & $1^{*}$ & $\begin{array}{c}\text { f \& e } \\
\text { w. action }\end{array}$ & \multicolumn{2}{|c|}{$\begin{array}{l}\text { transient exper. HRR } \\
\text { database }\end{array}$} & Woschni & yes & no & inlet manifold configuration & & [58] \\
\hline $\begin{array}{c}\text { Zellbeck et } \\
\text { al. }\end{array}$ & MTZ & 1999 & $\mathrm{~T} / \mathrm{C}$ & 4 & 4 & na & na & na & na & na & 4 & \multicolumn{4}{|c|}{ 8-D engine map ** } & no & no & VGT, electrically assisted T/C & $\begin{array}{c}\text { total vehicle } \\
\text { dynamic model }\end{array}$ & [108] \\
\hline Assanis et al. & SAE & 2000 & $\mathrm{~T} / \mathrm{C}$ & 4 & V8 & 3104 & 106.2 & 7.30 & 154 & 2,400 & 4 & $f \& e^{* *}$ & $\begin{array}{l}\text { single- } \\
\text { zone }\end{array}$ & Watson & Nusselt *** & yes & no & fuel control strategies & $\begin{array}{c}\text { total vehicle } \\
\text { dynamic model }\end{array}$ & [52] \\
\hline Benajes et al. & SAE & 2000 & $\mathrm{~T} / \mathrm{C}$ & 4 & 6 & 120 & 145 & 9.83 & na & 2,000 & $1^{*}$ & $\begin{array}{c}f \& e \\
\text { w. action }\end{array}$ & \multicolumn{3}{|c|}{ transient exper. HRR database } & yes & no & \multicolumn{2}{|c|}{$\begin{array}{l}\text { valves size, EVO, inlet man. volume, tuned inlet } \\
\text { man., exhaust port \& manifold insulation, inj. } \\
\text { timing, turbine size \& inertia, VGT }\end{array}$} & [62] \\
\hline Filipi et al. & $\begin{array}{c}\text { SAE } \\
\text { IJHVS }\end{array}$ & $\begin{array}{l}2001 \\
2004 \\
\end{array}$ & $\mathrm{~T} / \mathrm{C}$ & 4 & V8 & 3104 & 106.2 & 7.30 & 154 & 2,400 & 4,5 & $f \& e^{* *}$ & $\begin{array}{l}\text { single- } \\
\text { zone }\end{array}$ & Watson & Nusselt *** & yes & no & various VGT schemes & $\begin{array}{c}\text { total vehicle } \\
\text { dynamic model }\end{array}$ & $\begin{array}{l}{[53]} \\
{[56]} \\
\end{array}$ \\
\hline \multirow{2}{*}{$\begin{array}{l}\text { Filipi, } \\
\text { Assanis }\end{array}$} & \multirow{2}{*}{ ASME } & \multirow{2}{*}{2001} & $\mathrm{~N}-\mathrm{A}$ & \multirow{2}{*}{4} & \multirow{2}{*}{1} & 95 & 95 & 0.67 & \multirow{2}{*}{ na } & \multirow{2}{*}{ na } & 2 & \multirow{2}{*}{$f \& e^{* *}$} & single- & Watson & & yes & no & & & {$[50]$} \\
\hline & & & $\mathrm{T} / \mathrm{C}$ & & & 130 & 160 & 2.12 & & & 2,6 & & zone & vvalson & 1 & no & no & moment of inertia & & {$[50]$} \\
\hline Lin et al. & $\begin{array}{l}\text { SAE } \\
\text { IJHVS }\end{array}$ & $\begin{array}{l}2001 \\
2004 \\
\end{array}$ & $\mathrm{~T} / \mathrm{C}$ & 4 & 6 & 104 & 106.2 & 5.48 & 115 & 2400 & 4,5 & $\begin{array}{l}\text { Engine } \\
\text { (based }\end{array}$ & $\begin{array}{l}\text { map gene } \\
\text { on Watsol }\end{array}$ & $\begin{array}{l}\text { erated from } f \varepsilon \\
\text { on combustion }\end{array}$ & $\begin{array}{l}\& \text { e code } \\
\text { n model) }\end{array}$ & yes $^{\mathrm{c}}$ & no & & $\begin{array}{l}\text { hybrid vehicle } \\
\text { dynamic model }\end{array}$ & $\begin{array}{l}55] \\
{[57]} \\
\end{array}$ \\
\hline Liu et al. & ASME & 2001 & $\mathrm{~N}-\mathrm{A}$ & 4 & 1 & 95 & 95 & 0.67 & na & na & 6 & $f \& e^{* *, a}$ & $\begin{array}{l}\text { single- } \\
\text { zone }\end{array}$ & Watson & Woschni & yes & no & & & [30] \\
\hline Panting et al. & $\begin{array}{c}\text { Proc. } \\
\text { IMechE,D }\end{array}$ & 2001 & $\mathrm{~T} / \mathrm{C}$ & 4 & 4 & 110 & 140 & 5.32 & na & na & 4 & $f \& e$ & $\begin{array}{l}\text { single- } \\
\text { zone }\end{array}$ & Watson & na & no & no & $\begin{array}{c}\text { power of electric motor, fueling } \\
\text { strategies }\end{array}$ & $\begin{array}{c}\text { simplified } \\
\text { transient }\end{array}$ & [109] \\
\hline $\begin{array}{c}\text { Theotokatos, } \\
\text { Kyrtatos }\end{array}$ & SAE & 2001 & $\mathrm{~T} / \mathrm{C}$ & 4 & 6 & 115 & 125 & 7.79 & na & na & $1^{*}, 2$ & $f \& e$ & $\begin{array}{l}\text { single- } \\
\text { zone }\end{array}$ & Watson & Woschni & yes & no & inlet manifold volume & $\begin{array}{c}\text { compressor } \\
\text { surge }\end{array}$ & {$[105]$} \\
\hline Zweiri et al. & $\begin{array}{c}\text { Proc. } \\
\text { IMechE,D }\end{array}$ & 2001 & $\mathrm{~N}-\mathrm{A}$ & 4 & 1 & 95 & 95 & 0.67 & na & na & 2 & $f \& e^{* *, a}$ & $\begin{array}{l}\text { single- } \\
\text { zone }\end{array}$ & Watson & $\begin{array}{c}\begin{array}{c}\text { Hohenberg + } \\
\text { radiation }\end{array} \\
\end{array}$ & yes & no & & & [69] \\
\hline Payri et al. & $\begin{array}{c}\text { Proc. } \\
\text { IMechE,D }\end{array}$ & 2002 & $\mathrm{~T} / \mathrm{C}$ & 4 & 4 & na & na & na & na & na & $1^{*}$ & $\begin{array}{c}f \& e \\
\text { w. action }\end{array}$ & transien & ent exper. HRR & database & yes & no & & & {$[61]$} \\
\hline $\begin{array}{c}\text { Benvenuto, } \\
\text { Campora }\end{array}$ & $\begin{array}{l}\text { Engine } \\
\text { Res. }\end{array}$ & 2002 & $\mathrm{~T} / \mathrm{C}$ & 4 & V18 & 8 na & na & na & 7,200 & 1,000 & 2 & $f \& e^{* *}$ & two-zone & Wiebe & na & yes & no & & sequential $\mathrm{t} / \mathrm{c}$ & [120] \\
\hline Bi et al. & SAE & 2002 & $\mathrm{~T} / \mathrm{C}$ & 4 & 12 & 2150 & 180 & 38.2 & na & na & 4 & $f \& e$ & $\begin{array}{l}\text { single- } \\
\text { zone }\end{array}$ & Watson & Woschni & yes & no & various gears & $\begin{array}{c}\text { total vehicle } \\
\text { dynamic model }\end{array}$ & [116] \\
\hline
\end{tabular}

Table A. Summary of thermodynamic diesel engine simulations under transient conditions, in chronological order, incl. engines studied, model assumptions and parameters examined (cont'd) 


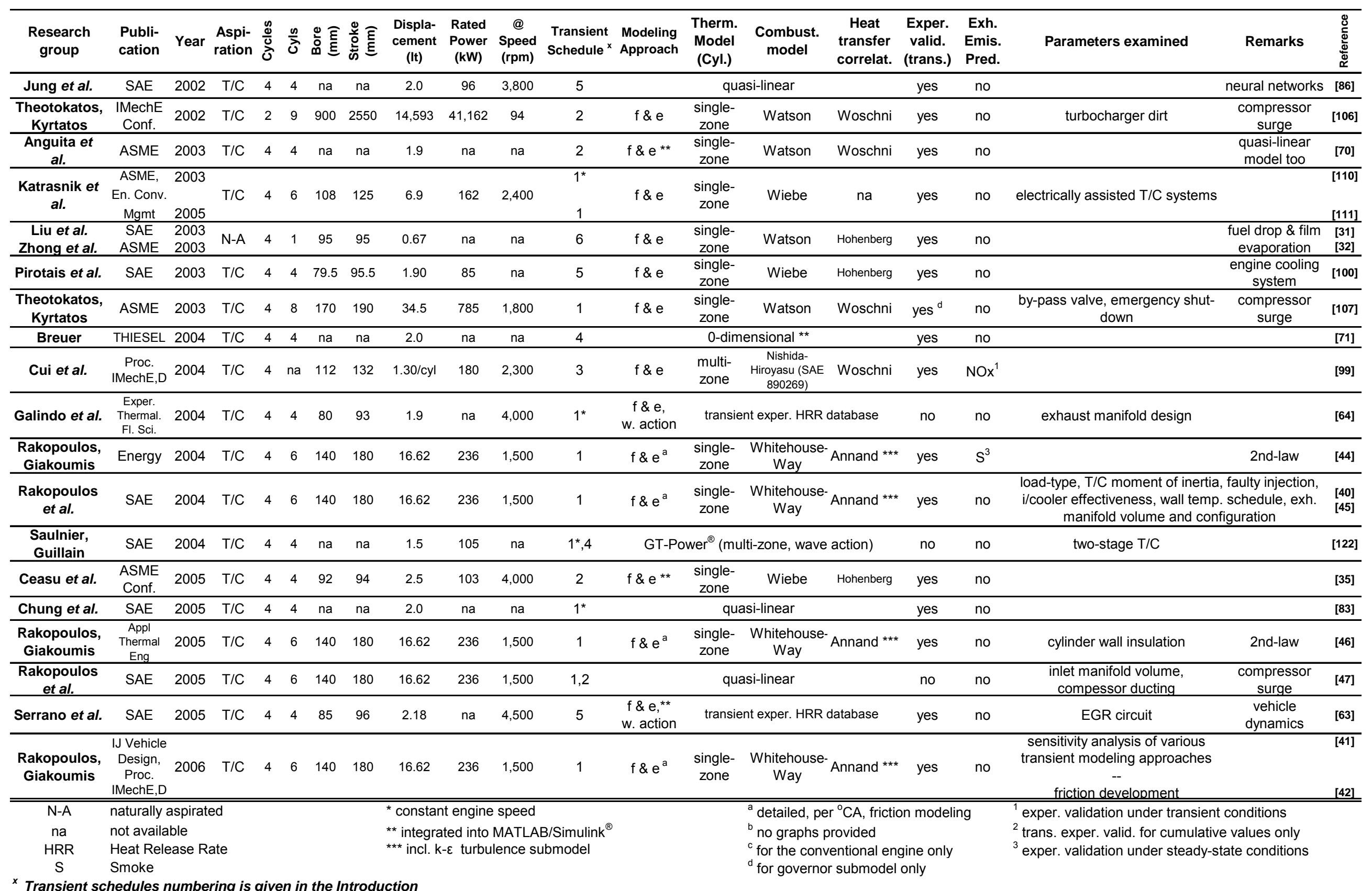

Table A. Summary of thermodynamic diesel engine simulations under transient conditions, in chronological order, incl. engines studied, model assumptions and parameters examined (cont'd) 